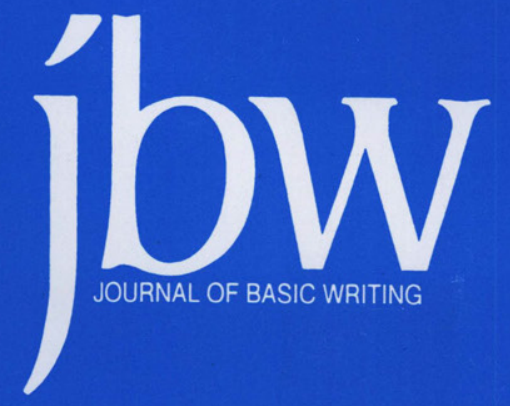

\title{
SPRING 1997
}

VOLUME 16 NUMBER 1

Race, Class, and Culture in the Basic Writing Classroom

Retrospection as Prologue

Jeanne Gunner and Gerri McNenny

Class Talk

Gary Tate, John McMillan and Elizabeth Woodworth

\begin{abstract}
Constructing Teacher Identity in the Basic Writing Classroom Jacqueline Jones Royster and

Rebecca Greenberg Taylor
\end{abstract}

Writing the Life of Mina P. Shaughnessy Jane Maher

From Remediation to Enrichment: Evaluating a Mainstreaming Project Mary Soliday and Barbara Gleason

Theory in the Basic Writing Classroom? A Practice Victor Villanueva, Jr.

Our Apartheid: Writing Instruction and Inequality Ira Shor

Cumulative Index for JBW: The First 15 Volumes (1975-1996) 


\section{LANGUAGE ACQUISITION A Journal of Developmental Linguistics}

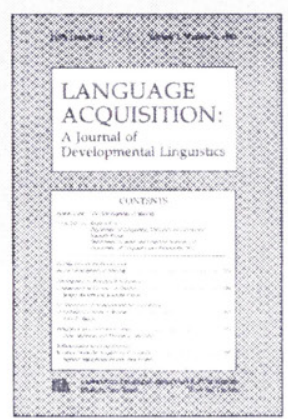

editors:

Robert Berwick

Massachusetts Institute of Technology

Thomas Roeper

University of Massachusetts, Amherst

Kenneth Wexler

Massachusetts Institute of Technology

\section{editorial scope:}

Contributions to this journal offer explanatory insights into, and advance our knowledge of, how language is acquired. Focusing primarily on experimental, linguistic, and computational approaches, the journal discusses the syntax, semantics, pragmatics, and phonology of language acquisition - merging the data of developmental psycholinguistics with recent discoveries in linguistic theory to yield a more adequate understanding of the growth of language. Coverage includes in-principle solutions to problems of how children select among possible grammars, discussions of relevant acquisition data, integrations of theoretical representations of languages to be acquired, and perspectives derived from second language acquisition, language impaired speakers, and other domains of cognition. Language Acquisition also discusses such topics as the relationship between disorders and acquisition, and studies of theoretical linguistics.

\section{audience:}

Researchers and professionals in linguistics, psycholinguistics, and developmentalists.

\section{Volume 7, 1998, Quarterly \\ Individual: $\quad \$ 39.50$ US/Canada \\ $\$ 69.50$ All Other Countries \\ Institution: $\quad \$ 200.00$ US/Canada$$
\$ 230.00 \text { All Other Countries }
$$

ISSN: 1048-9223

abstracted or indexed in:

Linguistic Abstracts; MLA International Bibliography; PsycINFO/Psychological Abstracts; Current Index to Journals in Education/Educational Resources Information Center; Linguistics and Language Behavior Abstracts

\section{Free Sample Issues Available.}

Lawrence Erlbaum Associates, Inc. 10 Industrial Avenue, Mahwah, NJ 07430 201/236-9500 FAX 201/236-0072

Call toll-free to order: 1-800-9-BOOKS-9...9am to 5pm EST only. 


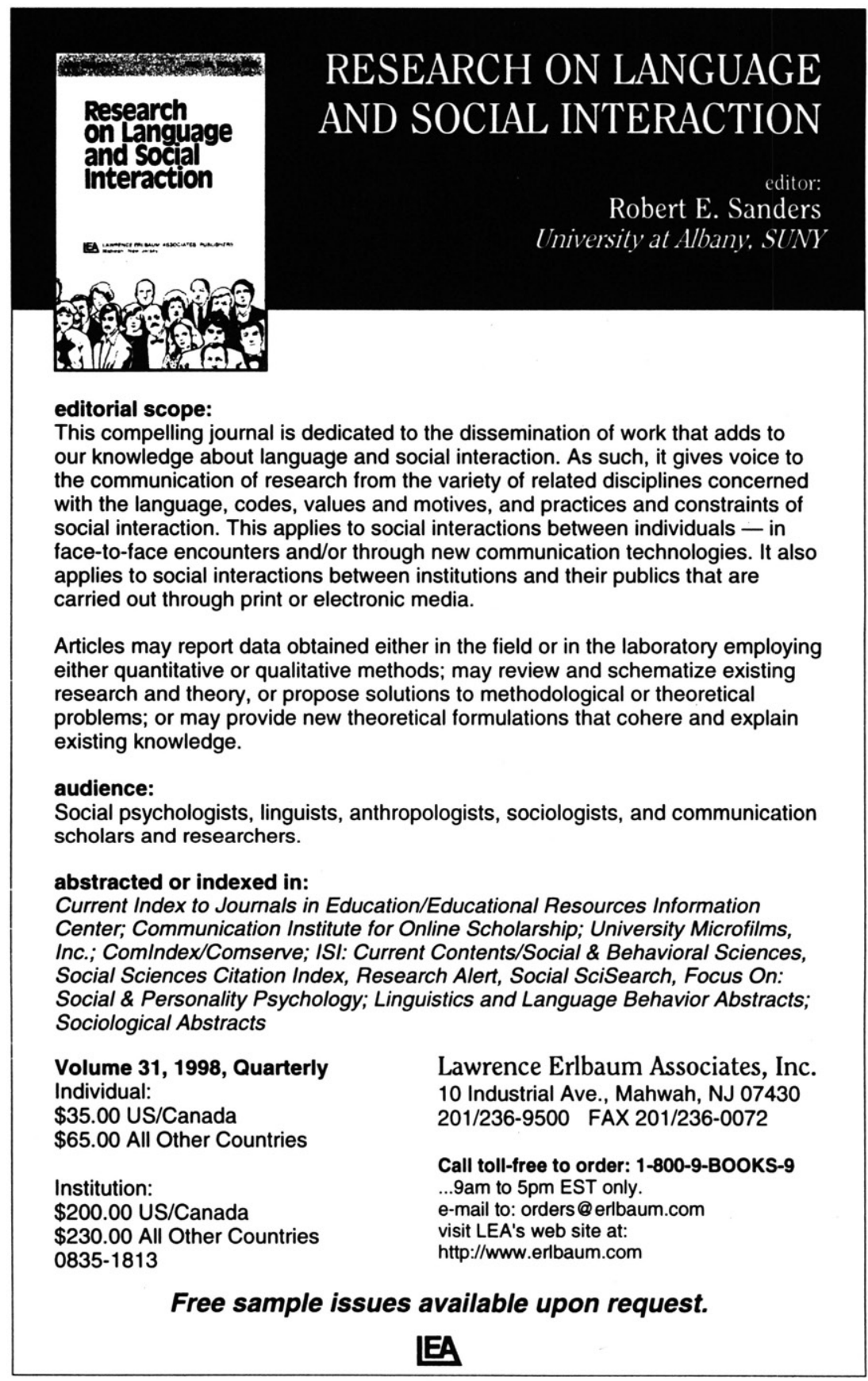




\section{composition}

\section{Freshman English News}

\section{Volume 25, Number 1 Now Available}

Featuring essays by

John Clifford and Janet Ellerby, Lauren Sewell, and Teresa M. Redd

\section{Call for Papers}

Composition Studies requests submissions for its new feature on course design. This feature, which will appear regularly in future issues, allows writing/rhetoric teachers at all post-secondary levels a unique opportunity to publish full descriptions of curricular development. Visit our web site for the complete project statement and submission guidelines.

Quality essay submissions on issues of general interest to rhetoric and composition teachers and scholars are also strongly encouraged. Three titled, letter-quality copies conforming to current MLA guidelines for format and documentation, free of authors' names and other identifying references, should be accompanied by a cover letter.

\section{SUBSCRIPTIONS}

Individuals $\$ 12$ • Institutions $\$ 25$ • Graduate Students $\$ 9$

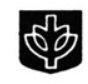

DePaul University

Department of English • 802 W. Belden Avenue • Chicago, IL 60614-3214 


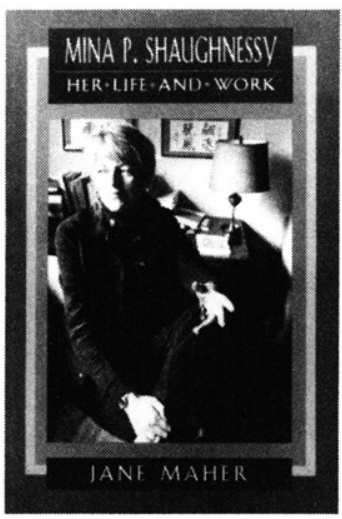

\title{
Mina P. Shaughnessy Her Life and Work
}

\author{
Jane Maher
}

"In addition to quietly telling the story of her subject's life, Nassau Community College professor Jane Maher judiciously excerpts eloquent remembrances from Shaughnessy's fellow dwellersin-the-trenches at the 1970s City University of New York... giving a real sense of the time's climate."

\section{-Publishers Weekly March 24, 1997}

ven before the publication of her pioneering work, Errors and Expec-
tations, Mina P. Shaughnessy was recognized as the leading figure in
the field of basic writing and as a devoted advocate of Open Admissions. Her career at City College and the CUNY Instructional Resource Center spanned the turbulent years of Open Admissions, and throughout the late sixties and seventies she worked with a commitment and intensity to her students that was unparalleled. Author Jane Maher has recaptured that intensity in her account of Shaughnessy's remarkable personal and professional life. As a result of her work, Shaughnessy came to realize that "the open admissions experiment, wherever it has been seriously undertaken, has yielded a few truths that I . . . would walk the plank for-and one of them is that the young men and women we call remedial have the capacity (by now the proven capacity) to become competent writers and to do so, if everyone works very hard, even within the harsh limits imposed by the college timetable."

Although Shaughnessy's career was relatively brief - she died in 1978 at the age of 54 -her work as a teacher, a scholar, and an administrator has had a profound and permanent effect on basic writing as a discipline and on the education of underprepared students. From her roots in South Dakota to her professional life in New York City-expertly chronicled here by MaherShaughnessy won international recognition fighting for the rights of those students who had been denied for so many years the right to a college education; in addition, she helped teachers of basic writing realize that teaching these students to write well "is not only suitable but challenging work for those who would be teachers and scholars in a democracy." 331 pp. 1997. ISBN 0-8141-5029-2

No. $50292-4038$ \$25.95 (nonmember) $\$ 18.95$ (member)

To order, call NCTE Headquarters toll free at 1-800-369-6283. 


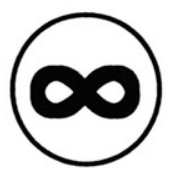

The paper used in this publication meets the minimum requirements of the American National Standard for Information Science -

Permanence of Paper for Printed Library Materials, ANSI Z39.48-1984.

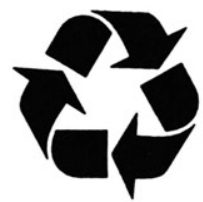

The text stock is also recycled.

\section{This publication is} available in microform from UMl.

Please send me information about the titles I've listed below:

Name

Title

Company/Institution

Address

City/State/Zip

Phone (_

\section{$\mathrm{U} \cdot \mathrm{M} \cdot \mathrm{I}$}

A Bel I \& Howell Company 300 North Zeeb Road, Arn Arbor, M 48106 USA 800-521-0600 tollfree 313-761-4700 collect from Alaska and Michigan 800-343-5299 toll-free from Canada 


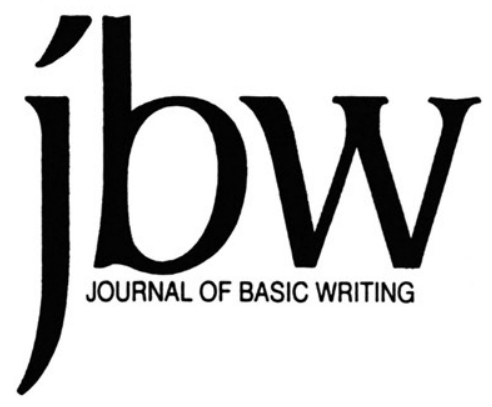

VOLUME 16 NUMBER 1 SPRING 1997

The Journal of Basic Writing publishes articles of theory, research, and teaching practices related to basic writing. Articles are refereed by members of the Editorial Board (see overleaf) and the Editors.

\title{
George Otte and Trudy Smoke
}

Editors

\section{Linda Camarasana and Carl Whithaus Editorial Assistants}

\section{Mary E. Carney, Subscriptions}

The Journal of Basic Writing is published twice a year, in the spring and fall. We welcome unsolicited manuscripts and ask authors to consult the detailed "Call for Articles" in this issue. Subscriptions for individuals are $\$ 10.00$ for one year and $\$ 19.00$ for two years; subscriptions for institutions are $\$ 15.00$ for one year and $\$ 29.00$ for two years. Foreign postage is $\$ 5.00$ extra per year. ADDRESS:

\author{
Journal of Basic Writing \\ Instructional Resource Center \\ The City University of New York \\ 535 East 80th Street \\ New York, NY 10021
}




\section{JOURNAL OF BASIC WRITING \\ EDITORIAL BOARD}

Peter Dow Adams

Essex Community College, Baltimore

Akua Duku Anokye

University of Toledo

Chris M. Anson

University of Minnesota

David Bartholomae

University of Pittsburgh

Sarah Benesch

College of Staten Island, CUNY

Bill Bernhardt

College of Staten Island, CUNY

Patricia Bizzell

College of the Holy Cross

Lynn Z. Bloom

University of Connecticut, Storrs

Nancy Carriuolo

University of New Haven

Richard Courage

Westchester Community College, SUNY

Donald Daiker

Miami University

Suellynn Duffey

Ohio University

Sarah Warshauer Freedman

University of California, Berkeley

Karen L. Greenberg

Hunter College, CUNY

Brenda M. Greene

Medgar Evers College, CUNY

Muriel Harris

Purdue University

Irvin Hashimoto

Whitman College

Warren Herendeen

Mercy College

Myra Kogen

Brooklyn College, CUNY
Patricia Ondek Laurence

City College, CUNY

Elaine O. Lees

Carlow Hill College

Andrea A. Lunsford

Ohio State University

Jane Maher

Nassau Community College

Peter Miller

College of Staten Island, CUNY

Susan Miller

University of Utah

Nathaniel Norment, Jr.

Temple University

Jerrold Nudelman

Queensborough Community

College, CUNY

Jane Peterson

Richland College, Dallas County

Community College Distnct

Nell Ann Pickett

Hinds Community College

Charles I. Schuster

University of Wisconsin, Milwaukee

Tony Silva

Purdue University

Lynn Quitman Troyka

Oueensborough Community

College, CUNY, ret.

Karen S. Uehling

Boise State University

Billie J. Wahlstrom

University of Minnesota

Evelyn E. Webb

Mississippi State Board for

Community and Junior Colleges

Harvey S. Wiener

Adelphi University 


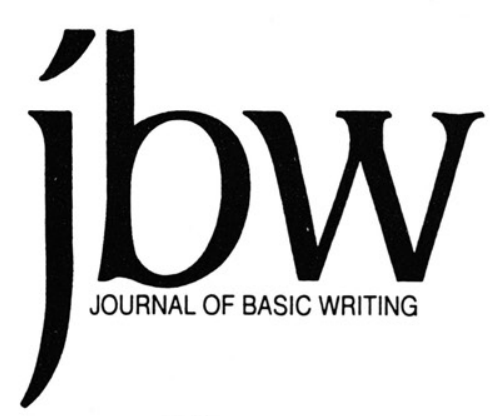

VOLUME 16

NUMBER 1

SPRING 1997

Editors' Column

Retrospection as Prologue

Jeanne Gunner and Gerri McNenny

3

Class Talk

Gary Tate, John McMillan, and Elizabeth Woodworth

Constructing Teacher Identity in the Basic Writing Classroom

Jacqueline Jones Royster and

Rebecca Greenberg Taylor

Writing the Life of Mina P. Shaughnessy

Jane Maher

51

From Remediation to Enrichment:

Evaluating a Mainstreaming Project

Mary Soliday and Barbara Gleason

64

Theory in the Basic Writing Classroom?

A Practice

Victor Villanueva, Jr.

Our Apartheid: Writing Instruction and Inequality

Ira Shor

91

Cumulative Index for JBW:

The First 15 Volumes (1975-1996) 105

News and Announcements 


\section{CALL FOR ARTICLES}

We welcome manuscripts of $10-20$ pages on topics related to basic writing, broadly interpreted.

Manuscripts will be refereed anonymously. We require five copies of a manuscript and an abstract of about 100 words. To assure impartial review, give author information and a short biographical note for publication on the cover page only. Papers which are accepted will eventually have to supply camera-ready copy for all ancillary material (tables, charts, etc.). One copy of each manuscript not accepted for publication will be returned to the author, if we receive sufficient stamps (no meter strips) clipped to a self-addressed envelope. We require the MLA style (MLA Handbook for Writers of Research Papers, 4rd ed., 1995). For further guidance, send a stamped letter-size, self-addressed envelope for our style sheet and for camera-ready specifications.

All manuscripts must focus clearly on basic writing and must add substantively to the existing literature. We seek manuscripts that are original, stimulating, well-grounded in theory, and clearly related to practice. Work that reiterates what is known or work previously published will not be considered.

We invite authors to write about such matters as classroom practices in relation to basic writing theory; cognitive and rhetorical theories and their relation to basic writing, social, psychological, and cultural implications of literacy; discourse theory, grammar, spelling, and error analysis; linguistics; computers and new technologies in basic writing; English as a second language; assessment and evaluation; writing center practices; teaching logs and the development of new methodologies; and cross-disciplinary studies combining basic writing with psychology, anthropology, journalism, and art. We publish observational studies as well as theoretical discussions on relationships between basic writing and reading, or the study of literature, or speech, or listening. The term "basic writer" is used with wide diversity today, sometimes referring to a student from a highly oral tradition with little experience in writing academic discourse, and sometimes referring to a student whose academic writing is fluent but otherwise deficient. To help readers therefore, authors should describe clearly the student population which they are discussing.

We particularly encourage a variety of manuscripts: speculative discussions which venture fresh interpretations; essays which draw heavily on student writing as supportive evidence for new observations; research reports, written in nontechnical language, which offer observations previously unknown or unsubstantiated; and collaborative writings which provocatively debate more than one side of a central controversy.

A "Mina P. Shaughnessy Writing Award" is given to the author of the best JBW article every two years (four issues). The prize is $\$ 500$, now courtesy of Lynn Quitman Troyka. The winner, to be selected by a jury of three scholars/teachers not on our editorial board, is announced in our pages and elsewhere. 


\section{EDITORS' COLUMN}

Our field is perhaps too given to proclaiming "turning points" (to say nothing of "paradigm shifts"), but it was clear, to us at least, that some significant change was in the works by the time of the Conference on College Composition and Communication convention in Phoenix this past March. The number of sessions devoted to basic writing was more than triple what it had been (a mere 8 in '94 and '95, up to 12 in '96, suddenly 26 in '97). Further heightening this heightened interest, this increased recognition of basic writing, was an escalation in declarations that it should disappear. Nothing brought these developments into focus like the Conference on Basic Writing all-day workshop on Race, Class, and Culture in the Basic Writing Classroom.

"Workshop" is a bit of a misnomer. Oh, there were workshoplike activities, and some account of them is given here, but those within CBW at least realize that the "workshop" is the closest thing basic writing has to a national conference - and has had since the $4^{\text {th }}$ National Conference on Basic Writing back in 1992, a conference that gave rise to another special issue of JBW (Spring 1993). Preparing the cumulative index we include in this issue, we were especially aware of that special issue - an awareness that no doubt had something to do with our contacting Jeanne Gunner and Gerri McNenny, the CBW workshop organizers, about the possibility of our doing a special issue based on the workshop. (At least we think we contacted them. It may have been the other way around. This issue has involved so much back and forth on e-mail that we despair of ever disentangling all the "threads.")

Once in Phoenix, it was impossible to miss the sense of change and significance in the air. The CBW workshop came to seem like the nexus of apparently fortuitous events (and chains of events) of real import: the impressive emergence of class as an issue (something Gary Tate reported on at the outset, Ira Shor drove home at the end), the recent publication of Jane Maher's book on Mina Shaughnessy, Victor Villanueva's already intense activity as the future program chair of $4 \mathrm{Cs}$, the culmination of Barbara Gleason's and Mary Soliday's multiyear, FIPSE-funded project on mainstreaming, and, by no means least, the way Jackie Jones Royster, like Gary Tate, showcased collaboration with a new generation hard at work in basic writing, so that this issue also includes relatively new voices: Becky Taylor, John McMillan, Elizabeth Woodworth. This seems especially important for the way that teachers' voices, especially of the sort too often silenced or muted, developed a special clarity and prominence at the workshop, a centering of attention we believe is actually enhanced here. 
In developing this issue, we have asked the contributors to give print variants on what they presented. In some cases, the workshop experience is closely replicated. In others, this less interactive medium of print has required a different sort of presentation, and we have a little bit to say about that in introducing each piece. But we are struck, now that it has come together, by how the offerings have much in common that transcends style or format-above all, a focus, often explicit, on the stories we in basic writing have to tell. We seem more interested in narrating than classifying, more interested in examples than generalizations, more attuned to cases than trends or patterns - though, as Ira Shor reminds us at the end, these stories are situated within larger stories, histories: narratives of a field - and a society - and not just work within it.

Of course, stories have various ways of getting told. Some require more participation from the audience to fill in the gaps, make the connections. One such, included in this issue, is the first full cumulative index of $J B W$. It is not too much to say that it is the story of our field - or at least $a$ story of it - and a highly suggestive, richly nuanced one at that, something a mere glance over the names and titles will convey. Brood over it as we have, and you will see that it bespeaks the tensions and paradoxes of a field characterized by exhaustion and enormous energy, continuities and discontinuities, brilliant insights from within and stubborn misunderstandings from without. With this issue, we add new names and titles - particularly impressive and suggestive ones - to this roster, this story, as we begin with the next 15 volumes and step further into the third decade of $J B W$.

- George Otte and Trudy Smoke 


\section{Jeanne Gunner and Gerri McNenny}

\section{RETROSPECTION AS PROLOGUE}

When we approached Jeanne Gunner and Gerri McNenny about their possible contributions to this special issue, we didn't know if we should ask for something on the order of an introduction or something more like a postscript. It turns out they did a bit of both, composing separate but complementary pieces. We've decided to frontload them, though they are (as Jeanne's individual title suggests) afterthoughts. Jeanne Gunner, formerly of the UCLA Writing Program and now Core Composition Director at the Santa Clara University, Chair of the Conference on Basic Writing from 1995-1997, offers the unusual opportunity of examining the motives, personal and professional, for mounting such an enterprise as the workshop represents. Co-Chair of Conference on Basic Writing, Gerri McNenny is Director of Composition at the downtown campus of the University of Houston and is hard at work on an anthology of essays treating mainstreaming vs. tracking BW students; she chooses to highlight the issue of class, certainly the prominent note struck that day (perhaps because it seemed relatively undernoticed before), and her discussion provides an excellent overview of and introduction to the presentations of the other participants.

\section{Jeanne Gunner}

\section{Afterthoughts on Motive}

The CBW-sponsored workshop, "Race, Class, and Culture in the Basic Writing Classroom," at the 1997 CCCC in Phoenix, came about for many professional reasons. Applying for a slot on the conference program, Gerri McNenny and I wrote that the session would take the place of the national CBW conference, which was becoming increasingly difficult to organize and increasingly expensive for members to attend. We also cited the need for our members to meet as a group, to have a place at the conference where the discussion would be focused on basic writing, where the central topic would be the emerging issues in the field, mainstreaming being the center around which these issues have recently coalesced. In the session, the theory and practice of mainstreaming were to serve as the basis for political critique of various orders: analysis of class, identity, and cultural awareness in instructors' own experience; presentation by CUNY researchers speaking from the historical site of open admissions and assessing their current mainstreaming project; and an historical analysis of basic writers' social and educational context, which was to serve as a basis for formulating one's own personal and professional stance on mainstreaming in relation to issues of access and institutional status.

In inviting the workshop speakers, we were quite aware of the political truism that the voices heard are the voices that validate. To have our issues "spoken into existence," in a sense, we looked in some 
cases to have speakers who themselves wield some professional and institutional power. Victor Villanueva, Gary Tate, Jacqueline Jones Royster, Ira Shor: were they themselves not so committed to inclusiveness, our invitations to them would really have been a kind of exploitation, of their names, status, and labor. Jane Maher brought with her the power and historical record invoked by the name of Mina Shaughnessy; if our field has icons, then Shaughnessy's image is clearly the pre-eminent one. Mary Soliday and Barbara Gleason provided the power of empirical research and FIPSE sponsorship, in their reports on their project. Our intentions were not elitist; Gary's co-presenters John McMillan and Elizabeth D. Woodworth and Jackie's co-presenter Rebecca Taylor are new members of the field, whose contributions to the day and to the national discussion were and are important. But in addition to the goals we reported to the CCCC selection committee was the motive of using the workshop and its participants to signal the topic's importance in the profession at large, and our list of speakers was one element of this desire to enhance the status of the workshop-to give it national prominence.

For most of us, I expect the workshop served other professional purposes as well. In my case, I was looking for what I initially considered a kind of professional synthesis. I used to define myself primarily as a specialist in basic writing, since my teaching, conference papers, publications, and professional affiliations at one point related almost exclusively to the BW field. As my career path shifted to writing program administration, however, I, with only occasional awareness of the fact, distanced myself from basic writing. I continued to teach the courses, but increasingly my professional conversations shifted to new topics; other, seemingly more central writing program issues demanded my time and attention; and WPAs, in conference sessions and journals, seemed not to address basic writing as a field. The debates over such BW concerns as access and mainstreaming took place in other professional arenas, despite the obvious connection to the administrators who oversee the curricular and faculty issues that these topics necessarily invoke. Only at the first CBW-sponsored workshop at the 1996 CCCC in Milwaukee, organized by Karen Uehling, Geoff Sirc, and Sylvia Holladay, did I begin to question the seemingly unintegrated, parallel relationship between basic writing and writing program administration, and to sense a need to draw these parallel lines in the conversation into some more dialogic relationship.

At the 1996 workshop, I served as a respondent to a paper presented by Charles Schuster on the WPA and basic writing. It was clearly a kind of first: because most BW instructors seem not to become WPAs, and most WPAs seem not to teach BW (in each case, for fairly obvious reasons related to the politics of rank and subject), little opportunity for exchange between the two groups had ever arisen. If we consider 
the ways in which basic writing figures into articles in the WPA journal over the past decade, we see that the field and its students are defined in limited and limiting ways - for the most part, they are objects in a discussion of placement, testing, and program assessment. Only in the past two years do discussions and program descriptions of mainstreaming projects appear in the WPA literature (see Cambridge et al.; Elbow; Grego and Thompson; Glau). If BW occupies a vulnerable and marginalized institutional position, then surely this vulnerability results in part from its alienation from the administrators best positioned to defend it. Helping to organize "Race, Class, and Culture in the BW Classroom" would be helping to bridge the two fields.

But I have to revisit the question of motive yet again, for what I brought away from the actual workshop experience enables me to see the motives I've cited above in yet a new light. In all cases, my motives include in some degree a concern for status: for BW as an academic field, for BW instructors and students as members of the field-and for me as someone whose identity is to a degree bound up in it. The workshop helped me to see that I am drawn to BW in part because I at once identify with and rage against the outsider status its members continue to have attached to them, a position that entails a sense of lost agency, of powerlessness. This identification and rage, I see now, is personal as well as intellectual. In the presentation by Tate, McMillan, and Woodworth, we were asked to consider in writing how the stories we tell about our backgrounds influence our teaching and life in the academy. Part of my story reads, "I'm acutely aware of my difference from my middle and upper class students, who make me uncomfortable: I am both threatened by and sometimes despising of them .... I grew up about eight miles from Princeton but never once considered applying there; it was another world that didn't exist for me. I'm conscious always of having my degrees from what a former English Department colleague once called, 'Oh, your state university' .... With [BW] students, I'm aware of feeling relieved to deal with those who are also different. The marginalization of BW students has ironically created a safe place for me in the academy." Again writing from experience, this time in response to Royster and Taylor's presentation, the same themes appear: "I realize my own rage at the system, at being disenfranchised by my rank, field, and gender."

So perhaps my real reason for organizing the workshop with Gerri was an unarticulated sense of conflict over my own social position, in the field and outside it, accompanied by a felt desire for agency, for power - the power to bring about change, to regain a sense of agency. If in my work I have overtly protested the assigning of low status to BW, I have felt oddly alienated when I have moved outside it-into the world of the WPA, for instance, which is less familiar on the levels of class origin and relation to power (no surprise that my work in this 
field is dominated by criticism of its hierarchical systems). My desire for synthesis of such realms reflects this anxiety over identity and status; like many BW students, I'm attempting to negotiate multiple cultural contexts, some of which I have experienced as conflicts of allegiance and a hierarchizing of personal and professional worth.

For me, the workshop was a wonderful vehicle for exploring the implications of the professional lives on the boundary that I and, I expect, many of us in basic writing contend with. By creating a space for the personal in the professional discussion, the workshop succeeded, not only as a forum for basic writing teachers, but as a catalyst for those of us challenged by it to reconsider identity, action, and interaction; to see the boundaries that we construct, and have constructed for us.

\section{Works Cited}

Cambridge, Barbara L. and Ben W. McClelland. "From Icon to Partner: Repositioning the Writing Program Administrator." Resituating Writing. Eds. Joseph Janangelo and Kristine Hansen. Portsmouth, NH: Boynton/Cook Heinemann, 1995. 151-159.

Elbow, Peter. "Writing Assessment in the 21st Century: A Utopian View." Composition in the Twenty-First Century: Crisis and Change. Eds. Lynn Z. Bloom, Donald A. Daiker, and Edward M. White. Carbondale and Edwardsville: Southern Illinois UP, 1996. 83-100. Glau, Gregory R. "The 'Stretch Program:' Arizona State University's New Model of University-level Basic Writing Instruction." WPA: Writing Program Administration 20.1-2 (1996): 79-91.

Grego, Rhonda C. and Nancy S. Thompson. "The Writing Studio Program: Reconfiguring Basic Writing/Freshman Composition." WPA: Writing Program Administration 19.1-2 (1995): 66-79. 


\section{Gerri McNenny Notes On the Future of Working-Class Studies in Basic Writing}

Since Jeanne has provided the background for the workshop, I'd like to discuss the future that considerations of race, class, and culture have in basic writing pedagogy and theory as they emerged in the workshop. While the impact that race and cultural location have on the teaching of writing has been more visibly explored in the past decade or so, class seems to be the newcomer. The invisibility of class as a site of struggle and a place wherein our students might regain a sense of empowerment has both historical and cultural roots.

The denial of class has a long history. Both in and outside of academia, the erasure of class has served a privileged minority well, masking those mechanisms that support their privilege while co-opting ideological frameworks in ways that are convenient to their continued status. Long held values consistent with our American idealism such as egalitarianism and the democratization of culture inadvertently act to deny class in ways that are convenient to the moneyed classes. Michael Lind, writing in his "Notes on the Progress of the American Class War," underscores the ways in which classlessness is encouraged in our popular mythology:

The American oligarchy spares no pains in promoting the belief that it does not exist, but the success of its disappearing act depends on equally strenuous efforts on the part of an American public anxious to believe in egalitarian fictions and unwilling to see what is hidden in plain sight. Anybody choosing to see the oligarchy in its native habitat need do nothing else but walk down the street of any big city to an office tower housing a major bank, a corporate headquarters or law firm, or a national television station. Enter the building and the multiracial diversity of the street vanishes as abruptly as the sound of the traffic. (36)

In effect, the invisibility of class facilitates a wishfulness that suppresses a critical scrutiny of the ways in which class, race, gender, and culture intersect and thereby shape institutions. Yet the importance of class distinctions on literacy development and writing pedagogy is increasingly apparent in a wide range of publications that seek to address the effacement of class from the academy. As Theodore Sizer, Jean Anyon, Joanne Kadi, Jacqueline Jones Royster, Anthony Petrosky, C. H. Knoblauch, Harriet Malinowitz and others have pointed out, the privileges of class and the access to resources and benefits it provides are 
neatly structured into the very institutions that are held up as a means of social mobility.

For our students, anxious to become a part of that popular mythological transformation, a critical understanding of class, a sense of ownership for their own class affiliations, and a recognition of how class privilege operates may be the last thing they want. Why, after all, would they want to challenge that which they yearn desperately to be part of? In fact, the hurdle that those of us in basic writing confront is our students' resistance to a critical scrutiny of the class system and its underlying assumptions - of individualism, free market values, and all the ideological baggage that capitalism packages itself in.

Yet, as Janet Zandy points out in her book Liberating Memory: Our Work and Our Working-Class Consciousness, the recovery of a sense of class consciousness is essential in helping our students reclaim a sense of identity and community that has been effaced by a dominant bourgeois culture which asks our students to collude in their own loss of identity. The common tendency to deny working-class backgrounds, as something that one gets rid of, "is an assumption that reduces human interaction and potential to mere commodity exchange and personal enhancement" (Zandy 1). Along with the self-objectification that such an attitude calls upon us to enact upon ourselves, it reduces us, in effect, to a mindless repetition of a classist ideology that sanctions the forces of capitalist privilege in our culture without really acknowledging or appreciating the value of our work. Moreover, it banishes the possibility of the development of a critical class consciousness, and with it a collective struggle. Zandy's analysis of the development of class consciousness is especially useful here in its critique of some commonly accepted polarities:

A critical, working-class consciousness is both expansive and grounded. Individual and collective. It is an alternative to the bifurcation of politics and culture, work and home. It recognizes ambiguity and contradiction without excusing the damage that one individual can do to another. It is multigenerational and historically situated, but, paradoxically, not dependent on linear time. This consciousness is not "success." It is not a safe harbor. It does not deny death. Nor is it bourgeois cynicism or despair. Working-class consciousness includes identity, but it is not fixed on identity. It is an aperture. A radical, portable alternative to the individualistic way out. It is that crucial attentiveness to others that fuels and enables resistance to injustice. (2)

The development of a critical class consciousness is more than a recapitulation of the idiosyncratic ways in which the individual elements 
of one's own life determine one's place, as many of us experienced at the workshop. To recover a sense of one's class identity is to explore the webs of relationship that create a sense of place and identity in a specifically conceptualized system. By doing so, all of us, teachers as well as students, can begin to understand the ways in which our knowledge of the world is constructed and framed within class-defined assumptions - assumptions that determine who is empowered and who is not, who is entitled to a sense of agency and who must simply submit to the ideological rationalizations of others, who should be the decision makers and who their followers. In effect, the recovery and ownership of a sense of class identity, along with the complexities that the multiple locations of gender, race, and culture contribute, enable students to adopt a critical perspective that would be impossible otherwise.

It was toward these ends that our workshop presenters aimed. In their discussion of class issues in and out of the academy, Gary Tate, presenting together with John McMillan and Elizabeth D. Woodworth (also of Texas Christian University), laid the groundwork by recapping the impact that Working Class Studies has had on Composition and Rhetoric in recent years. ${ }^{1}$ McMillan and Woodworth then went on to discuss the ways in which academic contexts present occasions for the erasing of narratives that would account for the class consciousness that shapes our students' critical perspectives. Workshop participants then examined in writing how the stories we tell ourselves and others about ourselves and our class locations influence our teaching and our lives in the academy. The result was a rich blending of narratives from across a wide spectrum of class locations.

Jacqueline Jones Royster and Rebecca Taylor of Ohio State University, in their presentation, "Constructing Teacher Identity in the Basic Writing Classroom," then led workshop participants in what Royster termed "the debunking of master narratives" by inviting attendees to identify their locations as teachers within institutional and regional contexts, thereby creating "a leverage point from which to reflect." By doing so, we as teachers can arrive at new solutions to the difficulties that class differences pose in basic writing classes, with the recovery of location as a factor in understanding our own roles and our students' difficulties.

Other workshop leaders helped to focus the dialogue by touching on some of the many issues central to basic writing. Jane Maher shared her research from her recently published book Mina $P$. Shaughnessy: Her Life and Work by revisiting the beginnings of the basic writing movement with a portrait of the extraordinary energy and commitment to equal access Shaughnessy brought to open admissions programs. Her awareness of her own good fortune and privileged position strengthened her advocacy for her working-class students in 
a revolutionary writing program that she hoped would begin to address those discrepancies. Victor Villanueva directed an exercise he conducts with his basic writing classes, creating word poems out of concepts. By directing participants to cut from their list of terms the number they could then use in writing, he demonstrated the constrictions that students likewise experience when we prohibit the use of their home community's languages.

Mary Soliday and Barbara Gleason from CUNY introduced workshop participants to their 3-year FIPSE Pilot Project on mainstreaming. Their video of students' presentations of their writing together with the holistic evaluation session that they led, with participants scoring writing samples from students' portfolios, persuasively argued for the mainstreaming of basic writers in other equally supportive programs. Concluding the session, Ira Shor 's "Farewell to Educational Apartheid: Basic Writing and Cultural Democracy" added an historical dimension to the workshop, retracing the roots of the contradictory forces at work in the democratic impulse in education and institutional policies for tracking. All of us were enriched by Shor's scholarly account of the impetus for the community college movement, the "cooling-out function of higher education," and subsequent efforts to place working-class students in vocational tracks that denied them further social mobility and failed to recognize their potential as critical thinkers and citizens.

Central to all our discussions was a concern for the ways in which academic discourse communities' mores and conventions have been mystified by unconscious class assumptions about agency and power. For our students and for ourselves, much of that can be deconstructed through an examination of the unmarked positions we're regularly presented with and through a recovery of our own class narratives. In her ten-year long project of collecting the narratives of working-class cultural workers, Janet Zandy gives us some clear insights into the value of autobiography in class struggles. She identifies what she calls "a usable past" and the value that reconstructing an account of one's past holds. "Memory," Zandy stresses, "has purpose. It is a bridge between the subjective and intersubjective - the private and unprivileged circumstances of individual lives - and the objective-the collective history of class oppression. It is a way of moving from personal pain to public and cultural work. The 'stuff' of one's life can be transformed into fruitful practices. Even grief can be put to good use" (4). As many of us at the workshop experienced, an effort to repossess one's origins, to see them as they were, replete with the class distinctions that often reproduce a classist bias, is essential to a critical stance. For our students, the stakes are equally high. For when they see the ways in which their imagined futures have been inscribed in the class assumptions built into the schooling and institutional acculturation 
they have experienced, they can begin to unravel that process. Without it, they probably won't. Whether they do so is a choice they should have.

\section{Note}

1. Especially significant is the role that the Center for Working Class Studies at Youngstown State University has had in foregrounding the influence of class politics inside and out of academia. YSU's Second Biennial Conference on Working Class Lives, held in June 1995, led the way in promoting a dialogue across the academy, among labor studies and public policy professionals, literary critics and rhetoricians, historians and union organizers, about the ways in which class continues to be effaced in our culture. Their work, combined with recent publications by Janet Zandy (Liberating Memory: Our Work and Our Working Class Consciousness, Rutgers 1995; Calling Home: Working Class Women's Writings, Rutgers, 1990 ) and issues by Radical Teacher (Spring 1995, No. 46) and Women's Studies Quarterly (Spring/Summer 1995) devoted wholly to issues of the working class, investigate the need to understand our own class histories, to inquire into the stories we tell about ourselves, about where we belong and who we are within designated class systems whose boundaries are often blurred by competing and unconscious allegiances. YSU's most recent biennial conference, held June 11-14, 1997, strengthened participants' commitment to a multi-disciplinary dialogue about class, labor, and academia.

\section{Works Cited}

Anyon, Jean. "Social Class and the Hidden Curriculum of Work." Journal of Education. Vol. 162 (1980). Reprinted in Writing Lives. Ed. Sara Garnes, David Humphries, Vic Mortimer, Jennifer Phegley, and Kathleen R. Wallace. New York: St. Martin's Press, 1996: 248266.

Kadi, Joann. Thinking Class: Sketches from a Cultural Worker. Boston: South End Press, 1997.

Knoblauch, C. H. "Literacy and the Politics of Education." In The Right to Literacy. Ed. Andrea A. Lunsford, Helene Moglen, and James Slevin. New York: MLA, 1990.

Lind, Michael. "To Have and Have Not: Notes on the Progress of the American Class War." Harper's Monthly. June 1995: 35-47.

Malinowitz, Harriet. "The Rhetoric of Empowerment in Writing Programs." In The Right to Literacy, 152-162.

Petrosky, Anthony. "Rural Poverty and Literacy in the Mississippi Delta: Dilemmas, Paradoxes, and Conundrums." In The Right to Literacy,. 61-73. 
Royster, Jacqueline Jones. "Perspectives on the Intellectual Tradition of Black Women Writers." In The Right to Literacy, 103-112.

Sizer, Theodore. " Public Literacy: Puzzlements of a High School Watcher." In The Right to Literacy, 9-12.

Zandy, Janet. "Introduction." Liberating Memory: Our Work and Our Working-Class Consciousness. Ed. Janet Zandy. New Brunswick, NJ: Rutgers UP, 1995.

Zebroski, James Thomas. "The English Department and Social Class: Resisting Writing." In The Right to Literacy, 81-88. 


\section{Gary Tate, John McMillan, and Elizabeth Woodworth}

\section{CLASS TALK}

The panel "Confronting Class in and out of the Classroom," put together by three colleagues from Texas Christian University, was the first out of the gate at the CBWworkshop. And the first speaker was Gary Tate. Author or editor of such works as Teaching Freshman Composition and Teaching High School Composition (with Ed Corbett), An Introduction to Composition Studies (with Erika Lindemann), A Writing Teacher's Sourcebook (with Nancy Myers and Ed Corbett), and Teaching Composition (a collection of 10 bibliographic essays revised and enlarged to 12), Gary can be said to be the writing teacher who taught us all how to teach writing, so it is both heartening and thought provoking to find him firding himself-and his field-exploring largely unmapped territory, making discoveries both personally and professionally significant. Joining him in this endeavor are two doctoral students: John McMillan, a "rhet/ comp" specialist and co-editor (with Gary Tate and Alan Shepard) of Coming to Class: Pedagogy and the Social Class of Teachers (forthcoming from Heinemann/Boynton-Cook), and Elizabeth Woodworth, whose research focuses on the challenges late Victorian women writers posed to representations of women but who has also had a hand in directing both the composition program and the writing-across-the-curriculum program at TCU. What follows gives a sense not just of what the panelists did and said (and how they interacted with the workshop participants) but the thoughts all this provoked.

\section{Thinking About Our Class}

Gary Tate

When I walked into the meeting room at the Hyatt in Phoenix where the basic writing workshop was to be held, I saw a room filled with round tables and chairs for participants and a microphone and lecture stand for the speakers. Because it seemed to me inappropriate to "lecture from above" on the topic of social class, I suggested that John, Elizabeth, and I just sit at one of the tables near the middle of the room so that our voices could be heard and so that we would be a part of the workshop. This worked well. And the presence of several workshop participants at our table as we talked gave me the feeling that a conversation was taking place. I began by pointing out that I would talk for a very few minutes about social class generally and about our feeling that teachers must attend to their own social class before bringing class into their classrooms, that John would talk, again briefly, about the power of storytelling in discussions of class, and that Elizabeth would then act as our teacher and give us all a writing assignment, the responses to which would be discussed later as the core of this portion of the workshop. Here is what I said:

Elizabeth and John and I are here today to propose four theses for your consideration: 
1. that social class - the perennial third item in the familiar trio, gender, race, and class - has been largely ignored in composition studies and in the academy generally,

2. that there are signs that this neglect is ending,

3. that the neglect of class must end if we are to understand our students as fully as we must if we are to teach them well,

4. and, finally, that before we can bring class into our classrooms in a meaningful, productive way, we must try to understand and come to terms with our own individual class histories, complex as these may often be.

Let me say just a few words about each of these points. Our neglect of class is not difficult to demonstrate, although it is difficult to understand. It has grown, I suspect, out of that peculiarly American feeling - $a$ feeling praised by those who profit from it - that we are a classless society and that matters of class are, thus, insignificant, even embarrassing. Many of us have an easier time talking about sex than we do about social class. Whatever the cause, we have not attended to social class in the way we have attended in recent years to matters of gender and race. One searches in vain through composition journals for anything more than an occasional reference to the subject. And the books in the field do only slightly better. The names of Mike Rose, Jim Berlin, Ira Shor come to mind, but beyond that, very little.

Fortunately, and I move to our second thesis, the situation is changing. Let me mention some signs. At the meeting of this organization in Milwaukee last year, there were, if I count correctly, three sessions devoted to issues of class: two roundtable discussions and one special interest group. All three of these sessions were packed - people sitting on the floor, standing in doorways, and so on. A good sign, we thought. And we were right. This year, there are twenty-one panels and roundtables, two special interest groups, and this workshop. (Let me add, parenthetically, that the number of sessions on race has increased even more dramatically. Last year there were five; this year there are forty-five: this workshop, three special interest groups, and forty-one panels, roundtables, forums, etc.) More evidence of this new interest. Last October's issue of College English (1996) featured an article by Lynn Bloom on "Freshman English as a Middle-Class Enterprise" and my review of two books about working-class academics. A few issues before that Lynn Bloom had also reviewed a book about working-class women in the academy.

Not much, but certainly better than in years past. A Center for Working-Class Studies has been established at Youngstown State Uni- 
versity in Ohio, and, in 1995, Youngstown State hosted a conference entitled Working-Class Lives/Working-Class Studies. They will host another such conference this coming June. To many of us, the ' 95 conference was a revelation. As I have said many times, it was the most exciting meeting I have ever attended, reminding me, as it did, of early $4 \mathrm{C}$ 's meetings, where small groups of enthusiasts, not much honored back home, gathered together for support, education, good talk, and, indeed, inspiration. If you are free the next time this conference is held, find your way to Youngstown, Ohio. You will never regret it. Or go to Omaha, Nebraska, the next time the University of Nebraska at Omaha holds its Pedagogy of the Oppressed Conference. Both of these conferences are good signs that the landscape of class studies is changing.

Another positive sign is that at least three collections of original essays on issues of social class and teaching are being prepared for publication: one by E.J. Hinds of the University of Northern Colorado, one by Sherry Linkon at Youngstown State, and the one that Alan Shepard, John McMillan, and I are editing at TCU. Finally, a sure sign that the neglect of class is ending: Benjamin DeMott has just edited a reader for first-year composition courses, entitled Created Equal: Reading and Writing About Class in America (HarperCollins, 1996). When publishers of textbooks for first-year composition classes take an interest in a topic, I think we can say with some certainty that that topic has arrived, late though it may be.

Our third thesis, that we must attend to social class if we are to understand our students as fully as possible, makes sense to us and we hope that it will to you. Just as our lives and the lives of our students are profoundly affected by gender, race, sexual orientation, and so on, so they are profoundly affected by social class, be that working class, middle class, upper class, or whatever categories you choose to think in. Although the primary focus of the work I've mentioned - and of much of the important work being done today -is the working class, certainly the attitudes, linguistic habits, behavior patterns of all our students are influenced, in part at least, by their class histories. If we believe Lynn Bloom when she says that Freshman English is a middle-class enterprise, then we must assume that students and teachers from middle-class backgrounds will feel more at home in the course than will others. Be that as it may, there is a rapidly growing body of testimony about the difficulty that working-class students - and teachers - have adjusting to the demands of the academy. And there is some evidence that students from the upper classes have similar difficulties. One of the contributors to our book writes eloquently of her difficult transformation from her life of wealth to her life as a graduate student in English. Here are her words: "[l]n preparation for graduate school, I sold my Mercedes, put my Rolex watch in the vault, and boarded a private Lear jet [her father's] with one suitcase and my cat, headed for 
a different life." Now I suppose that most of us would have trouble seeing her difficulties as equivalent to the difficulties of a working-class student struggling to survive, but my point is that we should not-as some of my colleagues seem to suggest-ignore all class difficulties not associated with the working class. The tricky thing about class is not just its fluidity, its complexity, but that it is so easily hidden. Just as the woman I quoted tried to hide her upper-class upbringing - not successfully, I can testify - so working-class students can hide their identities - or try to. The right clothes, the right hairdo, will hide much. What can often not be hidden, however, are the bad teeth, bad skin, the too-loud voice or brash manner (or silence), the struggle with "standard" English, and a host of other signs that will not escape the observant, caring teacher.

And so we would urge you today not to ignore the class positions of your students, because we are beginning to understand more and more about how these positions influence their lives in school, their learning styles, their behavior, their choices. Some of you here today, especially those of you from working-class backgrounds, could, I am certain, join me in remembering the pain and estrangement we have felt, as students and teachers, as we have attempted to "fit into" this strange and often hostile world of higher education, a world that has caused many of us to deny our past and to resort to coping devices of a sometimes dangerous kind. Drugs became my favorite coping device for many years, the dirty secret behind a career that has looked, on the outside, to be moderately successful.

This brings me to our last thesis: that before we can make productive use of our knowledge of students' class positions, we must seek to understand and to come to terms with our own. And that is not easy to do, especially for those of us who have been hiding our past-from others, and, more important, from ourselves. Or we have been fooling ourselves into thinking that we have left all that behind. As my ten-year-old granddaughter is fond of saying, airily, when I ask her if she still likes a certain kind of music or a certain kind of jelly, "Oh, I've moved on." The question is, can we move on? The answer, I think, is only a little. I very much like the way Janet Zandy puts it when writing about the working class in her anthology Calling Home (Rutgers UP, 1990): "If you are born into the working class and are willing to change your speech, your gestures, your appearancein essence, to deny the culture of your home and the working-class self of your childhood-then you might 'pass' as a member of the dominant culture. But you will never belong there" (2).

So the question is: Where do we belong now? Where have we belonged? Who have we been? Who are we now? How we answer these questions depends, as Carolyn Steedman points out in her brilliant book Landscape for a Good Woman (Rutgers UP, 1987), not so much 
on what has actually happened to us in our lives as on the stories we tell ourselves about what has happened. As I have begun to try to come to terms with my working-class past and to see how it has influenced my life, I realize that I have suffered not so much from the actual circumstances of my life, but from the stories I have been telling myself about those circumstances, stories, that in my case, left out entirely anything about social class, stories that had me struggling alone, the victim of my own personal weaknesses, my own ignorance, my own loneliness. Slowly, I have begun to tell myself different stories and it has made an enormous difference - in how I think, how I teach, how I live.

And so, this morning, it is to narrative that we must turn, to storytelling. Back to our very beginnings.

\section{John McMillan}

\section{Silos in the Suburbs}

When I think about my own social class, the best I can do is approximate. It is this about social class-talk that I particularly like, that it is overtly what perhaps every other kind of talk is covertly-a best guess, a shot in a dimly lit dark, a story. Of course, according to some definition of "common sense" you could quite easily say that I am middle-class. Certain stories of mine fit well with this common sense vision: I grew up in the suburbs, my dad has an MBA, I graduated from a private university.

But class is a sticky thing, and as there are problems in saying "men are like this, women are like that," etc., it seems to me that there are also some problems in resorting entirely to a kind of class-talk that says "middle-class people are like this, working-class people, that." Class talk can as quickly degenerate into overgeneralizations and proclamations as any other talk, I imagine. That is, it can morph into those kinds of declarations that are attempts to end conversations and to explain existing power relationships according to first principles. Nevertheless, class is sticky, and perhaps, above all, what I mean by this is that class-talk resists depersonalization; and personalization is about approximation, which is the best I can do. And so I am arguing that, more than a place for proclamations, social class is an occasion for stories. And so it is in the spirit of Jesus's reply to the young lawyer's "and who is my neighbor?" that I offer the following collage of tales, or, you might say the stories that are the beginning of my theory about my own social class. 


\section{Where it all began:}

Once, early in my undergraduate days, I was in a sort of church meeting where the preacher asked, "Did anyone here grow up on a farm?" Of course he didn't really ask it. He was trying to make a point about "real" work. He was talking about the loss of certain values. I raised my hand. I was the only one. There were two hundred people in that crowd.

I don't know why I did it. I'd done it without reflection. The preacher cocked his head and focused in on me. His look screamed that nobody was supposed to have answered that question affirmatively. It messed up his point. "You grew up on a farm?" he queried. "No," I stuttered, "I didn't." My voice was quivering. If I'd been standing I'm sure I would have fallen over. His face screwed up somewhere between a scowl and a snicker. He turned his head back and went on with his sermon.

Years later, older and tired of being embarrassed, I allowed myself to reflect a bit on that event. It was from that reflection that my theory grew. It is sufficient to say that, as random as my answer to the preacher was, I'm not so sure it was entirely wrong.

\section{A Theory:}

There are silos in the suburbs. There are church pews from tiny Pennsylvania Baptist churches in the office buildings of the city. Pre-dawn milkings and prayer meetings give shape to our days. The best I can do is approximate. So I'll say it again, There are silos in the suburbs; and, of course, they're in my classroom too.

\section{Allow me to explain myself. Let me tell you a story... or 3 or 6:}

My father was raised on a farm in Ohio; my mother was the oldest daughter of a Baptist minister who, over the course of her growing up, pastored congregations in rural parts of New York, Pennsylvania, and Ohio--places called Black Creek, Wellsville, Pavillion.

From what I can make of it, it went like this: when my father graduated from high school, he wanted to go to college. No one else in the family had ever considered such a thing. A few of them were even opposed to it. He enrolled at Ohio State University in Columbus, paid his way working as an R.A. during semesters and by raking asphalt in the summers. Got a job at Kodak upon graduation. They funded his MBA. I know less about my mother. The oldest daughter in a family of seven children, after a year of business school in Olean, New York, she went to work as a secretary at Kodak. They met and married, I was born three years later.

I grew up in a suburb in upstate New York. I lived in the same 
house until I left for college. When my brother was born, rather than moving to a bigger house, my parents decided to add on. With the help of relatives (my mother's father built a fieldstone fireplace in the new addition, peppering it with "stones from the holy land," I was told, gathered from a recent trip to Israel.) They built the addition off the back and cut out of the attic a room for my sister. My brother moved into her old room, downstairs, next to mine.

I started delivering penny papers door to door when I was eleven. You could work that young if you had a permit, signed by your parents. I graduated to the city paper a couple of years later and remember something of the excitement I had at the prospects of a real job where I collected money and got Christmas tips, where someone actually read what I was delivering. Eventually I passed the route off to my little brother. Later, in high school I could be found working at the local pizza joint six days a week.

My dad retired at age 49 . He and my mother bought an old farm house out in the country. They have a barn across the street. My mom works as a secretary at a real estate office in the city. My dad reads a lot and keeps up the yard, works on the house. They both tend to the garden.

I tell these stories because somehow they help explain me (me explain?) when I am confronted with questions about my own social class. In a world marked by commercials and Cliff's Notes, stories are terribly inefficient. They are long, slow, and, at their core, are in opposition to the illusion of exactitude we've all become addicted to. Jim Corder, in an unpublished manuscript, has said that his best guess is that even the most orthodox academic paper is really only the very end of a long, personal narrative ("On Argument, What Some Call 'SelfWriting,' and Trying to See the Back Side of One's Own Eyeballs"). And Wayne Booth has suggested recently that "authoritative" discourse, whatever that might be, derives its power from its ability to conflate a reader's "narrative" and "authorial" audiences ("Where Is the Authorial Audience in Biblical Narrative - and in Other 'Authoritative' Texts?" Narrative 4 [1996]: 235-253)--that is, if I understand Booth right, it could be said that a text's power comes from its ability to un-story itself, comes from its success in erasing and effacing the storyteller. I want to say that class-talk resists this erasing - which might explain why social class has been talked about so little in the academy. The personal narratives of class are written in permanent ink. To un-story class is to cease to talk about class.

From my own class stories I see characteristics I name "self-reliance," "discipline," "simplicity," "confidence," and "tempered defiance," the last term being a kind of encapsulation. of the previous four. I'm not sure if I like it yet, but I see myself trying to engender 
these characteristics in my students in invitations to negotiate grades and assignments, in requiring self-assessments, and in my recent grappling with contract grading. These are the cells around which my stories of myself as a teacher grow. So that, finally, any account of the effects of my own social-class upon my teaching is double-deep in narrative: It is making sense of how the stories I tell myself about my class affect the way I story my teaching. Which is why I say that there are silos in the suburbs, and that they're in my classroom too.

\section{Elizabeth D. Woodworth Chat and Write: Write and Chat}

During this "teaching" portion of the workshop, I offered participants this plan: "I'll talk briefly and generally about social class and me, and then I'll ask you to write a bit about your reflections on social class and you. Then we'll have a brilliant, lively, and illuminating discussion."

\section{Chat: Preamble}

Any time we want to talk about social class as an issue in a writing classroom, we have to first explore our own perceptions of our class. There are so many questions we can ask ourselves when we approach the issue of class it seems a monumental, even insurmountable, task. What is social class? Is a definition of class dependent upon our economic situation? Our race? Where we live? What we do for a living? What sex we are? Should all these factors be considered in a our exploration of social class?

In fact, right when we start asking questions about what class might be and what that means, the topic of social class wriggles out from under the lens of our microscope and defies demarcations and categorizations. It's just two short words, "social class." It ought to be a simple thing to discuss, to explore, to contemplate, but no, the connotations intrinsic to these two short words depend so much upon the individual (despite and because of cultural, racial, sexual, tribal affiliations). This difficulty, this reflection inward to the one and outward to the many, at the same time, necessitates a circular, an open and enfolding, connective approach.

A linear approach-suggesting one definition of social class or 
another, one narrative for all-must be impossible - because how can we be precise when we talk about class? How can we talk about class without talking about everything else we believe ourselves to be? How do we sort this out then? If this is a topic that concerns us, and it does or we wouldn't be here now, we have to start somewhere. And to begin, you begin with yourself.

I have, like both Gary and John, looked to the stories I tell myself, have told myself about where I come from. I've looked to the stories others have told me about where I come from: my grandmother, my mother, my father, other family members, my friends, my neighbors. I've looked to the stories I tell others about me-and how that might differ from what I tell myself. Then I've looked at how these stories determine the person I am in the classroom. How have I presented myself to my students? Has my behavior somehow subtly or boldly declared what I believe about my social class?

When I began to dissect the narratives which fill my life-the stories about who I am, my gender, my race, my class, I began to see how all my perceptions about me affect who I am as a teacher. I wasn't surprised, really, or unhappy to find that, as a teacher in a writing class, I'm deeply influenced by my, and my family's, past and profoundly influenced by who I think I am at present, and the stories I tell myself and others about who I'll be in the future. By just knowing that I can somehow begin to grapple with myself and the slippery issues of social class, this knowledge of my confused state regarding social class helps me to begin finding new ways of attempting to reach students, no matter who they are, or where they come from, or where they're going, no matter what they believe, or what they look like. When I can begin to untangle my many narratives about me, then I can begin to unravel who I am as a teacher-keep the parts I like, discard what doesn't work, and even experiment a little. But most importantly, I can begin to ask my students to consider what "social class" means to them; I can ask them to write about such reflections; I can give my writing students the opportunity to talk about what has so rarely been discussed openly - but, I believe, so clearly needs open discussion.

\section{Write: The Initial Assignment}

At this point I concluded my chatting and asked participants to take twenty minutes or so to write about themselves and class. The prompt below was announced and the "write" portion of our presentation began:

How do the stories you tell yourself and others - about yourself and your social class -influence your teaching and your 
life in the academy, especially in the basic writing classroom?

At the end of twenty minutes, I asked participants to share what they felt comfortable sharing, as little or as much as they had written.

Following this are two sections, responses and reflections: a response from one participant to the prompt, and my reflections on this and other's responses.

\section{Chat Again: Response}

One of the participants kindly offered us his text to include with this written version of our presentation. It is largely a reconstruction of what was written during the twenty minutes allocated (with some extra commentary where needed). The difficulty Gary wrote of earlier - that it's hard to talk about class, is evident here in my writing and in that of our volunteer participant/writer. But we did it anyway, difficult or no; we had a conversation about class and teaching and who we are and can be-contributing, in our own way, to the emergence of class studies as an important field of its own and an important part of composition studies.

Earlier John explained his notion that we "story" our teaching by using our own narratives to tell ourselves about ourselves as selves and as teachers. John says, "I tell these stories because somehow they help to explain me (me explain?) when I am confronted with questions about my own social class." The sample response works this way too: it is an explanation of self, self trying to understand social class, self confronting social class histories. These are the stories that must be told so that we can, as Gary puts it, "bring class into our classrooms in a meaningful and productive way."

Before I came to graduate studies, I was a bus driver in New York City for twenty-one years. After about thirteen or fourteen years, in the midst of a personal crisis, I decided I was living someone else's life, that I needed to make a drastic change of some kind.

I am now a grad student and a teacher. Because I am a nontraditional working-class entrant in academe, I view my students differently than my colleagues who have traveled the traditional acudemic path. I used to think of the teacher/student exchange in terms of "otherness": I am their Other, and they are mine. I am now what they aspire to be, and they represent for me my past. But, increasingly, I think of this exchange less in terms of difference and more in terms of likeness. I am more like them, and less like other graduate students, than I was formerly aware. I can no longer ignore the elite 
and snobbish attitudes which constitute too much of the discourse of grad students about their own students. They can't wait to be rid of them and get back to their "real" work, their literary research. However, I try not to throw the baby out with the bath water; I condemn their attitudes and not their love of literature. Why? This is my love, as well. But I have learned that I am never more comfortable than when I am among other "nontraditional" students (grad students or composition students) because it is at these moments that I feel that I have come home.

\section{Leo Parascondola, The Graduate School, CUNY}

Leo's response is an important one as it raises the issue of class within the academy, within English studies: the literature major vs. the composition major. Literature vs. rhetoric and composition - a rivalry that has long been a source of tension and also, as Leo suggests, split allegiances. A hierarchy exists in English studies which allocates rhet/comp studies to a second-class position. Talking about this class struggle is as vital for teachers of composition and literature as talking about their own social class histories, for by entering the profession of teaching English, they embark upon another journey in which class distinction is critical to self-perception, self-fulfillment. This is an issue that must always be part of our "class talk."

\section{The Last Chat and Write: Some Reflections}

I can only give impressions now of other responses, but the impressions have stayed with me long after the experience, long after the actual words shared by the participants. Part of this lasting sense of what happened has to do with me personally - a personal class history thing that needs explanation, perhaps.

Every time I talk with someone about class issues and we exchange stories, I feel like I'm at one of those 12-step meetings: "Hi. My name is Elizabeth, and I'm confused about class - mine, yours, the definition of class." But the more I talk about class and writing, the more I listen to other's stories, the better I feel. I come from a strange place of mixed race, mixed class, mixed gender-role messages. I was raised in a German-Irish family but am of Hispanic descent (as I recently learned just before my adopted mother died). My mother's family were impoverished upper class from Chicago. Dad's family were dirt farmers and railroad workers from North Dakota with so many kids they shared shoes, and each kid only had one good set of clothes, one set of everyday clothes. My parents insisted that I get a good education, prepare for a career, be the ideal wife when I got married, be an ideal mother, the perfect super woman. Of everything I felt like I had to be, "edu- 
cated" was the most important. My mother never finished college, despite several attempts over a twenty-year period, because she would not commit to school, but she insisted I totally commit to my education. Yet I also needed to know how to organize the perfect dinner party, how to garden, build shelves and such handy stuff, change a tire or an air filter, throw a baseball, cook tasty and nutritious meals, look great, be witty, be at home with a plumber or a CEO as my dinner partner, and throw a spiral pass (and when I wanted to grow up to be an NFL player, I was told ladies don't play football-huh?). My scattered sense of self, no doubt, contributed to the length of my undergraduate career - nine years, seven universities, six declared majors. I couldn't decide who I was-how could I possibly decide what I was going to do? And all along I feared that I would never graduate, or impossible of all dreams, get to graduate school and succeed.

Fortunately, John McMillan and I met the first day of graduate school and bonded over our shared fears that we somehow didn't quite belong. We confessed to each other that we felt uncomfortable in grad classes - just waiting for the elitist goon squad to come and knock on the door of the classroom: "Excuse us, we've come for Elizabeth and/ or John. There's been a mistake. You don't belong here. You must come with us." What happened after that neither of us was sure-but we were convinced about that much. In some ways, even before we started to think seriously about class studies, we were talking about our class backgrounds, sharing our stories, sharing our fears about who we were according to who our families had been, what they had done, who they knew, how we valued work.

Last year at 4Cs, I listened to Gary Tate confess similar feelings about his class and fears of belonging - or rather, not belonging - and how such fears, when repressed, could profoundly affect a life. I felt, with some variations, he was telling the same story John and I had told to each other several years before. For me, he crystallized what it was I had struggled for years to understand - my self-doubt came from my inability to talk about my class, from my unknown race, my mixed view of gender roles, my sense that somehow I might not belong to the academic set.

Listening to the workshop participants, many of whom confessed fears of inadequacy in academe, was like listening to myself. And their stories have stayed with me-melting into my own stories - the ones I tell myself, the ones I tell others, helping me to further explore the way my social class history has molded my present and is molding my future self.

A young woman spoke about her life, her class, her family, with tears in her eyes, trembling hands shuffling papers in front of her. She came from a working class family who had become increasingly distant from her as she became more formally educated. Both she and 
her family were proud of her achievement - a move to a higher class through education - but both wondered if she could really belong anymore. As she spoke, her words shook me - her worries were my worries-her experiences were mine. My dad's family of high-rise construction workers were pretty well split between pride in all my education and derision for my "useless" knowledge. Did I really belong among them anymore? Clearly we were both (she and I, dad's family and I) concerned about "class," status. Even my use of "dad's family" marks the distance I feel-somehow they don't feel like my own family, only a family of mine via Dad.

I became distressed, eyes making tears, as I saw her struggle to tell her story. Her courage made me want to jump up and run to her and tell her it was okay - she was telling the story of all of our struggles with class issues, she was telling the story of our shame, our discomfort with the very topic of class. The details didn't matter in a way. Not one other noise could be heard while she spoke. It was as if she had articulated the emotional and intellectual needs that had motivated the organization of the session, as if she had articulated the emotional and intellectual reasons we were there.

A shy young man shared his writing. He struggled to speak, too, as this young woman had, but was determined to do it. He was clearly shy about sharing, keeping his eyes on the text he'd just written, rarely looking up, pages shaking slightly as he read. His story was another one of fear and inadequacy in academe, exacerbated by his emphasis on composition studies. He had felt like the Other in the academy as a student, now he felt like the Other within his own academic department. Few teachers of composition could not relate. Class markers are everywhere - even in English departments - and it's a deeply moving experience to talk about what class means to each of us. And while it might have been difficult, it was necessary to the participants to share what they had discovered about themselves through writing.

An older man, brown of skin and with an accent I did not recognize, spoke about class as an issue for the new citizen, or the "alien." - He spoke of the hope of the United States, the apparent "classlessness" of our society as it was perceived in his home country. But he realized after living here that there is a class system, even if not clearly articulated by our culture. He seemed less disconcerted by the class differential than the lack of articulation. And he admitted that this could be (and probably was) a result of other cultural influences. Living in a supposed "melting pot," concerned with class issues, it seems crucial that we ask how the mix and contact of many cultural ideas of class are brought to bear on our discussion.

A young black woman spoke of the shock on her students' faces in a heartland college when they realized she would be their teacher. Black, a woman, and teaching college. Wow. For her, she was also 
shocked by her entrance into university teaching because of the lower socio-economic background she came from-something the students could not see, but a reality which added to her anxiety about being an authority figure. Her case, her response, her students' reactions are argument for striving to look at class, gender, and race as related issues. Could she possibly separate these in her own life? Can we separate these issues in our own lives? Can we start with class and move to race and gender as issues under discussion in our writing classes? Can we discuss one without the others? I think not.

Many more shared their responses-many ages, many races, many classes, women and men - all concerned with the ways we define ourselves, our class, our race, our gender roles. What was most important for me, many spoke about the ways they connected their "class-talk" with their teaching, particularly about how it encouraged them to reach out to students who are worried about not belonging or not making it. There was a general eagerness to share, despite the difficulty of doing so for some.

Like the first time you taste, do, or see something - there's joy and freedom and the desire to describe, and the fear that others won't understand your special experience. What this part of the day's workshop did (for me and for others) was alleviate the fear that "no one can understand me," that "no one is like me." And this conversation about class is exactly where we can start and what we can share with basic writing students who so desperately need to know they are not alone, who need to know that someone can and will understand them. That class markers are not brands that prevent success in the academy, but rather marks of distinction that need not-should not-be negative.

Throughout the remainder of the conference, participants stopped me regularly to say what an impact the workshop had on their thinking, how they enjoyed what had happened throughout the day, but mostly what I heard was that being able to write and talk about social class in a safe place was liberating. Isn't this what we hope to give our students in writing classes - the chance to write in a safe place? Isn't our agenda to give our students a chance to grow as writers? Don't we hope we can help them to places where they can think beyond where they've been before? Don't we hope they will find new ways of seeing themselves and others through their writing?

For Gary, John, and I, the workshop proved to be a fertile ground for further thinking and talking about class and writing, basic writing especially, as we made new friends, shared stories and ideas, learned new strategies for helping the basic writer, and came to understand a bit more about ourselves as selves and teachers. 


\title{
Jacqueline Jones Royster and Rebecca Greenberg Taylor
}

\section{CONSTRUCTING TEACHER IDENTITY IN THE BASIC WRITING CLASSROOM}

\begin{abstract}
A high moment in the workshop occurred when Jacqueline Jones Royster and Rebecca Greenberg Taylor directed participants to focus on ourselves and colleagues as basic writing teachers. After Royster explained how they had come to believe that too much attention had been concentrated on defining and categorizing our students, she led us in an informal survey to help us examine our own institutions for racial, gender, and class differences. We then wrote about our self-perceptions and aspirations and shared some of these. Next, Taylor powerfully presented a paper on a year in her life as a graduate student in the Rhetoric and Composition Program in the English Department at the Ohio State University and as a basic writing teacher during 1996-1997 in the OSU Basic Writing Program. Her teaching directly related to her interests in authority, identity, genre, and the teaching of writing. Jacqueline Jones Royster, the Vice Chair for Rhetoric and Composition in the English Department, is Taylor's dissertation advisor and has complementary interests in issues of identity, classroom culture, and the development of literacy.
\end{abstract}

Our focus is on the implications of identity in the construction of classroom culture. Our imperative was to emphasize that "identity" in the classroom is a person-driven enterprise, i.e., that such a term becomes most salient by referencing the unique characteristics of the actual people in the room and not through definitions that abstract general traits and push teacher/researchers toward the construction of identities in generic terms. All too often teacher/researchers in our discipline have centered attention on only one set of the people in the room, the students, with only peripheral attention being directed toward the other set, the teacher.

While articles such as Lu (1994), Johnson (1994), Gunner (1993), and Dean (1989) have raised awareness of the extent to which as professionals, we are all racialized, gendered, and political subjects in classroom space, the interrogative gaze in both theory and practice has generally been unifocally determined (i.e., defined by the negotiations of students) rather than multifocally determined (i.e., defined by the negotiations of both students and the teacher).

In being multifocal in our gaze, we shift attention from the students to the teacher and then examine the implications of this viewpoint, not only for the students, but for the creation of the classroom culture to which students are adjusting. Discounting the teacher as an 
active agent in the classroom wrongly positions students as subjectable primarily to disembodied systems and overly constrained by outcomes rather than converging processes. By focusing on teacher identity, we re-shuffle these relationships and re-make the balances in order to make recognizable the notion that the negotiation of classroom identity involves an interaction of all parties, sometimes with competing agendas.

\section{General Background}

The project that became the springboard for this way of thinking emerged from interactions between Royster and Taylor that came about through a set of graduate courses that Taylor took and two quarters of basic writing courses in the Ohio State University Basic Writing Program that Taylor taught. These experiences enabled Taylor and Royster, her graduate advisor, to have sustained conversation about a collective of issues. Working together, we realized that there are advantages in shifting both the location from which we were envisioning our mutual concerns and the analytical paradigm by which we were operating.

In terms of our own location as workshop leaders in the CCCC workshop, our questions remained cognizant of student experiences in classrooms. The shift, however, was to foreground the multiple ways in which issues of identity become more slippery and compelling when we refine this view to notice more directly the race, gender, class, age, culture, institutional position, etc. of the teacher as classroom subject. Our intent was: to acknowledge both sets of people in the room, students and the teacher; to shift the paradigm so that students are not perceived simplistically as the site and/or source of pathology and so that teachers are perceived as the primary site and/or source of power, privilege, and culture-making; and to recognize, as Keith Gilyard (1996) and Jerrie Cobb Scott (1993) suggest, the need to flip "the script" and "the marginalization coin."

In effect, we had become impatient with the discussion of identity, most especially in basic writing classrooms, as the students' problem, rather than also as the teacher's problem, and we wanted the dialogue to take into direct account the culpability of teacher location in the creation of learning space. In our work, we have been instructed by a conscious interrogation of our assumptions about who is likely to occupy basic writing classrooms on both sides of the desk, especially in public institutions. Recognizing how much classroom constituencies actually vary from institutional site to institutional site, what we have affirmed is how consistently characteristics of writing performance become conflated in research and scholarship with issues of identity 
(race, class, gender, age) and with issues of good character or ethos.

In addition to interrogating our own assumptions, we have also been informed by demographic projections for the United States to the year 2020 (Campbell 1994) that indicate shifts in who is likely to occupy classrooms in the next century. By all indications, regardless of how students in the classroom may be constituted in terms of identities, what is likely is that the teacher will probably not share particular identities with the students, including the possibility of race, ethnicity, class, age, gender, etc., but also including factors such as histories of academic success, institutional status, and "cultural" sense of being. All of these factors relate to issues of "location" in the classroom that we assert will indeed become increasingly important in all of our classrooms, but clearly in basic writing classrooms. At the levels at which students are most insecure about writing performance, i.e., in basic writing courses, "location" becomes exacerbated by the pressures of multiply defined experiences of marginality, based not only on personal identity but also on social and institutional identity or non-identity.

Our primary goal for the workshop was to debunk the myth of the conflation of race, class, culture, and character in the basic writing classroom, and to begin this process by acknowledging the teaching self. The goals of the workshop were:

To blend self-critique and institutional "location" in creating a leverage point from which to shift paradigms for theory and practice in basic writing classrooms.

To generate strategies for interrogating the multiple relationships encoded in:

how we represent ourselves in the basic writing classroom; how we represent our students in the basic writing classroom; how these representations shape and direct what we teach, how we teach it, and how we assess progress and performance.

In order to carry out this agenda, we chose activities that were designed to be hands-on.

At the beginning of the workshop, we conducted an informal survey (See Appendix 1) in order for participants to notice the differences among their institutional sites, their material environments, as well as their student populations. The results of the survey served to remind us in quite direct ways that material conditions do indeed vary. We found that while as a group we might talk about our institutions in generic terms, they were actually quite distinctive in several ways (e.g., in terms of regional location, size, age of the student body, diversity among the faculty along gender, age, and ethnic lines, mission of 
the institution, etc.).

With the survey as general backdrop, we engaged in short writing activities (See Appendix 2) to make use of the memory work that enriches discussions of classroom theory and practice. These activities included the participants thinking about perceptions of themselves in the classroom, about particular moments in their classroom during which questions of identity might be raised, and about possible gaps between how they represent themselves and how students might represent them. Having primed these memories, we structured applications (See Appendix 3) that were designed to help participants concretize perceptions, draw forth classroom-based challenges, and share strategies and solutions to contentious problems and issues. The applications were based on incidents that had arisen from Taylor's experiences in her classroom, covering a range of issues: the selection of reading materials; the use of collaborative activities; assessment issues; issues related to technology; issues related to gender, authority, ethnicity, and so on.

The heart of our session, however, and the part that in the end seemed to yield the most was the sharing of Taylor's classroom experiences as she, a white woman raised in a Jewish household in Richmond, Virginia, entered a "multicultural" classroom filled with students whose success as writers and whose success with negotiating their academic and institutional identities varied considerably.

\section{Expectations, Alliances, and Identities: A Case in Point}

As teachers, we tend to operate without questioning the extent to which practices deviate from the ideal, socially sanctioned ideologies of society or how our individual processes of self-identity interplay with the self-identity of students. To fail to critically examine the practiced vs. the preached ideologies of society or the student vs. the teacher's self-identity is to support, through uncritical dysconsciousness, the recycling of attitudes that resist changes that benefit those marginalized in school systems. (Jerrie Cobb Scott, "Literacies and Deficits Revisited")

I remember reading Jerrie Cobb Scott's "Literacies and Deficits Revisited" for the first time in the Spring of 1996. As a graduate student in a seminar designed to introduce us to the field of basic writing and to prepare us to teach in my university's own basic writing program, I was asked to draft a bibliographic essay focused upon the field's most recent (1990's) scholarship. I knew right away what I wanted to investigate: how notions of identity-gender, class, race, region, 
ethnicity - shape contemporary basic writing scholarship. All of my work as a student of rhetoric and composition had previously addressed the relationship between identity, authority, and the teaching and valuing of student writing, and I expected these issues to prove especially crucial to the field of basic writing, where (for highly problematic reasons) students often represent a variety of cultural, racial, and economic categories of difference. But I was unprepared for what my brief bibliographical study of the Journal of BasicWriting and other composition journals would yield. While the issue of student identity permeated every facet of the scholarship, explorations of teacher identity seemed almost absent. I began to feel as if ghost writers were at workquite literally. Who were these teachers, these researchers, representing the words and lives of their students? How did they figure into their own discussions?

Even now, nearly one year after reading "Literacies and Deficits Revisited," Scott's essay resonates quite powerfully for me. It points toward the tendency in basic writing scholarship to define basic writers. Whether defining these students in terms of their membership (or lack thereof) within academic discourse communities, or in terms of their cognitive "skills," the drive to define, and I would argue, objectify, students persists. Sometimes teachers and researchers focus the definitional act on the students' written products as metonymic standins for the writers themselves. Perhaps most disturbingly, as William Jones reminds us in "Basic Writing: Pushing Against Racism," sometimes they utilize the term basic writer to serve as "euphemism and code for minority students" (74). As a white teacher I am perhaps most troubled by Jones' argument, but I will not respond to that argument by forwarding yet another definition of basic writers. Instead, like Jerrie Cobb Scott, I argue that basic writing scholars must cease to concentrate so intensely upon the act of defining these communicative "others," objectifying them and claiming all of the power that comes with the act of naming itself. I suggest that basic writing teachers and researchers must begin instead to question our own identities, examining critically the relation between who we are and the work we make possible for our students. This work is necessary for all teachers, but for white, middle class teachers of basic writing, who may find themselves, as Royster reminds us, feeling different from those who occupy the other side of the desk, the work is especially crucial. If Scott is right about the dangers of seemingly dysconscious (albeit wellintentioned) attitudes that reproduce the status quo, we must ask what it means for composition researchers and teachers not to address their own identities, to assume that multiple literacy practices can take place in a single classroom without the kind of "violence" that J. Elspeth Stuckey describes (1991). The challenge to teachers and researchers of basic writers is to "flip" what Scott so aptly calls the "marginalization 
coin" (51) in order to allow themselves to be described, discussed, defined, or named.

This challenge drove my research in the graduate seminar last year. I remember the end of the quarter looming, along with my appointment to serve as a TA for the basic writing program the following autumn. I knew that my own identity would radically impact my teaching of the course, that my ways of valuing student texts, of determining what I would consider meaningful, had everything to do with who I was and where I came from. Before I stepped into that basic writing classroom in the fall, I needed to stop and ask: What am I doing here? What drives me to work in the context of a basic writing classroom? What do I expect of my students and how did I construct those expectations?

But scholars like Jerrie Cobb Scott remind me that making a quick reference to my own race/class/gender at the beginning of my own scholarship is not enough. I must answer the questions I raise above, but such questions should not act as ends in themselves; instead, I use such questions as a means to interrogate my own teaching practices in order to imagine new kinds of questions. Naming who we are does not let us off the ethical hook. Actually, I am not really looking to my race, class, and culture as individually distinguishable factors that impact my teaching. Instead, I consider my race and class as two examples of the multiple sites that constitute what I name my culture(s). Thus a host of other factors, including age, regional affiliations, educational history, and institutional location are also part of what shapes who I am as a teacher in my classroom, a distinction which does not negate the need for white teachers to critique their racial and socio-economic identities. Rather, the distinction helps me to broaden that critique so that it encompasses other identities in helping me to realize how race and class are always implicitly a part of other sites of identity formation. In broadening the view, the goal is to historicize and critique the sites of identity formation and the sources of my own knowledge about basic writers. Thus I can articulate how and why I "am" in the basic writing classroom.

\section{Voicing Identities in the Basic Writing Classroom}

While teaching basic writing in the Fall of 1996, I undertook an independent study of teacher identity with my mentor and advisor, Jacqueline Jones Royster. What started as a bibliographical exploration for a graduate seminar became a more tangible project. I kept a teaching journal to help me study my own identity, as it was constructed by me and by my students. At the same time, I continued my review of basic writing scholarship, problematizing the ways in which teach- 
ers and researchers of basic writing represent their students without naming or critiquing themselves. My daily teaching journals reflected my own concerns regarding my position as a new teacher/scholar of basic writing, and by examining those concerns alongside others' approaches to teacher identity in basic writing scholarship, I explored potential sites for my own acts of uncritical dysconsciousness. As illustrated below, what became most informative in transforming this project into a CCCC Workshop presentation was the process of juxtaposing my voice with the voices of my students in order to study, reflect upon, and generate questions about the process of teacher identity-formation in the basic writing classroom.

Some of the characters in these journal entries are my students, but most of the characters are me: the TA struggling to stay theoretically grounded, the new teacher at the Writing Workshop trying to negotiate membership with colleagues, a white instructor worrying about her relationships with students of color, a woman troubled by gendered alliances among her students, and a suburbanite facing her own representations of rural students and their values. My competing identities, the characters here, don't always get along, and the setting has an awful lot to do with the plot. Within my journal entries, I represent student voices as they spoke during classroom conversations, via e-mail or personal conferences with me, and through their written responses to classroom assignments. Troubling for me in representing my students in writing, even when I use their own words, is that the nature of any written representation of "real" events is always just that - a linguistic representation, not an "actual" transcription capable of conveying totally what was said and what was communicated. I feel compelled to say that these stories are, of course, products of my own shaping and not intended to be set forth as unmediated "truth."

\section{The Pre-Quarter Orientation: TA or Not TA?}

The staff of the Workshop seemed so dedicated, enthused, and it was great to be among colleagues who love to talk about teaching again. But I definitely felt like the junior colleague, the student among professionals, and I resisted some of those activities. When we practiced hypothetical placement test reading, no matter how many sample essays I saw, I couldn't quite determine how to "place" an essay into one of our department's courses. When I asked what I thought made a student text successful, I said "it's communicative in context." I remember the other workshop staffers smiling at me politely.

It strikes me now how desperately I seemed to want to define myself as a graduate student visiting the Basic Writing program - not as a permanent resident. How many others find themselves, like me, expecting merely to "pass through" their basic writing teaching appointments? At my own institution, questions concerning the 
professionalization, scholarly commitment, and even work ethics of our basic writing teachers seem to arise frequently. How do such institutionally driven doubts affect basic writing scholarship and pedagogy?

After a particularly difficult October staff meeting at the Workshop, I write: Last week, while we were discussing our observations of one another's classes, the highest compliment seemed to be, "I visited $x$ 's class and he was practically invisible." I will never be invisible in my classroom. Invisibility for a TA means powerlessness, lack of authority. But I'm afraid to speak up in these staff meetings because I'm a beginner. I'm worried that I'm starting to define myself as some sort of rebel here. That's not who I want to be.

I'm not sure that I overcame that rebellious streak; rather, I reconceptualized it as the year wore on, working hard to balance my need to ask questions of my colleagues with the recognition that I was, in fact, inexperienced. Interestingly enough, I think my colleagues, too, reconceptualized me as they saw how my questions were helping me to bring the parts of myself - student, teacher, scholar - together in my work as a teacher at the Workshop.

Once the quarter began, my journal addressed my expectations about who these basic writers would be-and how I would find ways to make connections with them.

September 25: Great Expectations

I got my roster before I taught class today. The first thing I noticed was ethnicity. Or should I say, I noticed my own attempts to guess the ethnicities of my students, and then to pretend that I wasn't noticing. Was Juan Carlos a native speaker of Spanish? Where was he from? How many of the Asian names on my roster belonged to ESL students, and how many of them named students born and raised in the Ohio suburbs? Did I really only have two women in the class? How would they deal with Kingston's The Woman Warrior? Once I matched names to faces, I found out that "T.L." was actually a Tiffanie - thank God! She seemed really interested - her writing sample suggests she's given a great deal of thought to the challenges she faces as a Black woman at the university. She's a sophomore, though. What happened last year? Did she take the course once? I never even took Freshman Comp. What experiences, if any, will my students and I share? Do we have to share experiences in order to work together successfully?

As the quarter progressed, I found that spending time in two buildings, one which houses the basic writing program and the other the English Department, caused me to lose track of more than just my gradebook and coffee mug. Sometimes I felt like I lost a little bit of my self - the part of me I most clearly defined as Graduate Student - each time I made the trek from the English department to the basic writing program facility. But something else gradually replaced the part I had lost: a questioning, engaged, and often troubled teacher. 


\section{September 29: The Outsiders}

The other TAs in the English department don't really understand why I'm interested in teaching basic writing five days a week, and after the basic writing staff meetings I feel as though my colleagues there think I am "questioning" them and their pedagogy. I suppose I do question the program - but not its pedagogy or its right to funding. I'm really questioning the institutional structures that put such a course in place. I mostly worry about how I handled my students' questions about 052. I think I let them know that I, too, am frustrated by the placement system. I suspect that they'll continue to say, "show me the difference between my paper and a 110 student's paper." Then who will I turn to? Bartholomae's work? Mike Rose's books? How should I answer such a question?

Interestingly, once my students began sharing their drafts in midOctober, I became the cultural outsider. It's an experience I highly recommend.

\section{October 15: "Yet Do I Marvel"}

I'm noticing that my own responses to student papers are somehow engaging the question of culture - even if I choose not to articulate that to the students themselves. For instance, Demetrius' first response log batch came in, and I noticed that when describing the protagonist in The Chocolate War ${ }_{L}$ Demetrius began to use a stylistic device that I could only describe as sermonic. He spoke in his journal about Jerry (the character) and his ability to "restoreth" the spirits of his teammates and friends. Such moments are fascinating for me-markers of a rhetorical tradition outside my own tend to make me want to stop, admire, ask questions. But would it be appropriate to share such moments with students? To talk to them about the intersections of culture and rhetoric? Or, does my response simply imply that I' $m$ too willing to generalize about African American students' discourse because I've read Smitherman or Gates? What's the best way to talk about community literacies and not fall into a kind of generalizing?

\section{Late October: Invisible Man}

Jason, who moved here from China as a high school student, continues to worry me. The other night he wrote me via e-mail, expressing his disappointment that his classmates were not writing to him as often as he liked. "I wait for the rooster," he wrote, referring to the Eudora icon, "but he never come." Jason's quietness in class and his eagerness to speak over e-mail have contributed to my students' marking of him as Other. Sometimes I even forget he's in the room. What role should I play in helping Jason to assimilate? Should he assimilate at all?

What strikes me now as I read my journal responses to both Demetrius and Jason is how two facets of my own identity, my race and my own research agenda, colored my pedagogical instincts. As a graduate student enmeshed in discussions of contrastive rhetorics (Shen 1989) and critiques of assimilationist projects (Lu 1992, Giroux 1992), I seemed incapable of considering Demetrius' rhetoric and Jason's de- 
sire for acceptance from any other perspectives. As a white instructor I might have been engaged in dysconscious acts of transgressive voyeurism (Royster 1995), reading Demetrius in terms of "nonmainstream" rhetorical traditions and attributing Jason's difficulties only to cultural difference. I found myself moved not to action, but simply to further contemplation. What might I have done instead to make Demetrius' text a part of a larger classroom discussion? How might I have asked other students to respond to Jason's request for e-mail?

In November, frustrated with classroom interaction, lack of student preparation, and low morale, I turn to my workshop colleagues for support. "It's mid-term," they remind me. But I knew more was at stake. I was terrified that my lack of experience had been translated to my students, who knew, after all, what "TA" meant in their other classes: TA's were graders, proctors, apprentices "stuck" working with first-year students while secretly (or not-so-secretly) longing to escape to their laboratories. Worse, perhaps they suspected what I often worried about myself - that their classroom was the laboratory and I was merely learning how to teach.

\section{Mid-term Reflections: "I felt a funeral in my brain"}

Even as the writing in my class seems to be improving, attendance is falling off. Rosa has missed eleven class days - Tiffanie eight, though many were excused absences. When Dylan comes, he doesn't bring his materials. Gordon is increasingly withdrawn - committed to his fraternity and just sort of scraping by in my class. Mike threatened me with a 6:30 a.m. wake-up call on the first day of Winter Quarter ("Your husband will think I'm your boyfriend"), and followed that comment with a pornographic e-mail to me this week-muppets doing pretty unspeakable stuff. Apparently, he believes I am the kind of person who would find humor in Web Porn. As Elizabeth Ellsworth would say, this does not feel empowering. Boundaries are being crossed by Black students and white ones, by women and men, by "good students" and forgetful ones. And where is the article of research that helps me deal with this?

I feel like I've spent the last two weeks trying to let students know that I realize I am complicit in all of this, but some boundaries can't be crossed if I am to be an effective teacher. I am becoming increasingly aware that any discussion of teacher identity in the basic writing classroom needs to take into account multiple facets of identity. My institutional identity, my age, my gender, my place in the department, my tenuous place within the Writing Workshop, and, of course, my race and class need to be considered.

All of these crucial shapers of identity came to the forefront for me when my students took the floor as presenters and discussion leaders, and I became one of the participants.

December's Presentations: The Sound and the Fury

Today the three women, Casey, Tiffanie, and Rosa presented on "sexism in 052." Rosa read from her paper about her mother's ovarian cancer. 
She then told us what it was like for her to be one of three women in a class of men, describing how she altered the language of her paper so that she wouldn't upset male members of the class, particularly her peer group. That backfired. Gordon blew up, disgusted that Rosa thought he was "too dumb" to understand her. I tried to step in, explaining that she wasn't calling them dumb, but that Rosa felt uncomfortable discussing some issues with them. Was I placating Gordon or defending Rosa? When Tiffanie spoke, all hell broke loose. She claimed that all of the men who preferred Kingston's book were "Mama's Boys," while the ones who preferred Cormier's book were sexists. I watched the men on the left side of the room (students from rural areas) suck in their cheeks and count to ten. Others shut down completely. When Casey, the third woman, spoke, she prefaced her comments by saying that she had never felt discriminated against as a woman in our class. How was I to respond? Whose position was I to validate? I felt hurt and betrayed. I've certainly never been accused of not fostering feminist texts/values in my classroom. But I know I was hyper-aware of the number of men in my course, and I didn't push them to discuss gender on a daily basis. I had bitten my tongue on several occasions, worried that my male students might perceive my feminism as threatening. But I didn't want the women to be put on the spot all the time as the "representatives" of womankind.

Our reading of Maxine Hong Kingston's The Woman Warrior even further complicated my own understanding of my role within the classroom. When should I speak, and when should I remain silent?

\section{"No Name Woman" meets Dick Vitale}

I have assigned my students, in groups of five, to lead discussion once over the course of the quarter. The first two groups are talking about The Woman Warrior. Today's group (three white men from rural areas, Mike, Mike, and Mark, one white woman from Cleveland named Casey, and Shirish, a newly-made American citizen originally from India) "presented" by subjecting my class to thirty excruciating minutes of Dick Vitale on tape. The tie, they argued, was that Vitale motivates his players through story-telling the same way that Kingston's mother motivates her daughter by telling her the story of the "No Name Woman." All eyes, save mine and Tiffanie's, glazed over in worshipful abandon! These students bought Vitale's cliches and generalizations about the power of sports. "A boy, a ball, a dream," he repeated like a mantra. And I thought, what about the girls? And what does it mean to tell generations of boys that the ball is the dream? I raised these questions, but all of my students shot me down pretty quickly. Talk about culture shock. All of my students extolled the virtues of Vitale's way of seeing the world. Tiffanie and I just shook our heads and sighed.

\section{The Grapes of Rap}

The second group, comprised by all of the African American students (Tiffanie, Dylan, and Demetrius) and Rosa, a bilingual student from Mexico, presented the class with a video today, a 25 minute MTV special memorializing rapper Tupac Shakur, an artist whose films I admired and whose music I 
knew very little about. I have such mixed feelings about this group's alliance. I want so badly for students of color, many of whom speak to me about racism in their dorms, to find networks of support. But my class is dividing rapidly along racial/ethnic lines. Do I assume heterogeneous groups are more effective educationally? I think as a high school teacher in Virginia I did. But now I'm not so sure. Maybe heterogeneous groups make me, not my students, feel safe. This group argued that like Kingston, Shakur uses personal experience to shape his texts. They wanted us to consider Shakur's life and death from this perspective, and then discuss our responses to the video.

The class was polite (a few eyes rolled and the boy next to me, Nathan, winced visibly as he heard of Shakur's sodomy charges). I took notes on the video. Shakur spoke powerfully and made it clear that he had to speak from and for his community. He also explained why, even though he had made a great deal of money as a rapper, he continued to live in South Central. "Where are the neighborhoods where I can be both safe and among my own people?" he asked. I felt the white student next to me bristle, but he continued to watch, tapping his foot in impatience.

The group asked us all to share our quick responses to the video. "I liked," Jason replied. He offered no further explanation. Several of the white students from rural communities muttered their responses, but one student completely surprised me by launching into a thorough discussion of Shakur and his work. I don't think the group expected Gordon to be a Tupac fan, and neither did I. I welcomed the surprise. Nathan asked about Shakur's violence. "After prison, did he keep beating people up?" Demetrius and Tiffanie fielded the question, but didn't really satisfy Nathan.

Later in the quarter, Mike told us why he had been so uncharacteristically silent after the video. "How many of us from farms even have cable TV? Do you really think we had all heard of Tupac Shakur? I only got MTV for the first time this year, in the dorm." A response like this easily gets forgotten in the midst of all of the scholarship about CUNY, SEEK, and Open Admissions programs in what Mike and Nathan call "the big city."

Final Portfolios: Grim Fairy Tales

While sharing their portfolios today, the classroom became a Dale Carnegie meeting as students vowed to submit their work to the evil Writing Workshop Committee and skip right over 053. After nine weeks of hard work, we were back to the question of placement. Nobody celebrated the improved writing as an accomplishment; rather, the improvement they saw in one another's work was important only if it granted direct access to English 110. Even as I told my students that courses like 052 are the reason they are admitted to the university - that if these courses were eliminated, so, too would the university eliminate them - they continued to script the Writing Workshop staff as the "bad guys" preventing them from reaching their "true potential" in 110 - only I could champion them to the rest of the Workshop. They seemed unable to understand that $I$, too, was a part of that system. 
I suspect now that my students sensed my own contradictory feelings about the work I did as their teacher. The issue of placement was so powerful for Mike, whose mother is an English teacher and whose father is the vice-principal of the town middle school, that he uses it to structure the cover letter for his final 052 portfolio. In that letter, he figures the Writing Workshop as an "Evil Stepmother" preventing this "Cinderella Class" from going to the "Ball" - English 110.

Conclusion: Grim Fairytales Revised

Perhaps the most eloquent storyteller of the quarter was Casey, a young white woman from a large city whose silence throughout the quarter is reflected in my journal; her name appears less often than anyone else's. She struggled quietly, and her final essay, an allegory written in response to the prompt, "Tell the story of 052," moved all of us. What it suggests about the identities our students themselves find most meaningful is quite provocative. Casey's paper reads as follows:

"The City of O52"

Many, many miles below the ocean stood an enchanting city with the identification number 052. This city was trapped infinitely on the floor of the ocean in a large glass bubble. . The members of the city were an unusual group of individuals. Not one person carried the same personality trait or the same physical feature. Although the members seemed to be nothing alike, each one of them bonded together by the simple fact that they were unhappy to be stuck in a city confined to the bottom of the ocean.

The members of the city 052 were placed there by the government because they were considered to be slightly behind the rest of the world in intelligence... [their] work was not much fun, but was there to educate them and to better enable them for the real world... The first few days were a little uncomfortable or even confusing for every member of the city. Being in a city that was underwater was a little bit different then the way they were used to living....

There was one member of the city that was ahead of everybody else, and her name was Becky. Becky had been in this city for many, many years but was only there to guide those with assumed less intelligence. They were all a little surprised by Becky, because they had expected someone a little stricter and less happy. .. The whole group seemed to be bonding, at least that's what most of them thought. They seldom had contact with the real world but when they did, they learned that the work that was getting done in the underwater city was as complicated, and took more work than the work that was getting done in the real world. Many of the members of this interesting group became frustrated by this fact. "This is so unfair that the education we are getting down here will not count towards credit in the real world," said Nathan. Nathan always seemed to be bringing up this point every time the group met. Tiffanie and Mike agreed with Nathan. That is why the group probably bonded 
so well, even if only a few people spoke up, everybody felt the same...

Casey believed that a kind of "bonding" took place despite cultural, gender, racial, and regional differences. And I smile even now at Casey's depiction of me as a "laughing, happy individual" - that certainly isn't how I represent myself in my journals. Her reading of me as someone with experience, someone who has been in the city "a long, long, time" gives me pause. How do we negotiate our constructions of our own identities with our students' depictions of us? When I reread those journals, I noticed how I wrestled with notions of authority, defined variously in several instances. When students were absent, I attributed those absences to my status as a TA who couldn't "make them" come to class; I questioned my institutional authority. When I refused to push students to critique Dick Vitale's ideological stance, I denied myself a chance for feminist advocacy, perhaps subverting my own political authority, but privileging my students'. When I resisted engaging the question of multicultural rhetorics while reading Demetrius' work, I subjugated my identity as a white reader to my expertise as a rhetorician, creating a lack of professional authority, but perhaps recognizing a student's cultural authority.

What I wish to emphasize now is not a sort of "revelation." I won't argue that, yes, I had authority all along and that Casey's text helped me see that. Instead, I want to suggest that the keeping of a teaching journal - which required me not only to reconstruct classroom experiences, but to pay attention to the act of construction itself, to come to terms with how who I am prevents and/or enables me to reevaluate classroom practice-helped me to understand classroom authority in more dialogic terms. That journal allows me to ask the new kinds of questions I imagined at the outset of this essay: How did my own expectations of having to negotiate racial difference first and foremost affect the pedagogical decisions I made throughout the quarter? Was that difference, in fact, the difference my students most perceived? What other factors constitute teacher/student cultures and identities? What kinds of mechanisms shape the relationships between those factors in the classroom, determining which factors are most powerful in any given moment? Perhaps most importantly, how can interrogation of teacher/scholar identities alter the landscape of existing basic writing pedagogies?

\section{Implications for Teaching and Research}

From this collective of workshop activities, we walk away with direct challenges for what identity means in terms of classroom transformation. Our starter questions for analyzing scenarios from the basic writing classroom have acquired new life in that they have become 
the places where our rendering of challenges begin.

What issues emerge from a shifting of our view of identity and culture formation in basic writing classrooms to include the merging of teacher and student locations in classroom space?

How do teacher "location," student "location," and institution matter in the ways that each of us might center the gaze in the classroom and articulate the nature of the teaching/learning engagement?

How can we use our conscious awareness of self, students, place, and enterprise in making the basic writing classroom a richer (i.e., more positive, productive, intellectually invigorated) literacy development arena?

What advice or "cautionary tales" do we need to remember?

Clearly, we do not have prescriptions for these questions. The first three certainly constitute a rather complex agenda for research, scholarship, and classroom practices. The fourth question also brings with it ill-formed responses. However, as our experiences resonated during the workshop with the experiences of the participants, we realized that we are indeed not starting from scratch in being both warned and well-instructed by the experiences and expertise that we have developed in basic writing classrooms over the last thirty years especially.

Implications for Research and Scholarship: The scholarship in basic writing, as we discussed earlier, does not focus on teacher identity. When teacher identity is considered, scholars often provide only brief statements at the beginning of essays (e.g., "I am a white-middleclass-woman-at-a-large-state-university"), rather than sustaining selfcritique throughout the piece. How might we better imagine ways to enact our identities, to question them, to consider how these identities impact our classrooms? Can a teaching journal, such as the one demonstrated here by Taylor, be considered worthy as a research tool or as a rhetorical form worthy of study? What forms would/should scholarship that is more attuned to teacher identity take?

As evidenced by the form of this article, even when we try to concentrate on teacher identities and their construction, we face challenges of ethics and representation. For one thing, student voices creep into the center of our concerns and are often the most compelling voices that we hear. How can we make room for those voices and still sustain a dialogic balance - us, them, the systems around us all? Is it possible, 
for example, to focus on teacher identity without engaging the voices of our students? If it isn't possible, how do we incorporate their points of view? How do we ethically represent their experiences? Can we begin to talk about teacher and student identities as mutually constitutive? What are productive ways to do so? What can this kind of reconceptualization offer the field of rhetoric and composition in terms of methodologies in research and scholarship?

In one way, this article is yet another call to story as a very useful methodology for sharing classroom experiences - this time with the gaze on the teacher. Our call, however, is also for a critical step back from our narratives to make them reach out more inclusively and more meaningfully for the general landscape of our work. At this point, our view is that we need to think, not only about ourselves in classroom space, but also about the art of storytelling in terms of its theoretical and political implications. What have we learned about the telling of stories? How do we assign meaning and draw value for the classroom cultures from which our telling comes?

Implications for Teacher Training and Classroom Pedagogy: Re-imagining the work of basic writing programs in the twenty-first century demands that we break the cycle of classroom representations that permit our own locations as teachers to go unnoticed and uninterrogated. Who we are and how we are as human beings impact upon our pedagogical choices. Being aware of this reality permits us to see success and failure in our classrooms with different eyes, with a different sort of critical questioning. We can become more sensitive to the possibility that what in the past we may have attributed to issues related to student identity may also be a function of issues related to our own identities. Is a "problem" a matter of ill-literacy or multiple literacies? Is a "problem" a function of student ignorance and inexperience or teacher ignorance and inexperience? Can a given usage be explained within institutional contexts or home contexts? Is the "problem" tied to performance or to the nature of engagements that we ourselves forge between ourselves and our students, or between ourselves and our institutions, or between those of us inside the classrooms and the systems that operate around us? What do we as teachers really know about the literate possibilities maximally available to us in a classroom? How have we learned to make good use of what we know? How have we learned to discover what else we might need to know and make use of?

In large part, the demographics of students in writing classrooms are shifting significantly, but the demographics of teachers entering writing classrooms don't seem to be keeping a comparable pace. Writing teachers, and especially basic writing teachers, tend to be white women. Given the differences in these demographic factors, the obvious probability, as indicated previously, is a variety of mismatches 
between teacher and students. Whatever a teacher's personal, social, or institutional identity, however, whether that person conforms to the norm for teacher demographics in basic writing classrooms or not, what is clear is that we need to re-think teacher training and to rethink classroom pedagogies with these factors in mind.

Obviously, we are not at all suggesting that only insiders in a particular discourse community have the capacity to teach other members of that community. We are not interested in even belaboring this point. We are suggesting that teachers think more consciously and reflectively about the implications of difference in the classroom. How can we utilize knowledge of differences across personal, social, and institutional lines to respond better to student needs or to adjust our own needs when we encounter students who seem unfamiliar to us? What do we do when the identities that we hold most dear are not the features with which our students are connecting? In Taylor's case, for example, her sense of herself as a white female instructor was less important to her than her sense of herself as a teaching assistant who was forging a professional/institutional identity for herself.

This article suggests, then, that teachers might benefit from taking into account ways to engage in dialogue with students about how they are seeing us and not just about how we are seeing them. A critical question, therefore, is how do we develop habits as teachers, and especially as teachers in training, that support: the explorations of difference in classrooms including the ways in which our own locations contribute to this complexity; the accumulation of specific knowledge about students and student performance as a multiliterate enterprise; or about the use of that knowledge in developing the flexibility to match variable strategies with variable classroom needs and to construct classroom cultures that are positive and productive?

In terms of basic writing classrooms as a specific site of engagement, are we being systematic in training people for the particular needs of students at this level? How many teachers are simply "passing through," as in Taylor's case, i.e., learning from the site but not necessarily planning to make careers there? Should we be moving as a profession to draw more colleagues to basic writing as an area to which one is professionally devoted and not just generally interested? In other words, who are we thinking of when we think of "basic writing teachers" for the twenty-first century? What are the pedagogical implications of our answers? What are the implications for teacher training?

Implications for Re-considering Invisible Literacies: In the contemporary scholarship in which "basic writer" is often conflated with minority students, many kinds of literacies remain hidden. Issues such as how regionalisms and geographical alliances affect writing instruction seem to get left out of consideration. The concept of literacy as shaped by specific contexts inside and outside of the university is not 
always used to greatest advantage. The dominance of "open admissions" at particular colleges and universities sometimes dominates our views of what literacy is or is not in ways that prevent us from seeing the strengths of our own students. For example, as teachers who work often with rural students rather than urban and suburban students, we have had to re-think some basic assumptions, such as how the presence or absence of cable television affects resources for writing. Our experiences with this project have led us to take into much fuller account the ways in which conflating race or ethnicity with lack of membership in academic discourse communities actually deflects attention away from other kinds of issues. Looming large among these issues is how writing professionals at all levels might productively critique the "gatekeeping" roles of first year writing that seem to be built automatically into the very fiber of our academic system.

\section{One Last Word}

At the end of this article, we feel compelled to make one last statement. While caution in all that we do seems well-advised given how complicated classroom challenges inevitably are, the commitment to more sustaining theories of classroom engagement and more generative and respectful classroom and scholarly practices is a challenge worth accepting. Affirmed by our experiences in the workshop, watching and listening as other teachers from across the nation saw ways in which their views of issues and challenges merged with ours, we were incredibly inspired to re-commit ourselves to this work in the company of others who were doing likewise: Taylor to her work toward her dissertation; Royster as she continues to investigate issues of identity, agency, and authority in multiple environments. In the meantime, in recognition that the task of debunking mythologies demands the sharing of counter viewpoints, we submit to the discourse on classrooms this view of teachers, not just students, in extending the call to others to make a different, more inclusive, more interactive case for how attention might be brought to bear on issues of classroom identity.

\section{Selected Bibliography: Teacher Identity and Basic Writing Research}

Bizzell, Patricia. "What Happens When Basic Writers Come to College?" College Composition and Communication 37.3 (1986): 294-301. Campbell, Paul R. Current Population Reports: Population Projections for States by Age, Sex, Race, and Hispanic Origin, 1993 to 2020. Wash- 
ington, D.C.: U.S. Department of Commerce, 1994.

Dean, Terry. "Multicultural Classrooms, Monocultural Teachers." College Composition and Communication 40.1 (1989): 23-37.

Gilyard, Keith. Let's Flip the Script: An African American Discourse on Language, Literature, and Learning. Detroit: Wayne State UP, 1996. Gunner, Jeanne. "The Status of Basic Writing Teachers: Do We Need a 'Maryland Resolution?'" Journal of Basic Writing 12.1 (1993): 57-63.

Hindman, Jane. "Reinventing the University: Finding the Place for Basic Writers." Journal of Basic Writing 12.2 (1993): 55-76.

Hourigan, Maureen M. Literacy as Social Exchange: Intersections of Class, Gender, and Race, New York: SUNY, 1994.

Hull, Glynda, Mike Rose, Kay Losey Fraser, and Marisa Castellano. "Remediation as Social Construct: Perspectives from an Analysis of Classroom Discourse." College Composition and Communication 42.3 (1991): 299-329.

Johnson, Cheryl L. "Participatory Rhetoric and the Teacher as Racial/ Gendered Subject." College English 56.4 (1994): 409-419.

Jones, William. "Basic Writing: Pushing Against Racism." Journal of Basic Writing 12.1 (1993): 72-80.

Laurence, Patricia. "The Vanishing Site of Mina Shaughnessy's Errors and Expectations. Journal of Basic Writing 12.2 (1993): 18-27.

Lu, Min-Zhan. "Conflict and Struggle: The Enemies or Preconditions of Basic Writing?" College English 54.8 (1992): 887-913.

--. "Professing Multiculturalism: The Politics of Style in the Contact Zone." College Composition and Communication 45.4 (1994): 442-458.

McCarthy, Cameron and Warren Crichlow, eds. Race, Identity, and Representation in Education. New York: Routledge, 1993.

Mutnick, Deborah. Writing in an Alien World. Portsmouth: Boynton/ Cook, 1996.

Neuleib, Janice. "The Friendly Stranger: Twenty-Five Years as 'Other.'” College Composition and Communication 43.2 (1992): 231-243.

Patthey-Chavez, G. Genevieve, and Constance Gergen. "Culture as an Instructional Resource in the Multiethnic Composition Classroom." Journal of Basic Writing 11.1 (1992): 75-95.

Reagan, Sally Barr. "Warning: Basic Writers at Risk-The Case of Javier." Journal of Basic Writing 10.2 (1991): 99-115.

Rondinone, Peter. "Teacher Background and Student Needs." Journal of Basic Writing 10.1 (1991): 41-53.

Schor, Sandra. "The Short, Happy Life of Ms. Mystery." Journal of Basic Writing 10.1 (1991): 16-25.

Scott, Jerrie Cobb. "Literacies and Deficits Revisited." Journal of Basic Writing 12.1 (1993): 46-56.

Severino, Carol. "Where the Cultures of Basic Writers and Academia Intersect: Cultivating the Common Ground." Journal of Basic Writing 11.1 (1992): 4-15. 
Shen, Fan. "The Classroom and the Wider Culture: Identity as a Key to Learning English Composition." College Composition and Communication 40.4 (1989): 459-466.

Tobin, Lad. "Reading Students, Reading Ourselves: Revising the Teacher's Role in the Writing Class." College English 53.3 (1991): 333-348.

\section{APPENDIX 1}

\section{INFORMAL SURVEY FOR}

BASIC WRITING WORKSHOP PARTICIPANTS

1. For what kind of institution do you work?

- two-year college

-four-year college

-two-year technical college

- technological college/university

- research university

2. Are you:

- a writing/other skills teacher in a basic writing program

- an administrator of a basic writing program

- other

3. How many years have you worked with students in basic writing classrooms?

$-1-3$ years

$-4-9$ years

-10 years or more

4. How much diversity is evident among your teaching faculty?

$-25 \%$ people of color

$-25 \%$ men

$-50 \%$ or more people of color

$-50 \%$ or more men

- majority white

- majority women

5. How many of you work in programs that are:

- separate administratively from freshman writing

- included administratively with freshman writing

- a majority of teachers that are tenure track

- a majority of the teachers that are non-tenure track

6. What are the percentages of people of color in the program? 
- under $5 \%$

- under $10 \%$

-about $25 \%$

-about $50 \%$

-about $75 \%$

-about $90 \%$

7. How many of you are associated with programs in which the correlations between the basic writing students and the general college/university are in balance in terms of:

- race

- gender

-age

- cultural belief system

- majors

- urban vs. rural

- private vs. public schooling

\section{APPENDIX 2}

Let's begin with some short writing. I'd like you to generate three lists just to get the juices flowing. Think about a specific class - preferably a writing class that you're currently doing, or might have quite recently completed.

- List 3 adjectives that you think that your students would use to describe you now that the course is over or about over.

- List 3 adjectives that you think that these same students would probably have used on the very first day of class.

- List 3 adjectives that you would use to describe yourself in the classroom and specify whether your choices are closer to how you really are or how you hope that you are.

Spend a couple of minutes reviewing your lists and jot down a sentence or two specifying whether you see differences in the lists and how you might account for there being or not being discrepancies.

Now, I'd like you to write a short, short story about a real incident. Choose one moment from your teaching that involved a question of identity or image. Explain what happened, how you felt, whether this issue is ongoing or resolved for you. 
Save your story until later, but turn now to two people who happen to be seated near you. Talk about the adjectives that you generated. See if you can come up with a list of issues to share with the full group that seem to show themselves in your conversation.

Share the list of issues.

\section{APPENDIX 3 \\ SCENARIOS: CONSTRUCTING TEACHER IDENTITY IN THE BASIC WRITING CLASSROOM}

\section{Reading Materials}

You are teaching Robert Cormier's The Chocolate War, a novel classified as "young adult" and one that prompts discussion of peer pressure, teacher authority, gendered behaviors, individuals and communities (feel free to substitute the young adult novel of your choice here). Several students in your basic writing course are writing in their journals that they are enjoying the experience of engaged reading for the first time in their academic careers. Yet in classroom discussion, other students are claiming that the text is "too easy," that it is a text appropriate for "middle schoolers."

-How do you speak to both groups' of students' concerns?

- How do you select reading materials for a basic writing classroom?

\section{Collaboration}

You are teaching basic writing in a multiethnic classroom. You decide to assign peer groups for the quarter that are heterogeneous, and you pay particular attention to issues of race, culture, class, and writing strengths. Your African American students request to work together, thereby offsetting the "balance" you had worked to achieve. Suddenly, the peer groups seem to be structured along racial lines.

-How do you respond to the request?

- How do you determine the structure of peer response groups in your basic writing classroom?

\section{Structure}

Your basic writing pedagogy privileges a process-oriented, holistic approach to drafting and revising. You encourage your students to enlist a variety of prewriting strategies, but you do not prescribe them; likewise, you talk to students about "focus ideas" or an "implied thesis," but you do not ask students to begin their prewriting by drafting a thesis statement. One of your students, an Asian American 
enrolled in his first sociology course, pulls you aside after class. "I have a complaint," he says. "Today in Sociology 101, my teacher asked me to turn in my thesis statement and topic outline for my research paper. When I turned my stuff in, she said I didn't know what a thesis or an outline even was."

- How do you answer your student?

- How do you balance an emphasis on writing conventions with other possible emphases in the classroom?

\section{Gender}

Two white students, one from a rural community and the other from a suburban area, are presenting their findings concerning sexual harassment and the "P.C." movement to a multiethnic basic writing class. Only one of the ten students is female. As you listen, you become aware that the presenters are speaking about sexual harassment issues in highly problematic ways. However, these two students have expressed their frustrations regarding their own discomfort with your "multicultural curriculum" throughout the quarter.

- How do you respond to the presentation?

- How do you facilitate the ensuing discussion?

- How do you determine an appropriate focus or set of values for your own course?

\section{Assessment}

Upon completing a quarter of your basic writing course, you feel that one of your students should, in fact, bypass the second quarter of the basic writing sequence. You tell this student that he can submit a portfolio of his work to you, and that you will write an accompanying letter of recommendation to the coordinator of the Basic Writing program advocating this action. Your other students hear it is possible to "bypass" the rest of the sequence.

-How do you speak to the group about the process?

-How do you explain who "belongs" in a basic writing pro -gram and who doesn't?

\section{Technology}

Your basic writing class meets in a computer-assisted classroom where you often utilize an on-line discussion program. You have set up two discussions or "chat rooms" for your students to participate in; the two discussions center around the "English Only" debate. As is often the case, the students divide themselves along ethnic lines; all of the Hispanic students choose to enter one chat room, while the white students enter the other. You, the teacher, are able to "float" between 
the chat rooms. You notice that the white students have begun a discussion of Mexican migrant workers and issues of class that is highly problematic, but the Hispanic students on the other side of the room are not aware of the discussion.

- How do you participate in the troubling discussion?

- How do you encourage cross-talk?

\section{Experience}

You are teaching Mike Rose's Lives on the Boundary to your multiethnic basic writing class. Your Latino and African American students are excited by the book, but your white, rural students connect with the text on only one point: they argue that they, like Mike Rose, have been victims of testing mix-ups.

- How do you encourage both groups to think critically and creatively about the book?

- How do you account for differences in personal history and experience in your classroom pedagogy?

\section{Agency and Authority}

You are a teacher of basic writing in a multiethnic classroom, and your class is working on collaborative projects involving contemporary language issues: Ebonics, bilingualism, the "English Only" debate, and the "P.C." movement on college campuses. A group of African American students presents their thoughts on Ebonics to their classmates. One of the speakers contradicts herself several times as she reads from the Oakland City Amendment; she cites the amendment, then "translates" to her classmates in highly problematic ways. To complicate matters further, when the presentation is over, the students pose all of their questions to you, not to the group.

-What role should you play in negotiating the discussion?

- How do you simultaneously: encourage critical questioning; hold students accountable for accuracy, clarity, and precision when they lead discussion; and require respect for others in the basic writing classroom? 


\section{Jane Maher}

\section{WRITING THE LIFE OF MINA P. SHAUGHNESSY}

In a day filled with thought-provoking and insightful sessions, Jane Maher's stands out because in her talk on her new biography, Mina P. Shaughnessy: Her Life and Work, she introduced us not simply to the elegant, successful Mina P. Shaughnessy, but more movingly to the struggling, determined, and yet frequently thwarted Shaughnessy. Foregrounding her own working class background, Maher told us about how she had attended college as an adult and just missed being one of Shaughnessy's students. Shaughnessy herself was from a working class family who, as many of our students and their families do, believed in the power of education to change lives. Jane Maher is an associate professor in the Basic Education Program at Nassau Community College where she teaches basic writing. She has written several biographies; still the story of Mina P. Shaughnessy's life was special to her because it revealed the early days of our field and of open admissions, and the story of motivated and courageous students and teachers, and of one woman who believed in them.

I am often asked how I became interested in writing a biography of Mina Shaughnessy. I never met Mina; however, I could have been one of her Open Admissions students. After I got married in 1968, I enrolled at the College of Staten Island, CUNY, part time, in the evenings. I attended classes from 1969 until I finally graduated in 1976; during these same years, Mina was working very hard, and meeting much resistance, as she tried to implement an open admissions program at City College that would offer students at City and in the other CUNY divisions the opportunity to develop the skills they would need to succeed in college.

After I graduated from the College of Staten Island, I enrolled in a master's program at Columbia University where I earned a degree in American and British literature. In 1979, during my last semester at Columbia, I was accepted into an intern program being run at Kingsborough Community College. This program was designed to enable those of us who had the "credentials" to teach at the college level - credentials based on a graduate degree in literature - to get some actual experience teaching basic writing. People like Mina had begun to realize that there was simply no training available in composition for those of us completing masters and doctoral degrees, and so this intern program was inaugurated.

After less than a week in my classroom at Kingsborough, I went to Jack Wolkenfeld, the man who had hired me, and begged him for help: my students wanted to learn, it was clear that they could learn, the only problem was I didn't know how to teach them. Jack told me 
about a book that had been published the year before, Mina's book, Errors and Expectations. He told me it was essential that I read this bookit was the only work of its kind. And he also told me that everyone in our profession who had heard of Mina Shaughnessy was mourning her death - she had died a few months before. That was the first time I heard Mina's name. I got the book of course. I've been teaching basic writing ever since-and what's interesting about Mina's book is that the more I teach, the better the book gets.

And so I always admired Mina Shaughnessy's work and understood how deserving she was of the reputation she had as a leader, the leader in our field. And of course, I came across her name scores and scores of times - in my reading, in my conversations with colleagues, at conferences, and in my graduate work as I completed a Ph.D. in English Education at New York University. Although she was always larger than life to me - one of the "big names" - I knew very little about her personal life.

In the meanwhile, I had become interested in the genre of biography. I had completed my first biography in 1983; it was about Robertson and Garth Wilkinson James, the younger brothers of Henry and William, particularly their valiant service as officers in the first all-black regiments during the Civil War. I wrote my next biography to complete my dissertation requirements at New York University: the story of the life of William C. Stokoe, a professor at Gallaudet University who simply would not be deterred in his fight to have American Sign Language recognized as a language despite enormous resistance and ignorance. So I had written two biographies by this time, and I began to think that maybe I knew what I was doing.

In 1992 I drove to Maryland to attend the Basic Writing Conference, and something happened there that eventually led me to think about writing the biography of Mina Shaughnessy, this "figure" who was always larger than life to me. There's an award given every two years called the Mina P. Shaughnessy Award in recognition of an article judged the best to have been published in the Journal of Basic Writing in the past two years.

When the winner was announced, I remember thinking that there must be some mistake: the article, if it was the one I thought it was, had - in my opinion - misrepresented Mina's work. I didn't say very much at the time, but when I got home, I reread the article, and I began to realize that the person who had written the article did not seem to understand the conditions under which Mina was working in the late 60 s and early 70s, nor did she seem to understand what Mina was trying to accomplish. I thought about writing a response to the article, and I even spent many hours rereading Errors and Expectations in preparation. But I find that kind of writing enervating - you're spending all 
your energy subverting or resisting someone else's ideas-it's the least satisfying kind of intellectual work, I believe. So I abandoned that idea.

I began instead to think about writing Mina's biography. I had written two biographies, I had attended CUNY, I had taught at Kingsborough, also part of the CUNY system. And maybe most important, as a result of my experience as the first coordinator of the Basic Education Program at Nassau Community College, I understood all too well the politics of academia.

I conducted more than 40 interviews in preparation for writing Mina's biography, and these interviews were quite something, because Mina, in addition to being an absolutely brilliant scholar and dedicated teacher, knew - and was loved and admired by - some of the most interesting people in the United States: Adrienne Rich; Irving Howe; Patricia Neal; Judge Lottie Wilkins, the first female AfricanAmerican Supreme Court Justice in the City of New York; Marilyn French; Calvin and Alice Trillin; Alison Bernstein, a vice president at the Ford Foundation; Benjamin DeMott; Janet Emig; Ed Corbett; E.D. Hirsch; Timothy Healy, president of Georgetown University and later of the New York Public Library.

In addition, I interviewed four college presidents, along with many of the leaders in the field of basic writing-most of whom were younger than Mina, and all of whom started their careers working with Mina. In fact, several of them were hired by Mina to teach at City College, and their detractors, those who did not wish Open Admissions well, called them "Mina's minions."

I also traveled to Spearfish, South Dakota, to meet Mina's brother, George Pendo. Spearfish is about ten miles away from Deadwoodthat's where Wild Bill Hickock was shot in 1876. Mina did not grow up in Spearfish; her parents moved there after she left for college. She grew up not far from Spearfish in Lead, a classic mining town - very dusty, and very ugly. But the town is surrounded by the Black Hills of South Dakota - those hills were Mina's skyscrapers - and although Mina came to love New York and vowed never to leave it, she also loved those hills. She always kept a picture of the Black Hills on her desk, and seeing those hills during my visit enabled me to understand immediately why she loved them.

Mina's brother, who died soon after I completed the first draft of my book, was a very gentle man, very quiet, very proud of his sister, although he always claimed that he didn't really know much about Mina's work in New York. He was very pleased that I was writing Mina's biography, and he gave me every letter that Mina's mother had saved, along with so many other valuable papers - photographs, notebooks, even copies of The Golden Magazine in which Mina had published children's stories. On my way home to Connecticut from South Dakota, I was grounded for hours because of a snow storm in Den- 
ver - it could have snowed for days for all I cared. I sat in the airport reading the letters Mina had written after she left home to go to college and later when she moved to New York. During the time I spent in the airport reading Mina's letters, intimate details began to emerge, along with those more banal details that comprise a life.

It is at times like these when a biographer begins to feel the burden, the responsibility of the task. There I sat with Mina's papers in my lap. Mina's brother had entrusted them to me-I was about to try to tell a life. Imagine trying to get someone else's life right. Many months later, I would mention this to Adrienne Rich, who had been hired by Mina in the late 1960s to teach basic writing at City College. "Of course you can't get it right," she told me, "but you can get it righter."

Knowing that Mina's father was a miner who had only completed the eighth grade suggested to me the possible origins of Mina's devotion to open admissions students. (And I am not using that word lightly: Mina was absolutely devoted to her students - she put them above all else, especially politics.) Mina's father worked in the Homestake Mine for almost thirty years, first below ground "mucking," and much later as a foreman. But as long as he was a miner, he worked for someone else, he worked very hard, and he never got paid enough. Albert Pendo was determined to get out of the mine - and he didwhen he was almost 65 he bought a ranch and he and Mina's mother Ruby became ranchers, again working brutally hard, but this time for themselves. When Mina first met those Open Admissions students who were causing so many other professors to wring their hands in dismay - even disgust-claiming that these students couldn't read or write properly, therefore they didn't belong in college, it's easy for me to imagine Mina thinking of her own father: with his eighth grade education, he couldn't read or write "properly" either, but that wasn't his fault any more than it was the students' fault. Mina never confused a lack of training with a lack of ability.

Mina herself was an excellent student, earning A's and B's throughout her entire educational career, except for a few $C^{\prime} s$ in physical education. Mina majored in speech and theater at Northwestern University, and she was a talented actress. However, after a year in Manhattan working part-time and auditioning for parts, she decided to return to school. First, she enrolled in theology courses at Wheaton College in Chicago, then she enrolled in Columbia University's master's program in literature. Mina loved her graduate courses and developed a life-long passion for the work of Henry James and Chaucer. It was during this period that Mina held her first teaching job - at The National Bible Institute, a small college that was affiliated with the Bible Presbyterian Church. Mina was exhausted juggling her own graduate course load with the demands of teaching two literature courses: she had so little money at the time that she told her brother that she some- 
times ate Jello three times a day.

Soon after Mina earned her master's degree, she was offered a job as a research assistant to Raymond Fosdick, a prominent New York lawyer who worked for the Rockefeller family and who had been asked to write a biography of John D. Rockefeller, Jr. (Raymond Fosdick was the brother of Harry Emerson Fosdick, for whom the Rockefeller family had built Riverside Church). Mina told her brother George that she had to learn, very quickly, to stop making "rich as Rockefeller" jokes. Mina worked with Fosdick for almost three years and wound up writing half of the book. She actually met John D. Rockefeller, Jr. while she was doing research at Williamsburg in Virginia. Adrienne Rich once pointed out the irony of this situation: the miner's daughter meets the richest man in the world. Mina was an astute observer of the human character, however, and she did not hold Rockefeller in awe. Although she admired him, she once wrote to a friend, Priscilla Brandt, that "somehow he missed some of the major human wrenches - one knows that Shakespeare would not have put him in a play."

While Mina was conducting research for the Rockefeller biography, she met Donald Shaughnessy at the New York Public Library. He was completing the requirements for a Ph.D. in history at Columbia University at the time. On their very first date, they discovered that they had been born on the same day and that they were both left handed. They got married less than three months later, and six months after that, soon after Mina completed her work on the Rockefeller biography, she and her new husband went to Italy for a year where he taught in a school for the children of American diplomats, and where they were so short of funds that Mina had to find a part-time job. Raymond Fosdick got her an assignment rewriting the recollections of an assistant pastor of the Riverside Church - she described the memoir in one of her letters to Priscilla as "badly written and permeated with that sort of limp and pallid good will which one associates with assistant ministers in Protestant churches."

Priscilla Brandt has saved the fifteen letters that Mina wrote to her from Italy - and they are extraordinary letters - because of their literary style, of course, but also because they reflect Mina's desire to "do something beyond what we are doing." At this time, she wrote to Priscilla of her frustration:

Certainly it has been a persistent ghost with us both, this conviction within us that we ought to be doing something beyond what we are doing, that there should be more unity to our efforts, and more direction. Instead our energies are splattered over innumerable projects and responsibilities - almost all of them important and rewarding, but none of them ever quite satisfying that deep desire for "a place in the sun," per- 
haps, or more accurately, for some modest little channel through which one can communicate, with skill and form, her own impression of reality.

When Mina and her husband returned to New York from Italy, they rented an apartment in Manhattan, and Mina tried unsuccessfully to find a college-level teaching job, sending out hundreds of resumes. She finally accepted a full-time job at McGraw Hill as a senior editor, and she remained there for five years.

Mina still wanted to teach, however, and she finally was offered a part-time job at Hunter College in their evening continuing education program. This was the mid sixties, pre-Open Admissions, and many of the students in Mina's evening classes at Hunter were those who were required to attend at night because they did not meet the academic requirements to attend full-time during the day. Some of Mina's colleagues at Hunter had begun to complain about the quality of these students, many of whom were the sons and daughters of Irish or Italian laborers and civil service employees, almost always the first generation in their family to attend college. Mina's teaching experiences at Hunter prepared her for the resistance and racism she would soon encounter as Open Admissions expanded: her students were overwhelmingly white, and they exhibited writing problems that led many of the faculty members at Hunter to bemoan their fate and the fate of Hunter. (One of Mina's colleagues at Hunter refused to talk to me because he doesn't believe that a biography should have been written; it's people like Mina, he claims, who "ruined" the City University of New York.) When Mina began to encounter the same writing problems at City, where there were far larger numbers of minority students, she did not make the same mistake some of her colleagues were making, thinking that these students write this way because they are members of minority groups. Mina knew better: the students wrote that way because, as she said in the Preface to Errors and Expectations, CUNY was opening its doors not only to a larger population of students than it ever had before, but to a wider range of students than any college had probably ever admitted or thought of admitting to its campus:

the children of the lettered and the illiterate, the blue-collared, the white collared, and the unemployed, some who could barely afford the subway fare to school and a few who came in the new cars their parents had given them as a reward for staying in New York to go to college; in short, the sons and daughters of New Yorkers, reflecting that city's intense, troubled version of America. 
Mina also knew from her experience at Hunter College, "that the students were in college now for one reason: that their lives might be better than their parents', that their children's lives might be better than theirs so far had been."

Mina knew better than to criticize the writing skills of these students or to use these skills to determine their intelligence or their "right" to attend college: she had spent several years at McGraw Hill editing some very badly written books - if professional authors couldn't write well after having attended some of the best universities in the nation, why should these recent high school graduates be expected to write proficiently?

About a year later, Mina was offered a full-time job at Hofstra University on Long Island. At Hofstra, Mina met Alice Trillin - the beginning of a life-long friendship. Alice recalls that she would often drive Mina back to Manhattan after classes, and they would discuss their students' writing. Alice remembers that she and Mina began to notice "patterns" of errors - the same patterns that Mina would identify and describe several years later in Errors and Expectations.

Mina also met Marilyn French during the years she taught at Hofstra - and more than twenty-five years later, Marilyn French still remembers "wonderful rides to and from school on the Long Island railroad with Mina, talking about teaching and literature and life." Mina's poetry at the time reflects the fact that she was still, to some degree, a "traditional" teacher, concerned with her students' response to literature, to the canon.

Although Mina's position at Hofstra was a full-time one, she continued to work at Hunter part time for two more years, hoping that she would be offered a full-time position - but she knew that without a Ph.D., her chances were terribly slim. The lack of a Ph.D. would haunt Mina for the rest of her career: her enemies - the enemies of Open Admissions-used it as an excuse to fight every one of her applications for promotion.

Even before the advent of Open Admissions in 1970, several of the faculty members at City College had decided to work toward establishing a program for minority youth. They named it the pre-baccalaureate program; it later became the SEEK program and soon after that, Open Admissions was implemented in all of the divisions of CUNY. Faculty members were needed who knew how to teach writing to underprepared students; suddenly a Ph.D. in literature became far less important than some sort of practical experience. Mina and Alice Trillin were hired to teach these new students at City, but the summer before Mina was to begin teaching, the director of the Pre-Bac program suffered a heart attack, and the chair of the English department asked Mina if she would be willing to take over as director of the 
new, experimental program for about 300 students. No one realized that the number of students would grow precipitously within the next few years as the changing political climate in the city and the country began to force this society into recognizing the discrimination that minorities had faced in every aspect of society - including education where the student population in the CUNY system was still overwhelmingly white.

Mina said yes to the offer to direct the program. Today, there are people who like to take credit for having the "foresight" to place Mina in charge of what would quickly become the largest basic writing program in the United States. (It was Mina who coined the word "basic" - until then it was called "remedial.") However, none of the fulltime, tenured faculty members wanted such a job. Most of them were more concerned with their "true" mission - teaching literature and literary criticism and getting published. Writing was a mere skill: "teaching verb endings to illiterates" was the way that one of City College's professors described it.

I don't think Mina realized initially the nature or the seriousness of the resistance she would encounter at City, but she learned fast. Many faculty members ignored her, insulted her, accused her of destroying City College. On one occasion, someone placed pornographic pictures in her school mail box with the word "whore" scrawled across them. Mina was able to hold her own, however. Les Berger, the dean who had originally hired Mina said of her demeanor and countenance:

She would hold her head up high, look people in the eye. She would never get into a struggle or an argument. Even the elitists on campus didn't struggle with Mina directly - she somehow managed, with her appearance and her demeanor, to rise about the petty behavior that so many people were engaging in at the time. And there was that theatrical training. Mina may have been depressed, disgusted, overwhelmed - who knows what emotions she felt during those tumultuous yearsbut she never showed them in the arena. She "performed" for one of the toughest academic audiences in the country at that time, and the performance was always flawless.

That's not to say it was easy for Mina. She rarely complained, but in a letter to Marilyn French, she described the profound change her position at City was having on her life:

I am writing from under water - way down deep in a churning, murky, frenzied world full of sentence fragments, and sweet, betrayed students, and memos and suspicious colleagues.... 
Well, as you can see, I am going mad. I cannot imagine keeping up with the many demands this job makes and I am too busy to contemplate the outcome. Strange, but I simply cannot imagine what it would be like now to not think every day about black and white....

There were protests on the City College campus during this period, and Jean Campbell, one of Mina's students, remembers the way that Mina reacted to the riots and shutdowns:

As long as we could get on campus, [Mina] refused to cancel her classes. Mina had decided that she would practice her "politics" in the classroom, not on a soapbox. She told us she was providing the SEEK students with the tools to think, to write, and to read; that was the greatest contribution she could make. From anyone else, perhaps, this would have been hard to take, maybe even impossible, but there wasn't a black or Puerto Rican student on that campus who didn't know that it was Mina Shaughnessy who fought hardest for the SEEK students. In fact, when some of the buildings were occupied, the students did a lot of damage in some offices-but not Mina's. She was the best thing that ever happened to us, and everyone of us knew it.

Mina had many rich and satisfying relationships, but her work was her life. Mina's husband had taken a job with the state department, so he was often out of the country for months, even years at a time. While Mina was still at Hunter, it had been determined that she couldn't have children. Mina remained absolutely devoted to her parents, especially her mother, but they were in South Dakota. Mina and Donald Shaughnessy would remain married until Mina's death in 1978, but clearly Mina realized that she needed to find a direction and a career that would satisfy her.

She found it at CUNY. One thinks of the letter Mina wrote to Priscilla while she was in Italy in 1956 when she talked about that "conviction that we ought to be doing something beyond what we are doing" - "some modest little channel." That modest little channel turned out to be one of the greatest revolutions in the history of education in this country-perhaps the world.

The late sixties were heady times in New York and in the United States - the civil rights movement had inspired many people to use their talents to help underprivileged minorities, and quite a few of those people found their way to City College where Mina hired them to teach basic writing. One of them was Adrienne Rich, who had already achieved great recognition as a poet. Rich recalled what it was like 
working with Mina during those years:

Mina was effective in the classroom because she met each human being as such; there were no stereotypes in her head and this was evident in how she responded to questions, gave instructions, met students outside of class. She also had a wonderfully lucid and structured mind, a passionate love for literature, and a genius for ordering material so that it could be readily absorbed by someone coming newly to it. Her whole stance was reassuring. She never seemed to "wing" it or glide along on charm or personality. She was grounded, and I think students felt and trusted that.

Mina began work on Errors and Expectations soon after she started teaching at City College and completed it about six years later. During this time, Mina kept a chapbook in which she saved clippings, made notes and observations, raised questions. This chapbook, actually a blue three-ring binder, reflects, perhaps even better than the final product, the fact that basic writing was, as Mina often said, a "frontier." Mina drew on many sources; she never believed that she had the one theory or the one answer or the one method. She knew the value of, the need for, cooperation and collaboration. Mina respected her colleagues and her students - and she learned from them - the chapbook shows Mina's "process" as Errors and Expectations began to take shape and form. Mina struggled with ideas just as her students did.

Mina spent several years writing Errors and Expectations, but when the book was published by Oxford University Press in 1977, the response was immediate and overwhelmingly enthusiastic, just as Mina's editor, John Wright, had known it would be. Mina was truly surprised by the favorable response to the book. Wright remembers that Mina was still not convinced that people understood her intentions in writing the book - and maybe she was right. In one of the last sentences in Errors and Expectations, Mina noted that unless we improve the quality of college education for all students we could not move deeper into the realizations of a democracy-one wonders how far we've come in the past 20 years in achieving that goal.

Mina was ebullient over the extraordinarily favorable reviews and good sales - of the book, but at about the same time, Mina began to suffer health problems, and she could not get an accurate diagnosis for many months. Len Kriegel, one of Mina's closest friends and supporters, remembers sitting and talking with Mina one day when suddenly she reached into her purse, pulled out a bottle of Pepto Bismol, and "took a swig." Mina's doctor had told her she had an ulcer. "We laughed about it at the time," Len recalled, "little did we realize that Mina had cancer." Mina would wage a two-year battle against her dis- 
ease, and like everything else she did, she never gave up.

Mina was never fully appreciated either at City or CUNY - in fact, she moved to the CUNY Instructional Resource Center only after she was denied a promotion that she clearly deserved. And when she arrived at the CUNY Instructional Resource Center, she not only encountered a wave of budget cuts that literally closed CUNY for two weeks, she encountered petty jealousies that caused her much consternation. This, coupled with the devastation Mina felt over her mother's death in 1975, took a large toll on her. Despite these problems, however, Mina began to earn extraordinary recognition on a national levelbetween 1973 and 1977, she delivered eight addresses at major conferences, and in every address, as in every memo, every article, every letter Mina wrote, it was the students she supported and defendedagainst colleagues, against administrators, against politicians, against a society that viewed these students as deficient, as unworthy, as usurpers.

In the last address that Mina delivered, entitled "Basic Writing" and delivered at the 1977 MLA, Mina concluded by saying:

To prepare only some people to flourish in a democracy and then to argue that they are the only people with the native ability to do so is to consent to the existence, within the boundaries of what we call public education, of the most exclusive country club of all. Open admissions has been one way of exposing this inequity and of trying to do something about it. My examination of student writing has not only, I hope, documented the extent of the inequity in one American city but has suggested that the damage is not irreparable, that even the flaws and errors in the writing of ill-prepared students can lead us to more enlightened teaching that respects both the problems and the remarkable possibilities of basic writing students.

Mina had become so consumed with her work at City, and later at the CUNY Instructional Resource Center, that she never had enough time for her own reading and writing. However, Mina continued to write poetry: about her students, about her friends, about those issues that caused her pain. Mina wrote the following poem for Alice Trillin, on the occasion of Alice's 40th birthday. Alice had survived lung cancer, and at the time, Mina was waging her own battle against cancer.

Having been through rough territory

where thistles really pierce

and cliffs loom insurmountable at times, shading whole days, 
You know the journey into forty is just a fiction, a line chalked across our lives because the digits change, even though we are still stalking adventure, still longing for our mothers, still believing that the world is only as old as we are.

So please beautiful girl, become forty as if you have just skipped over a hopscotch line and all the fun is just beginning and ornery Time has not yet even thought yet about calling you home to supper.

Mina did extraordinary work under extraordinary circumstances during an extraordinary time in New York City's history - but in actuality, the period of time in which Mina accomplished so much was incredibly brief - within ten years Mina went from being an adjunct instructor at Hunter College to being the foremost scholar and researcher in the country in the field of basic writing - one can only imagine where her career would have gone, what she would have accomplished, had she not died so early. Toward the end, Mina knew that she was dying, and ironically, her illness and the long stretches of time when she was forced to remain in the hospital recovering from surgery and enduring radiation treatments, afforded her the time to write poetry again. One of the last poems she wrote, entitled "The Invalid," records her realization that she was dying-Mina wrote it from her hospital room on the 12th floor of the Memorial Sloan-Kettering Cancer Center:

I watch from my window

The people doing the work of the world

Floor upon floor of them

Too busy to note that the

winter afternoon has lit

them up like film strips.

They are busy in the world

I lately lived in.

Mina died on November 16, 1978. Her work forms a legacy that will remain with us as long as we care about the quality of education we offer to all of our students. For Mina, it was always the students: she put up with the politics, the personal attacks, the setbacks, all for the students, and she did it with a composure that inspired and comforted those who were fighting the good fight with her. Mina explained why she did this at the end of a speech she delivered entitled "The Miserable Truth," in which she tried to inspire her fellow teachers who were feeling demoralized not only by severe budget cuts but by the 
belief that no one in power cared very much about them or their students - $\mathrm{a}$ belief that many of us are feeling today, almost thirty years later:

So the lion got out of the cage before the gates were shut. But we had better keep learning how to teach writing because the brothers and sisters and cousins of our students will be back. If we can transcend for a moment the personal disappointments and uncertainties that surround us now, we can perhaps agree that that is a fairly strong truth for a miserable time. And it is a truth we helped to make.

\section{Note}

The information and quotations contained in this essay were obtained through interviews and correspondence with the family, friends, and colleagues of Mina P. Shaughnessy, and they are being used with their consent. 


\section{Mary Soliday and Barbara Gleason}

\section{FROM REMEDIATION TO \\ ENRICHMENT: EVALUATING \\ A MAINSTREAMING PROJECT}

Barbara Gleason and Mary Soliday, both established authors on issues of cultural and language diversity, have for three years overseen a FIPSE-funded alternative to remediation-and at the very school where Mina Shaughnessy oversaw the establishment of basic writing. At the CBW workshop, they showed a compelling videotape containing interviews with students, faculty, and external evaluators and then had participants experience some of the assessment techniques used to evaluate the project's success. The medium of print requires a different approach, and so the authors have given what is at once an account of their project, a detailed description of their means of assessing it, and, perhaps most important, suggestions for how and why similar endeavors might be mounted elsewhere.

In 1993, we secured support for three years from the Fund for the Improvement of Post-Secondary Education (FIPSE) to create a new writing course at the City College of New York (CCNY). The twosemester writing course we envisioned - the Enrichment pilot project substituted for the established sequence of two remedial courses and one college-level course. Throughout the life of this project, we assessed its effectiveness by conducting a two-pronged evaluation. Formative evaluation provided ongoing evaluation which we used to enhance the project's effectiveness; summative evaluation assessed the project's effectiveness after it was concluded.

In this essay, we want to focus on one aspect of our summative evaluation, an assessment of student writing and learning. The results of this evaluation suggest that this project in mainstreaming basic writers successfully addressed the needs of CCNY student writers. An external reader's assessment of student portfolios demonstrates that remedial-placed students were competitive with college-level placed students at the end of the two-semester course. Our analysis of student self-assessments reveals that students could clearly articulate their own learning experiences and that there was strong student satisfaction with the pilot course.

Although funding from FIPSE was vital to our own ability to conceptualize, implement and evaluate this project, we believe piloting mainstreamed writing courses to be possible without external funding in institutions when there is sufficient internal administrative support. A well-defined curriculum and a careful evaluation are fundamental to the potential success of pilot courses such as this one. 


\section{Remediation vs Enrichment}

The sequence of courses that the Enrichment pilot project replaced has borne the hallmarks of remediation since its inception in 1970 . These hallmarks include testing for placement into one of three courses; testing for exit, which serves as an institutional check on teachers and as a gatekeeper for students; and reduced credit or no credit for remedial courses. (Even the possibility of partial credit for basic writing courses ceased after Fall 1995.) In addition, at our College, students enrolled in basic writing courses are restricted from enrolling in five core curriculum courses (World Humanities 101 and 102, World Civilization 101 and 102, and Philosophy 101), a restriction that was extended to students enrolled in Freshman Writing during the life of this project.

Students are placed into remedial writing courses based on their scores on the City University of New York (CUNY) Writing Assessment Test (WAT). This is a fifty-minute impromptu that two readers score holistically using a six-point rubric. Individual colleges use these scores to determine a student's placement in various writing courses which may or may not bear credit. We contest this process of placement, and thus the validity of the CUNY WAT, as the sole measure of potential student success in a writing course (for placement) or as a predictor of success in college courses (when the test is used for exit from remediation). ${ }^{2}$

The traditional remedial sequence is characterized by lack of college credit, limited access to other college courses, and placement or exit via a single essay scored by readers other than the actual teacher of a course. In contrast to this sequence, the writing course we piloted carries full college credit (three credits per semester), no distinctions are made between those who placed into college level writing and remedial writing, and teachers decide whether students should pass their courses. Moreover, all students are allowed to enroll in the college's core courses if they have passed the CUNY Reading Assessment Test (RAT).

\section{Structure of the Pilot Project}

The Enrichment pilot writing program aims to build community on an urban, commuter campus. Students are allowed two consecutive semesters together with peers, class tutors, and teachers. The increased time spent in class facilitates the formation of relationships conducive to learning. Teachers come to know their students and provide more effective, more individualized instruction, especially during the second semester. 
Forming communities is vitally important for students on this urban campus. For many, enrolling full-time in college involves long hours of both study and work, and far fewer hours of recreation than would be the case on a residential campus. One survey of Fall 1994 project students reveals that 99 of 224 - or $44 \%$ - work part time or full time. Moreover, CCNY students frequently come from families with low incomes: $70 \%$ of all CCNY undergraduates receive financial aid (City Facts 1995-1996). Many students have family responsibilities for younger siblings or for their own children. It is all too easy for such students to be pulled away from the college campus by adult concerns. This project's two-semester writing course creates a space for students to become grounded in college life during the crucial first year.

The pilot project aims also to acknowledge and utilize our students' cultural diversity. A survey of 241 students enrolled in basic writing and college writing courses (Fall 1996) reveals that 47\% (115) speak English as a second language, are bilingual, or speak one first language and write English as another "first language"; 62\% (151) of these students were born outside of the U.S. This multiplicity of student languages is common to all CUNY colleges: $44.3 \%$ of the 58,629 freshman and transfer students admitted to CUNY in Fall 1992 reported English as a second language on their application forms; that figure is expected to increase to over $50 \%$ by the year 2000 (Report of the CUNY ESL Task Force, Spring 1994, 1).

We conceptualized a writing course curriculum that capitalizes on students' existing linguistic knowledge and literacies. This focus on existing knowledge - rather than on deficits - is a fundamental principle of the curriculum. This and two more essential principles remained in place even though the curriculum evolved over its threeyear life. A second principle is that language should be studied from a descriptive perspective (based on observations of actual language use) rather than solely in a prescriptive, handbook and usage frame (which was also used by many project teachers). Involvement in the study of language is key for students who are learning a new grammar (Standard Written English) and new discourse forms (academic structures and conventions). The third principle is that student writers are to be understood developmentally-as students whose language learning and writing abilities are processes and important objects of inquiry for students and teachers alike.

Project teachers developed their own assignments, but each year they also worked collaboratively on a set of projects that everyone taught. Curriculum coherence was further achieved by a generalized focus on language study during the first semester and on researching cultural themes during the second semester. Each semester, teachers assigned one research project whose parts were sequenced over several weeks. The first semester, students wrote literacy narratives, stud- 
ied language use in their own communities, and compared their spoken to their written use of English; they then conducted original ethnographic research, often in their communities or workplaces. These various forms of research aimed to encourage heightened awareness of language form and use and attention to language choices.

This first semester research also emphasized analysis and critical thinking. It therefore served as a bridge into critical reading and writing about texts in the second semester, when teachers focused on reading about a cultural theme such as the family, ethnicity, or popular art. In all three years of this project, students in many course sections learned about library research and writing from sources. In the last year, library research and research writing skills became required in all course sections. Both students and faculty strongly advocated the emphasis on library use and essay documentation that became more prominent during the project's third year.

According to project faculty and students, the ethnographic research project proved especially successful. This multifaceted project allows students to work on many different research and writing skills. Samples of student writers' ethnographies can be seen in several handsome classroom publications that teachers and students produced over the years.

In the second year, the faculty voted unanimously to require the teachers in the final year to use portfolios and to assign five common projects. These are the assignments included in our study of student writing, which we describe below.

\section{Participants in the Project}

Approximately 1,000 students enrolled in the Enrichment project courses, one of which was taught at the Center for Worker Education, an off-campus degree-granting program for working adults. Of these students, 168 placed into the lowest level of remedial English, and 483 into the next level; 365 placed into college-level writing, and 55 have no official placement information.

Twenty-eight teachers, including both project co-directors, taught the pilot course; one instructor taught two sections simultaneously and seven taught in successive years. All teachers met during monthly workshops; they also participated in formative evaluation by assembling portfolios of their work at the year's end. Teacher portfolios generally included a cover letter, samples of class handouts and student writing, a teaching journal, and supplements such as class videos and student writers' class publications.

Forty-one Writing Center tutors were assigned to work with the classes. ${ }^{3}$ These students were primarily undergraduates with majors 
from a variety of disciplines; a few tutors were enrolled in English Department graduate programs. In one pilot course survey, $61 \%$ of the students said they had made between one and several appointments each semester with their tutors; in the established writing courses, which have no classroom tutors, about a quarter of the students meet with a Writing Center tutor at least once. In order to evaluate this component of the project, we interviewed and surveyed tutors each year; in the third year, we videotaped one group interview of tutors and another group interview of teachers.

Finally, five consultants assisted us with this project. ${ }^{4}$ These consultants provided formative evaluation (e.g., assessing the quality of the curriculum in the project's first year), advice on developing project evaluation strategies, and summative evaluations. A consultant at CCNY downloaded student records and helped format a database for statistical analysis of student progress and achievement.

\section{A Study of Student Writing and Learning}

Our principal aim has been to pilot a college writing program for a highly diverse group of students on an urban, commuter campus. Our evaluation of the pilot course has involved both a statistical analysis of student progress and achievement and assessment of student writing and learning in the course. This second component of the project evaluation provides a more direct form of project evaluation.

In 1995-96 we adapted a curriculum evaluation design from Pepperdine University (Carroll; Novak). Whereas Pepperdine's evaluation encompasses the entire college experience, ours focuses exclusively on the writing course. We created a study in which outside readers, teachers, and students assess a student's performance in the pilot writing course. We describe these components separately in two parts: (1) outside readers' assessment of student writing; and (2) student self-assessments and project teacher assessment of the same students.

\section{Assessment of Student Writing}

We selected two students at random from each of the 11 courses offered in 1995-96 to participate in this study. These students assembled portfolios especially for this evaluation: each of the 22 portfolios included five assignments common to all the sections that were taught in the project's third year: a literacy narrative, an ethnographic research project, a library research project, a self-reflective essay, and a piece of the student's choice. Most portfolios did contain all five required pieces, though in a few cases teachers had modified assign- 
ments to suit their individual styles. Ten faculty members from the English Department (who had not taught the pilot course) participated in this evaluation. We divided them into groups of five. Meeting separately, each group read half the portfolios, so that each portfolio received five final scores.

In holistic assessment, the aim is to establish consensus among readers, which is usually achieved through norming sessions with a rubric. At Miami University, where portfolios are scored for incoming freshmen to determine placement, a committee achieves consensus in repeated norming sessions with anchor portfolios and a six-point rubric (Daiker). At SUNY Stony Brook, where portfolios are used to determine exit from writing courses, teachers use anchor papers when they calibrate twice each semester (Elbow and Belanoff).

In our case, since we were not making placement or exit decisions, we did not aim to achieve consensus among readers. Instead, we aimed to use portfolio evaluation to assess the pilot project's success at our institution. We had hoped to compare the writing of pilot project students with students' writing from English 110 (the established, one- semester college writing course). However, we could not do so because English 110 teachers emphasize different genres and skills and because there is no common curriculum in established courses that could be used for comparison.

We chose to assess uniform portfolios with a checklist reflecting primary pilot course goals. Instead of norming readers, we sent them an advance letter outlining our evaluation goals and their tasks as portfolio readers. We described the contents of the portfolios, noting cases in which teachers had modified assignments. We asked readers to award final scores to portfolios as if they were awarding final letter grades to their own students' portfolios at the end of an English 110 class at CCNY. Assessment specialists now emphasize the importance of allowing readers to draw upon their personal knowledge of student writers and standards when judging student writing (Huot). In asking readers to use their own criteria rather than ours, we hoped that this portfolio assessment would more closely approximate readers' actual standards as classroom teachers (Elbow).

We prepared a reader's checklist that we had adapted from a Pepperdine University reader's checklist form. The checklist asks readers to score portfolios analytically in eight areas before arriving at an overall score. The eight specific areas readers analyzed include modes of thinking (analysis, description and narration); textual features of essays (development, structure, grammar and mechanics); and goals specific to this project (creativity and risk-taking, research, and selfreflection).

One particular strength of the reader's checklist is that readers can write comments for each area analyzed and also after awarding 
the final grade. Eight of the ten readers participating in our study did write (optional) comments, some of them detailed, providing an explanatory reference for their final portfolio grades. These written comments allowed us to gauge whether readers considered every piece or awarded scores based on the first piece they read, as was the case in a study conducted at the University of Michigan (Hamp-Lyons and Condon).

In their written comments, readers often referred to specific essays in the portfolios, indicating that they had read all five pieces. Sometimes they suggested this by describing their impressions of a student's overall growth: "VERY different pieces from [English] 111 to [English] 112," concluded one reader. "This writer went from 'below' average, in my view, to 'above' average, in my view ... This is dramatic growth - from 'D,' if you will, to 'B.'" Readers frequently indicated, too, that they didn't award a grade based upon the first essay because their judgments changed while they read. One reader commented, "At first the portfolio seemed promising but as I read I was struck by the writer's intellectual immaturity." On other occasions, readers suggested that they judged the whole portfolio within the context of an imagined classroom experience. For example, after awarding a B to a portfolio, one reader concluded: "'Above average' would seem to be a B - but depending on other factors - participation, attendance, work with peer group-I might well give this student an A. Literacy narrative was excellent, ethnography also very good."

These outside readers reflect the diversity of our department and of composition programs nationwide. The ten professors were diverse in rank, ranging from a full professor with long experience at the college to an adjunct instructor relatively new to the institution. These professors were equally diverse in their intellectual backgrounds: literary criticism and theory, composition and rhetoric, linguistics, and creative writing. In their current involvement in teaching and assessing writing, this group also varied: some use portfolios in their classes or are certified readers for the CUNY WAT, while others have never used portfolios or have not taught remedial writing or college writing at CCNY for several years.

Unsurprisingly, this group expressed diverse biases towards particular assignments and writing pedagogies. For instance; one reader concluded,

The student is somewhere between an outright B and an outright $C$ student. Based on these papers, I'm inclined to award a $B$ rather than a $C$, but (as with the other students), I miss being able to judge partly on the basis of in-class writing.

For the same portfolio, another reader wrote, 
The self-selected paper (essentially literary analysis) is significantly weaker in development and arrangement than the other pieces. The self-reflective piece is impressive. This portfolio, in particular, seems to support the idea that the FIPSE-type assignments inherently lead to better writing than traditional literary criticism topics. The ethnography and research paper, for example, are light years "better" than the literature analysis piece.

Both readers awarded Bs to the same portfolio, but each expressed an opinion of the merits of the portfolio's contents and thus of the experimental curriculum. The first reader's comment suggests that for him as a reader, this and other portfolios present an incomplete portrait of their authors. Because it contains revised, finished pieces, the portfolio could highlight the student's strengths and downplay potential weaknesses (which might show up in first drafts or in-class essay exams). By contrast, the second reader's comment appears to suggest the opposite: that the portfolio's self-selected piece of literary criticism obscures rather than maximizes the student's strengths.

These kinds of differences among readers surfaced often in the written comments but less often in final scores. The overall final scores indicate that our readers agreed more often than they disagreed when awarding final letter grades. Table One, which lists the grades for all 22 portfolios, shows that readers reached consensus on a portfolio's final grade well over half the time. Fifteen portfolios received scores clustered across two grades, for an agreement rate of $68 \%$ among readers. This is a very high rate outside the context of normed holistic scoring, where an $80 \%$ agreement rate between two readers, not five, is considered reliable. Moreover, as Dispain and Hilgers point out even with norming, achieving consensus with portfolios is more difficult than with single essays, often because readers have trouble awarding single scores to multiple writing samples in different genres.

Table One further indicates that despite readers' sympathies with or antipathies towards this experimental project, they judged the students' writing to be competent and more than competent. Out of 110 readings, the readers awarded 56 As and Bs to the portfolios. Half the time, then, they judged portfolios to be excellent or very good. Thirtyseven times, readers awarded portfolios average grades; in 13 instances readers judged portfolios to be below average or failing. Overall, readers also judged the portfolios to be stronger than weaker, awarding 16 A grades as opposed to $2 \mathrm{~F}$ grades.

Table One also organizes the final scores in terms of students' initial placements - remedial or college-level. (Students with unclear placement histories are identified in an explanatory note.) Scores listed 
in Table One show that the eight remedial-placed writers in this sample, mainstreamed with college-placed students, produced competent work as a group. The outside readers awarded the remedial-placed students 12 Bs and 23 Cs. None of these students received an A from a reader, but only two of the portfolios received $\mathrm{D}$ grades, and there were no failing grades. Thus, a third of the time, readers judged the remedialplaced writers to have produced very good work; most of the time, they judged this group to be good or average (in the $B / C$ range).

Table One shows that the readers awarded more varied scores to the 11 portfolios written by the students who placed into college-level writing. For instance, this group provoked more disagreement among readers, as evidenced by portfolio nine, which earned an A, B, C and D from four readers and a split $B / C$ grade from the fifth. Overall there are also more split grades (1 split score for each letter grade). This group earned more As and Ds--twelve As (Portfolio \#13 garnered five of these) and $7 \mathrm{Ds}$. When compared to the portfolios written by remedial-placements, the college-placement portfolios were stronger, earning more As and fewer Cs. But these portfolios were also weaker than the remedial-placement portfolios, earning twice as many Ds and Fs.

According to ten outside readers, the 22 students in this random sample met the goals of the pilot course. Students who would have taken a non-credit writing course were competitive with students who were eligible for college-level courses. Most students produced very good or good analytical, descriptive, and narrative essays that reflect the standard conventions of college essay writing. And most students demonstrated an ability to evaluate their own writing, to reveal growth over time in a portfolio, and to conduct research inside and outside the college library - all prominent features of the experimental curriculum.

\section{Student Self-Assessments}

In addition to the perspectives of ten outside readers, we also surveyed the student authors of these 22 portfolios in order to learn about student perceptions of their learning experiences in the pilot writing course. Student self-assessment and student satisfaction should be seriously considered in an evaluation such as this for two principal reasons: (1) for all college students-and for City College students especially-attending college is a significant investment with important consequences; (2) student satisfaction has been found to be positively associated with retention and undergraduate gpa (Astin, 310) and student self assessment has been found to "have some modest validity when compared against actual pretest-posttest changes in performance" (Astin, 222 [referring to research by Anaya]). Of particular interest to us is a finding in the same research that student satisfaction 
with "overall college experience" is positively associated with number of writing skills courses taken, student-student interaction, faculty-student interaction, and institutional diversity emphasis.

For this study, we modified a student self-assessment questionnaire from Pepperdine University. ${ }^{5}$ The questionnaire asks students to evaluate their learning by rating perceived change in 17 different abilities and attitudes, e.g., revising, organizing ideas, and motivation to write. Both teachers and students rated a student's learning by checking one of four categories: significant change, some change, little change, or no change. Teachers also explained why they awarded the student a grade and how they evaluated student performance generally. Students were interviewed by Writing Center staff about their responses to this questionnaire. ${ }^{6}$

As can be seen in Table Two, the 21 students who completed this survey most frequently identify "significant change" or "some change" in six areas: 1 . writing longer essays (20); 2 . organizing ideas (19); 3. critical thinking/ability to analyze (19); 4. finding ideas to write about (18); 5. relationships with teachers, tutors, peers (18); (6) editing for style (18). On the other hand, only 12 of these 21 students report "significant change" or "some change" in speaking skills-a less prominent feature of this curriculum.

Writing longer essays was reported by students most often as an area of "significant change" or "some change." Interestingly, this is one of the three most highly rated areas of change observed by teachers as well. Writing longer essays is an especially important area of improvement for inexperienced, unmotivated, or weak writers. These students often suffer from writer's block, either because of anxiety related to writing or because they lack expertise in invention and revision. Explaining why he noted "significant change" in both finding ideas to write about and writing longer essays, one student explains that in the past he had "always suffered a writer's block" and that he "always used to be very brief." However, his teacher's comments on his drafts for this course encouraged him to write more and ultimately produce longer essays.

We believe that, in addition to learning specific strategies of invention and revision, students can learn to produce longer essays by breaking down a writing project into manageable units. The Enrichment curriculum features sequenced writing projects with interrelated tasks, allowing students to combine shorter pieces of writing into longer essays or research reports. The fact that students and teachers noticed most improvement in this area indicates to us that teachers did in fact introduce this key element of the curriculum into their classrooms and also that many students succeeded in learning this taskspecific approach to writing.

Relationship to teacher, tutor, and peers was one of the three 
categories marked most frequently by students as an area of "significant change." Twelve students report "significant change" in this category and six more marked "some change." Teachers noticed student change in this area somewhat less frequently. Nevertheless, we are encouraged to learn that $18 / 21$ students noted significant or some change in relationships and that teachers noted change in relationships for 16 of 22 students.

This reported growth in the area of classroom relationships suggests to us that teachers succeeded in constructing environments conducive to effective communication. It also suggests that the two-semester course structure contributed to building classroom community - a principal goal of this pilot project. As one student puts it, "I think the peer issue is because we were together for a year. That relationship grew faster than any other relationship." A second student confirms this view of the two-semester course: "I felt that being together with the professor for one year was just wonderful. Because you sort of get to know each other and know what to expect and know not only for that class but for other classes."

One might well ask whether or not student self-evaluations even matter for program evaluation. We believe they do. Although people generally do not grasp the full complexity of their experiences, students do know something of whether or not they learned, what they learned, and how well they learned. It is true that students' self-reports do not offer evidence of the degree of proficiency achieved. However, a close reading of the interview transcripts for this study reveals one dominant pattern: all students are able to comment specifically on their development over time as writers, readers, speakers, and researchers. Their vocabularies include terms such as revision and proofreading, but also Standard English, works cited, MLA format, microfiche, and annotation. Students are able to articulate what they did and did not learn well, and what they particularly appreciated about the course.

In this study, student self-reports are at least partially validated by our teachers' reports-not on a student by student basis-but in overall responses for each of 17 abilities or attitudes (Table Two). Students and teachers alike find most change overall in four categories: finding ideas to write about; writing longer essays; organizing ideas; and critical thinking. All of these abilities are key to the Enrichment curriculum. Critical thinking, or ability to analyze ideas, is particularly important for this writing course. We theorized the entire curriculum on the premise that consciousness of language and reflection on one's own experience of language and literacy are key to literacy development. The writing projects that anchor this curriculum all require critical thinking and analysis.

In general, the results of this survey questionnaire indicate that 
students were very satisfied with their own learning in English 111 and English 112. More importantly, the student interviews indicate that students can speak very concretely about what they did learn. The most enthusiastic comment comes from a student who could have enrolled in English 110 - the established one-semester college-level course - but chose instead this two-semester experimental course:

I hated writing like I said before. Now I can sit down and just write write write write write or type type type type type, whatever. That is, like, the best thing that ever happened to me.... This course is ideal. I think it's not only good for people who have problems with English or writing or whatever. It's just a great course. It teaches you the basic things that you didn't even know that you should have known from elementary school. So the value of this course, this course is excellent. I would recommend it to anybody.

\section{Conclusion: The Value of Mainstreaming}

We end with this student's comment because she entered her composition course with a passing score on the CUNY WAT and, according to her teacher, strong skills that she then developed over two semesters. Yet, as she remarks to the peer interviewer, the course is "not only good for people who have problems with English or writing," but for "anybody." We agree with this student's assessment: while mainstreaming is a viable alternative for our remedial program at CCNY, it was more urgent to create a pilot project responsive to all students on our urban campus.

The array of positions that scholars have expressed on the subject of mainstreaming remedial students into freshman writing courses (Elbow, "Response"; Grego and Thompson; Hull et al; "Rethinking Basic Writing"; JBW Special Issue; White; Rodby) does not settle the issue of whether we ought to abolish remedial courses. Instead, this debate highlights the fact that basic writing courses play distinct historical, curricular, and political roles within their institutions. Rather than continuing to debate whether mainstreaming is effective generally, we need to analyze the roles that these courses play within their institutional contexts and follow that analysis with a careful consideration of alternatives.

What should guide our revision of particular programs is, first, an assessment of remediation's purpose within an institution and its impact upon students and teachers. Such an assessment could include the history of specific writing courses/a writing program and its symbolic role within an institution; forms and uses of institutional testing; 
teachers' practices and their authority within the writing courses; existing resources; funding; course size; tutorial services; relationships among remedial writing courses, college writing courses, general education/core curriculum requirements, and the courses in departments that students major in; other remedial programs on campus; and the population of students that the course serves. Second, any alternative should have a programmatic emphasis: it should include a coherent approach to curriculum and support for tutoring and faculty development. And third, a thorough documentation of the alternative program's success has to be incorporated into any plan from its inception. Perhaps our greatest insight from this project has been a heightened awareness of our need to document and evaluate our writing courses. Such evaluations are valuable resources for program development, they enhance our ability to be accountable, and they enable us to more effectively represent the interests of our programs.

Though several forms of evaluation suggest that remedial-placed students performed well in our pilot course, we do not recommend that CCNY (or any other college) simply abandon remedial writing courses. In our final report on the project, we recommend that CCNY provide students the option of a two-semester college writing course that bears full college credit and that is supported by faculty development, tutoring, and formative evaluation. We argue that the college should provide the same support for students who placed into college-level writing, a course in which remedial students will eventually enroll. In other words, we should re-imagine courses for basic writing students within the context of a coherent curriculum and a responsible writing program. As Mike Rose pointed out years ago, the language of exclusion encompasses most writing instruction within colleges and universities, not just basic writing programs. Enrichment, then, ultimately means incorporating remedial courses into mainstream, professional ways of thinking about writing instruction, supporting teachers and students, and evaluating writing programs.

\section{Notes}

1. The final report for The City College Writing Program: An Enrichment Approach to Language and Literacy (1993-1996) can be obtained from the authors (English Department, City College of New York, NYC, NY 10031).

2. See Ricardo Otheguy, The Condition of Latinos in the City University of New York; Judith Fishman, "Do You Agree or Disagree: The Epistemology of the CUNY Writing Assessment Test"; and Barbara Gleason, "When the Writing Test Fails: Assessing Assessment at an Urban College." 
3. See Mary Soliday, "Shifting Roles in Classroom Tutoring: Cultivating the Art of Boundary Crossing."

4. Three consultants submitted project reports: Suzy Groden (first year report); Keith Gilyard (final report); Matthew Janger (statistical analysis of student progress and achievement). Richard Larson advised us on program evaluation.

5. Lee Carroll designed the Pepperdine questionnaires.

6. We would like to thank Kim Jackson, Soultana Nolan, Chant Andrea Funchess, and Mary Fiero for conducting these interviews.

\section{Works Cited}

Anaya, G. Cognitive Development Among College Undergraduates. Unpublished doctoral dissertation, Department of Education, University of California, Los Angeles, 1992.

Astin, Alexander W. What Matters in College? Four Critical Years Revisited. San Francisco: Jossey-Bass, 1993.

Carroll, Lee Ann. "Fifty Students Writing: A Faculty Perspective of Cross-Disciplinary Portfolio Assessment." Conference on College Composition and Communication, Milwaukee, WI, March 1996.

Daiker, Donald. "Discrepancies in Evaluating Anchor Portfolios.: College Composition and Communication Conference, Phoenix, AZ, March 1997.

Despain, LaRene and Thomas Hilgers. "Readers' Responses to the Rating of Non-Uniform Portfolios: Are There Limits on Portfolios' Utility?" WPA: Writing Program Administration 16.1-2 (1992): 24-37.

Elbow, Peter. "Response to Glynda Hull, Mike Rose, Kay Losey Fraser, and Marisa Castellano." CCC 44 (1993): 587-88.

--. "Writing Assessment: Do It Better, Do It Less." In Assessment of Writing: Politics, Policies, Practices. Eds. Edward White, William D. Lutz, and Sandra Kamusikiri. NY: MLA, 1996. 120-134.

Elbow, Peter and Pat Belanoff. "State University of New York at Stony Brook: Portfolio-based Evaluation Program." In Portfolios: Process and Product. Eds. Pat Belanoff and Marcia Dickson. Boynton/Cook: 1991. 3-16.

Fishman, Judith. "Do You Agree or Disagree: The Epistemology of the CUNY Writing Assessment Test." WPA 8.1-2 (1984): 17-25.

Gleason, Barbara. "When the Writing Test Fails: Assessing Assessment at an Urban College." In Writing in Multicultural Settings. Eds. Carol Severino, Juan C. Guerra, and Johnella E. Butler. New 
York: MLA, 1997. 307-324.

Grego, Rhonda and Nancy Thompson. "Repositioning Remediation." CCC 47 (1996): 62-84.

Hamp-Lyons, Liz and William Condon. "Questioning Assumptions about Portfolio-Based Assessment." CCC 44 (1993): 176-190.

Huot, Brian. "Toward a New Theory of Writing Assessment." _CCC 47 (1996): 549-566.

Hull, Glynda, Mike Rose, Kay Losey Fraser, and Marisa Castellano. "Reply to Peter Elbow." CCC 44 (1993): 588-89.

Journal of Basic Writing. Special Issue: Fourth National Basic Writing Conference Plenaries. 12.1 (Spring 1993): 1-89.

Novak, Cynthia Cornell. "Becoming Colleagues: Undergraduate Writing Center Tutors as Portfolio Research Fellows." Conference on College Composition and Communication, Milwaukee, WI, March 1996.

Otheguy, Ricardo. The Condition of Latinos in the City University of New York. A Report to the Vice Chancellor for Academic Affairs and to the Puerto Rican Council on Higher Education. June 1990.

"Rethinking Basic Writing." Interchanges CCC 47 (Feb. 1996): 101111.

Rose, Mike. "The Language of Exclusion: Writing Instruction at the University." CE (1985): 341-55.

Rodby, Judith. "Revising a First-Year Writing Program: Cultural Studies Workshops Replace Basic Writing." College Composition and Communication Conference, Washington D.C., March 1995.

Soliday, Mary. "Shifting Roles in Classroom Tutoring: Cultivating the Art of Boundary Crossing." The Writing Center Journal (Fall 1995): 59-73.

Sommers, Jeffrey, Laurel Block, Donald A. Daiker, and Gail Stygall. "The Challenges of Rating Portfolios: What WPA's Can Expect." WPA 17 (1993): 7-29.

White, Edward. "The Importance of Placement and Basic Studies: Helping Students Succeed Under the New Elitism." JBW14.2 (Fall 1995): $75-84$. 
Table One: Portfolio Evaluation by English Department Faculty

\begin{tabular}{|c|c|c|c|c|c|c|c|c|c|}
\hline $\begin{array}{l}\text { Portfolio } \\
\text { Number }\end{array}$ & $\mathbf{A}$ & A B & B & B C & C & C D & D & DF & $\mathbf{F}$ \\
\hline$\# 1^{\star \star \star}$ & & & 2 & & 1 & & 2 & & \\
\hline$\# 2^{\star}$ & 2 & & 3 & & & & & & \\
\hline$\# 3^{\star \star}$ & & & 1 & & 3 & & 1 & & \\
\hline$\# 4^{\star \star}$ & & & 1 & 1 & 3 & & & & \\
\hline$\# 5^{\star \star}$ & & & 2 & & 3 & & & & \\
\hline$\# 6^{\star}$ & & & 3 & & 2 & & & & \\
\hline$\# 7+$ & & & 1 & & 3 & & 1 & & \\
\hline$\# 8^{\star \star *}$ & & & 1 & 1 & 3 & & & & \\
\hline$\# 9^{\text {* }}$ & 1 & 1 & 1 & 1 & 1 & & & & \\
\hline$\# 10^{\star \star \star}$ & & & 1 & & 4 & & & & \\
\hline$\# 11^{\star \star *}$ & & & 3 & & 2 & & & & \\
\hline$\# 12^{\star}$ & 3 & 1 & & & 1 & & & & \\
\hline$\# 13^{*}$ & 5 & & & & & & & & \\
\hline$\# 14^{*}$ & & & 3 & & 2 & & & & \\
\hline$\# 15^{\star \star *}$ & & & 1 & & 4 & & & & \\
\hline$\# 16^{\star}$ & 1 & & 4 & & & & & & \\
\hline$\# 17^{\star}$ & & & 2 & & 2 & & 1 & & \\
\hline$\# 18^{\star}$ & & & & & 1 & 1 & 3 & & \\
\hline$\# 19^{\star}$ & & & & & & & 2 & 1 & 2 \\
\hline$\# 20+$ & 1 & & 3 & & 1 & & & & \\
\hline$\# 21^{\star}$ & & & 4 & & 1 & & & & \\
\hline$\# 22+$ & 3 & & 2 & & & & & & \\
\hline Total & 16 & 2 & 38 & 3 & 37 & 1 & 10 & 1 & 2 \\
\hline$\%$ & $14 \%$ & $3 \%$ & $34 \%$ & $3 \%$ & $33 \%$ & $0.9 \%$ & $9 \%$ & $0.9 \%$ & $0.9 \%$ \\
\hline
\end{tabular}

*Portfolios of students with freshman English (college level) placęment

\begin{tabular}{|c|c|c|c|c|c|c|c|c|c|}
\hline Subtotal & $12 \mathrm{~A}$ & $1 \mathrm{AB}$ & $20 \mathrm{~B}$ & $1 \mathrm{BC}$ & $10 \mathrm{C}$ & $1 \mathrm{CD}$ & $7 \mathrm{D}$ & $1 \mathrm{DF}$ & $2 \mathrm{~F}$ \\
\hline$\%$ & $21.8 \%$ & $1.8 \%$ & $36.36 \%$ & $1.8 \%$ & $18.1 \%$ & $1.8 \%$ & $12.7 \%$ & $1.8 \%$ & $3.6 \%$ \\
\hline
\end{tabular}

\begin{tabular}{|c|c|c|c|c|c|c|}
\hline ** Portfolios of students with basic writing (remedial) placement & & & \\
Subtotal & OA & $12 \mathrm{~B}$ & 2BC & $23 \mathrm{C}$ & $3 \mathrm{D}$ & $0 \mathrm{~F}$ \\
\hline$\%$ & $0 \%$ & $30 \%$ & $5 \%$ & $57.5 \%$ & $7.5 \%$ & $0 \%$ \\
\hline
\end{tabular}

† We were unable to determine placements (remedial versus college level) for three students.

Their portfolios were \# 7, \#20, and \#22. 
Table Two

21 Students' Self Reports on Learning in 17 Categories $\dagger$ 10 Teachers' Ratings of 22 Students in 17 Categories*

\begin{tabular}{|c|c|c|c|c|c|c|}
\hline Question Item & $\begin{array}{c}\text { Students } \\
\text { Reporting } \\
\text { Significant } \\
\text { Change } t\end{array}$ & $\begin{array}{c}\text { Students Seen } \\
\text { to Show } \\
\text { Significant } \\
\text { Change* }\end{array}$ & $\begin{array}{c}\text { Students } \\
\text { Reporting } \\
\text { Some } \\
\text { Change }{ }^{\dagger}\end{array}$ & $\begin{array}{c}\text { Students Seen } \\
\text { to Show Some } \\
\text { Change* }\end{array}$ & $\begin{array}{c}\text { Total } \\
\text { Students } \\
\text { Reporting }{ }^{\dagger}\end{array}$ & $\begin{array}{c}\text { Total } \\
\text { Teacher } \\
\text { Ratings* }\end{array}$ \\
\hline A. Finding ideas & 8 & 8 & 10 & 11 & 18 & 19 \\
\hline B. Writing long & 12 & 7 & 8 & 13 & 20 & 20 \\
\hline C. Revising & 12 & 11 & 5 & 9 & 17 & 20 \\
\hline D. Edit for Gram & 7 & 7 & 10 & 11 & 17 & 18 \\
\hline E. Edit for Style & 7 & 6 & 11 & 7 & 18 & 13 \\
\hline F. Organization & 10 & 8 & 9 & 12 & 19 & 20 \\
\hline G. Crit. thinking & 9 & 7 & 10 & 12 & 19 & 19 \\
\hline H. Prob. Solving & 7 & 4 & 9 & 12 & 16 & 16 \\
\hline I. Relationships & 12 & 7 & 6 & 9 & 18 & 16 \\
\hline J. Motiv. to write & 5 & 8 & 9 & 10 & 14 & 18 \\
\hline K. Perceived value & 9 & 8 & 7 & 8 & 16 & 16 \\
\hline L. Lib. Research & 8 & 8 & 8 & 10 & 16 & 18 \\
\hline M. Ways Learning & 9 & 6 & 7 & 7 & 16 & 13 \\
\hline N. Know Unknown & 6 & 6 & 10 & 9 & 16 & 15 \\
\hline O. Reading skills & 6 & 3 & 10 & 15 & 16 & 18 \\
\hline P. Speaking skills & 7 & 2 & 5 & 10 & 12 & 12 \\
\hline Q. Pres. portfolios & 9 & 3 & 7 & 10 & 16 & 13 \\
\hline
\end{tabular}

tStudents were randomly selected for this study. Of 22 students participating in this study, 21 completed questionnaires in which they report on their own learning; 18, 19, or 20 rated themselves as having achieved "significant change" or "some change" in six areas: 1. writing longer essays (20); 2. organizing ideas (19); 3. critical thinking/analysis (19); 4. finding ideas to write about (18); 5. relationships with teachers, tutors, peers (18); 6. editing for style (18).

*10 project teachers rated 22 students--two each from their own courses (one teacher taught two sections); 19 or 20 students were identified as having made "significant change" or "some change" in five areas: 1. writing longer essays (20); 2. revising (20); 3. organizing ideas in essays (20); 4. critical thinking/ analysis (19); 5. finding ideas to write about (19). 


\section{THEORY IN THE BASIC WRITING CLASSROOM? A PRACTICE}

Just when some of us were beginning to feel mentally exhausted from the stimulating workshop sessions, we were reinvigorated by Victor Villanueoa. With an infectious energy, he got eoeryone working, writing, sharing, and totally engaged in the process of making meaning with words. Victor Villanueva, Jr. is professor in the English Department at Washington State University at Pullman and author of the critically acclaimed Bootstraps: From An American Academic of Color. He is also Program Chair of the 1998 CCCC Convention and, despite being inundated with preparations for the most important conference in our field, he made time to write this paper detailing some of his techniques for enabling student success in his basic writing classroom.

\section{A Personal History of the Practice}

None of this started with me - these exercises and skits that I'm about to describe. They began with Ann Berthoff, in some sense, though mixed with Harvey Daniels and Susanne Langer, Kenneth Burke, ancient rhetoricians. And there was James Berlin, Henry Giroux, Paulo Freire, Antonio Gramsci, and my responses to a once popular line of research and theory. A complex web. And like a web, having purpose and design.

But let me unravel this a bit, explain some of the thinking that led to the practice that I'll demonstrate below. I came to Composition Studies during Composition's romance with cognitive psychology. Composition was trying to figure out what it is writers do when they write, what kinds of cognitive processes are at play during writing. The models created by folks like Linda Flower and John R. Hayes told us a great deal. But there were the Basic Writers, those who seemed unable to write with the same fluency as those described in the well-delineated writing models. Sondra Perl looked to those less proficient writers, those whose writing proficiency seemed rudimentary at best, basic. She demonstrated that the basic writers displayed all the complexities of writing behaviors found among the more traditional firstyear composition students. So saying, however, brought us no closer to understanding the disparity between basic writers and the first-year comp students we were more accustomed to seeing. One set of responses within a cognitive framework argued that the difference between the basic writer and the traditional was a matter of cognitive 
development. Basic writers hadn't yet reached a level of cognitive development which would allow for the abstract reasoning required of college literacy, they said.

The idea that basic writers - in some important ways people very much like me-were developmentally dysfunctional posed problems for me. Not only were issues of class and race or ethnicity being circumvented; there were seeming contradictions that weren't being accounted for: cognitively deficient, said one line of research; cognitively sophisticated said another. Mike Rose, a self-avowed cognitivist at the time, made it clear that developmental psychology was not sufficiently understood in the labeling of basic writers ("Rigid Rules"). That meant another explanation was necessary in explaining what made for the basic writer. My own take was to look at the social and the political (which would include the economic). Among other things, I found a variation of Basil Bernstein's studies on the ways different social class assumptions take shape in language. Although I oversimplify, Basil Bernstein found that students from working-class backgrounds spoke in what he termed a restricted code, in which discourse is fragmented because there is a sense of a communal understanding among speakers. Everything doesn't have to be spelled out when there is great commonality. The middle class, according to Bernstein, could not assume the same degree of shared knowledge as the working-class, so their discourse displayed an elaborated code. Everything is subject to negotiation and must thereby be fully articulated. That code, the elaborated code, is the code which is rewarded in academic settings. But Bernstein was not studying American college classrooms. In the composition classrooms I studied, I found almost the opposite took place. That is, the basic writing students, although having a restricted code when speaking among themselves, tried to write in an elaborated code to their instructor, believing themselves distanced from that instructor yet finding themselves unable to transact effectively in that code, not having been sufficiently exposed to it. In social-class terms, the working class didn't know how to write for what they perceived to be the middle class. The middle-class students, apparently feeling at ease in the discourse of the community, worried less about the academic discourse community than teacher expectations. Not feeling a distance from their teachers' range of experiences and ways with discourse, the traditional first-year comp students focused on matters of correctness and adherence to their perceptions of teachers' expectations. Maybe better put, the traditional first-year comp students placed more attention on teacher expectation in matters of form or correctness; whereas the basic writers focused almost exclusively on being heard, though not knowing how to manipulate text so as best to be heard. While they worried over how to elaborate their ways of seeing to what they perceived to be a foreign audience, they had an inadequate repertoire with 
which to be read by that audience. They could narrate as a rule but go no further in the ways of academic discourse.

The issue of basic writers and the ways of the academic discourse community was taken up by David Bartholomae. According to Bartholomae, although basic writing students have a wealth of experience, most often experiences of interest to those not of the same class or racial or ethnic background as the students, the students are compelled to frame those experiences and ways of seeing in a discourse they have little or no experience with. At the point in which first-person narrative is disallowed or discouraged (which should be quickly, as a matter of survival), basic writing students must pretend to be insiders within a foreign discourse community. Bartholomae doesn't say that basic writers need to learn basics, as in rules of grammar and the like (a cause of writer's block, according to Rose); he says, rather, that basic writers must learn the discourse conventions of academics (like all first-year writers, just more so). In a way, Lisa Delpit agreed, arguing that students of color, so often the students in basic-writing classrooms, do not believe they are being treated with respect when they are asked to engage in now-traditional writing-process pedagogy. Although the pedagogy arises from sophisticated theory and research, it is too often not perceived as such by too many of those we are seeking to reach.

How then to get basic-writing students to realize that, as Perl had shown, the processes they undergo are no different from others? How to have them realize that they possess innate abilities with language? How to demonstrate that their experiences have value? How to have students believe they will be treated with respect? One answer to all of these questions comes by way of an opening demonstration and lecture that I present to incoming students. This is almost a script that I present to experienced teachers, graduate students, and more typical first-year students in a predominately white institution. It was developed for basic writers, however, where it has proven its effectiveness, at least for me.

\section{The Script}

A basic-writing classroom. Not many before me, really, about twenty: a couple of students who have been through the series of ESL courses and still haven't placed in the regular 101 course, a couple of apparently (but not necessarily, I know) white male students, baseball caps on backwards, baggy T-shirts, slouched low in their seats, staring at the pen at the end of outstretched arms, doodling in the air an inch above the desk. A few apparently white women, the spectrum of hair colors with which women are too easily categorized: blonde-brunette- 
redhead, none dressed like the other, though all smartly dressed (The Cube, The Gap), all in their mid-twenties, maybe, poised, friendly faces somehow. The rest, a cross-section of America's people of color: African-American men and women, the men in caps that recall cab drivers of a generation and a half ago, brims to the back, baggy clothes, seemingly new athletic shoes (black swashes and maple leaf symbols prominently displayed on white); the women in tight-fitting blouses and bellbottomed pants and dress shoes, one African American woman sporting dark glasses and blonde hair. The latinos and latinas are shorthaired hatless men; women with hair teased high in the front, baggy pants; the women and the men in baggy plaid shirts over baggy white T-shirts. The American Indians are mainly men and women dressed much like the latinos and latinas, though some sport pointed high heeled cowboy boots and tight Wrangler jeans. Minor variations, often a mix of Asian Americans and Asian Internationals, a Malaysian, maybe, an Iranian or someone from the United Arab Emirates, but pretty much the same basic-writing classroom in the northwest, the southwest, the midwest.

A short, bearded man walks into the classroom, the air of familiarity with which he walks to the front desk marking his role. A mutual stare, the teacher and the students, expressionless.

"Take out a sheet of paper!"

Audible sighs, eyes suddenly shut and held shut softly for too long, or eyes rolled up to the ceiling for just an instant, postures changing to upright for most, the shuffling that comes at this command, even when notebooks are opened on the desk and pens are in hand.

"Here's what I want you to do. On the upper left hand corner of the paper, write a word, any word. On the right, its opposite. Hot [gesture with the left hand]. Cold [gesture with the right]. Up. Down. tone]."

"Don't hesitate [staring at those staring back]! Just do it [softer

Pens scratch on paper. Almost all resistance fades. Curiosity has the upper hand.

"Now, go to that word on the left and generate a list of 15 words. Just write what comes to mind. Don't worry about logical connections. If hot makes you think of weather, write down weather. If weather makes you think of sweat, write that down [some smiles]. Sweat to running or to deodorant; whatever. Write it down without stopping to think. Go!"

And they write. And the Authority points to those who stop and look up or look to the side in that look of a writer thinking of what to write, the stares one sees so often in college coffee hangouts and student union buildings: "Write. Don't hesitate." Very soon the pens stop and the Authority sees faces rather than the tops of heads, the eyes more engaged than a few minutes ago. 
"Now do the same with the word on the right; this time, generat-
ing 10 words."

And they do.

"You now have 27 words in front of you. Using 25 of those 27 words - and only those 25 words - compose a poem."

"You mean we can't add any helping words?"

"Using 25 of those 27 words, compose a poem."

Heads bend forward. A major undertaking, embarrassed smiles, some head-shaking sneers, some wrinkled brows, and always a couple (almost always literally two) who either stare at the page with pen poised but never touching paper or staring straight ahead or staring defiantly at the teacher. And he stares back with no sign of displeasure or discomfort. They fit his plan. They just don't know it.

Maybe ten minutes pass. A few are done, smiles of pride or embarrassment.

"Give it one or two more minutes."

Scurry.

Five minutes pass.

"Okay. Read over your poem and drop five words, making whatever changes you think become necessary in dropping those words."

A different kind of sigh. This time, relief. Three minutes, maybe.

"Drop three more words."

Some grumbles. Some glares. Another minute.

Students are asked to read the poems. Discussion-not about quality - but about what they hear in the poems. One poem from the blonde-haired, blue eyed, younger woman in khaki shorts, and sleeveless light blue cotton blouse.

Warm, soft smell

Tail, freckles

Sleeping poppy blue roads

Barking meadows, hot mountains

paws walk, castles,

Denmark

She reads softly, an English that speaks of California. Students say there's something there about her pet.

"Yeah, like she thinkin about her pet. She thinkin about her pet when she went on vacation to Europe."

"Yeah, but her pet's there with her, so maybe she lived there for a while." I mean?"

"Yeah, right. More like a trip instead of a vacation. Know what

This goes on in different ways for about two minutes. mind?"

[To the writer]: "So what do you figure might have been on your 
And we learn that the California white woman among us is really an immigrant from Denmark feeling decidedly foreign within this crowd, missing the dog she had as a child, taking a momentary journey home.

We do this over and again, hearing from five or six and discussing what we have heard. There are plenty of volunteers.

"So what's the point? The point is that when you say you have nothing to write, you mean that you don't know what the teacher wants you to write. And if you found you couldn't generate a list or compose a poem, it was either because you needed to know more about what I was up to or you worried that you wouldn't produce what I was after. You've been convinced that writing is a set of 'rigid rules and inflexible plans' [Rose's words]. But those rules and plans are later matters, what's written, not writING. What we have just done is gone through a writing process: a free generation of ideas, a composing of those ideas (since composing means putting this with that to come up with something different, like a musician composing, like saving food leftovers for a compost which will make new foods possible in some sense). Then I asked you to revise. This is kind of artificial, of course, since all I allowed was deletion. But y'all grumbled and groused when I told you to delete a second time. And the reasons for that was first, that you knew you were being messed with [smiles and nods, but no laughter; being messed with is not a funny matter; but having it acknowledged is different]; and second, you had come to like what you had done. What you wrote came from within and thereby had meaning for you, was like that ashtray at woodshop, nothing to put in a museum but something crafted by you. That's what writing can be: something from you, crafted by you. And finally, you published. You went public. And in going public, you found out how others interpret what you have written and how sometimes you yourself have to step back to interpret. Writing, all communication, is a matter of someone saying something to someone, even if that someone is the I speaking to its me.

"You see, writing is not a matter of inspiration, nor is it necessarily the special province of the gifted [using this very vocabulary as a matter of respect, a matter of introduction to the discourse of the academy]. Writing is a craft, a craft that can aspire to art-that cabinet that was first crafted by a cabinetmaker and was used, that then became an antique because it stood the test of time, that then became considered art, a Chippendale, say [a glint from a woman or two and one of the guys]. I'm talking about furniture, and you think of the topless dancing men. But that's how they get the name: they're men who crafted 
their bodies to become what some of y'all think of as art, maybe. The Chippendale furniture uses wood as its raw material. The Chippendale men use their bodies. Writers use their experiences, sometimes only their experiences with others' writing, but their experiences nevertheless, to express something to someone else. This is basic humanness.

"Let me do it this way. No experience is ever repeated. [Pause] No experience is ever repeated [said each time in a monotone]. No experience is ever repeated. Hear me out. There really isn't a contradiction in what I just did. The first time I said that, you looked at me seriously. It was a new idea for most of you. I got it from Plato who wrote that Socrates had said that. The second time, $y^{\prime}$ all looked at me a little funny, still thinking seriously and wondering about the apparent contradiction. The third time you started thinking I was downright silly. You did not experience those words the same way each time. The experience was not repeated. And time had passed. And even though I tried to keep my inflection the same, it couldn't have possibly been identical each time. The experience hadn't been repeated by me or by you. It only appeared to be repeated because of the words.

"Hold that in memory for a minute while I explore a related idea. We can sense more than we think we can sense. The five senses are only a scientific convenience. Our senses fall into one another. You can hear a blaring sound and think of a color. Some colors are loud, we say. Or you would say 'That tastes like crap.' How do you know? If you know empirically, by having actually eaten crap, I don't want to know [great laughter, but also that glimmer in eyes that all teachers know and try to recapture with every moment in every classroom]. We can say that because a taste and a smell and texture all suggest one another. That's why little children will not eat ugly food. We learn to taste despite looks (at least some of the time). Or think of the Eskimo. The anthropologist tells us that Eskimos have several words for snow. We don't in English. All we have are adjectives - powder, wet, dry, thick, et cetera. Even when we use the words as nouns -'A fine powder' - we don't think of powder; we think of snow, the word snow. How are we different from the Eskimos when it comes to snow? [The answer always comes]. That's right, snow is an integral part of the Eskimo's environment, a part of their context, in a way that it isn't for us, as a rule (and when it is, it's no longer snow; it's a storm or a blizzard-words which don't mean the same as snow; they're different things).

"Hold that for a minute too. I'll tie things together in a bit." [Now placing a drawing on the board: 


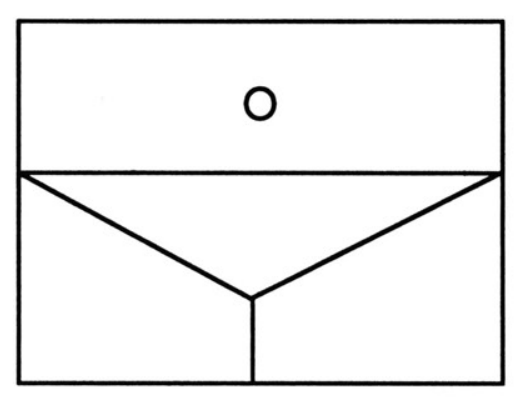

"What do you see?"

Responses come, hesitantly at first - a martini glass with an olive descending, an abstract Christ figure, a close-up of a woman in a bikini [for which one student once complained that I had drawn a dirty picture on the board - not all understand]. Soldiers fresh from Korea saw a cabinet with a knob for a drawer and two cabinet doors, as well as the bikini and the martini. An American Indian student in the southwest saw a sunrise over a mesa. Returning students after long hours working in offices saw a message envelope. Young men in the midwest and the southwest (but not in the northwest) saw the pocket to a cowboy shirt. What the students come up with is discussed, as well as what students-past have come up with.

"We perceive meaningless lines and our imaginations strive to give them meaning, but in order to make its meaning complete, it must be named. And the meaning and naming come from experience. Eskimos experience snow differently from Americans living south of Canada; the snow carries several meanings, so it acquires different names. All of you know words that don't translate well - the meanings of dude [mimicking the word with different inflections] or get outa here [mimicking] or words from another language that have no equivalents in English. Those phrases, or idioms, and those words carry cultural meaning that because they grow from within one culture's experiences don't always transport to another culture with different physical environments, and different values and concerns, with different ideologies or ways of seeing the world.

We can know more through our senses than we realize. And no experience is ever repeated. So how can we make sense of our world? Through language. We name the things that matter to us, to our cultures. Language is our sorting mechanism. To make sense, we name the things and the events that matter to us. Or we say one experience is very much like another-simile, remember from high school? analogy [writing the word on the board] - and we give it a word. No two home runs are the same, for instance, but hitting a ball a certain dis- 
tance and within a certain set of lines which gives enough time for a person or more to go to a certain spot becomes similar enough that, even though never identical to previous events of the sort, are similar enough to warrant a name-homerun, which lots of folks spell as one word, like a thing that needs a name.

"We use language to make sense of our world. It is the thing that makes us unique among beings on the planet. I' $m$ not saying language makes us different. We know that other creatures have language. But no other creature that we know of uses language the way we do. The wonders of science, the wonders of technology, none of it could have taken place without language, without the means by which we make sense of the world and communicate with one another. A rhetorician named Kenneth Burke [more about what that word rhetoric means will come up on other days] wrote that we are beings who are given to symbols. Now I'm not talking about symbols like you might have heard someone say was going on in a novel; I mean something that stands for something else. We are given to symbols - houses to represent whatever shelter we might have once known before we constructed houses (caves, say). Cars to replace our legs, symbols of an earlier form of transportation - car as short for carriage as short for horseless carriage that still has horsepower. Clothes to replace fat and hair and animal skins. Glasses for eyes. We love symbols. Math is a set of symbols that represent numbers of things. Algebra is a symbol of the symbol. But our basic symbols are language-sounds that represent things and ideas. And writing is the symbol that represents the sound that represents the thing or idea. That's how we know anythingthrough symbols. Language is [to the board]

E - P - I - S - T - E - M - O - L - O - G - I - C - A - L Epistemological - a word used by philosophers to mean how we come to know. Philosophers-a lot of them-are convinced that how we come to know is through experience and the experience is defined in language that we are exposed to from the moment we' re born (if not before).

"In other words, you are all already language users. In a sense, you are experts, since you've been using this thing - language-for so long. And you already know the symbols that represent the sounds (though I know it isn't always one-to-one, but that's historical; through was once pronounced with a guttural end that the $g h$ represented). But the point remains-you are all language users. You are all writers who can compose if you don't get hung up with rules. What you are at this point are simply folks who don't yet know how to translate what you know into a way that is used in this culture-the university. And of course, you still have more experiences tr gain, including the experiences that the books you will read throughout the years will provide.

"What we're talking about here is how to use a knife and fork- 
the conventions of a culture - the academic culture and later the culture of whatever your major will be. Go across the border to Canada. You'll see that proper manners with a knife and fork is to hold the fork tines down with the left hand, cut your food with the right, and bring the food to your mouth with the left hand, the tines still down [replete with gestures]. Proper U.S. etiquette is to put the knife down, move the fork to the right hand, and bring the food to your mouth with the tines up on the fork. Both ways make sense or are just as senseless. They're just matters of convention within particular environments. There are conventions of language use and conventions of evidence for arguments - "cause I said' never works here. That's what you've got to learn. Not how to write. But how to write within the conventions of the university."

We end the hour by returning to one of the poems the students constructed. On the board we work at translating it to prose. Then we fool with turning it to jargon. I make the final revision:

There is a recollection of the possession of a domestic canine companion. It contains small cancerous epidermal tissue and emits a scent that is pleasant to olfactory senses. It accompanies among flower-strewn byways, the while making sounds of possible contentment as we stroll the meadows overshadowed by apparently torrid mountainous regions, toward the ancient grand edifices of the land of the Danes.

I tell them that this if more baroque and fatuous than academic, really, and that we will speak of using jargon later [don't-until it's simply a part of the writer]. And we're done for the day.

\section{A Beginning}

There is no conclusion, only the beginning. A complex set of ideas that range from the Sophists, Plato, Aristotle to Kenneth Burke and Bakhtin has been presented to students with the assumption that they are worthy of an explanation of the pedagogy which they will take part in. An idea of worth is transmitted. Writing opens and closes the discussion-students' writing. The success that will come of this opening session is never complete: a couple of students will drop the course, one or two will stop working, most will not be converted into A writers. But most will believe themselves to be college students with conventions to learn. In the end, I will give them grades for their work as students, and I will tell each honestly what they would have likely gotten if the grade depended solely on their written products. We will talk of what they know of their writing processes, support mechanisms 
like writing centers where more work can take place in refining those processes. We will have done what can be done in the less than 40 contact hours we're afforded in classrooms over a semester or quarter.

\section{Works Cited}

Bakhtin, Mikhail. The Dialogic Imagination. Trans. Caryl Emerson and Michael Holquist. Austin: U of Texas P, 1981.

Bartholomae, David. "Inventing the University." When a Writer Can't Write: Studies in Writer's Block and Other Composing Process Problems. Ed. Mike Rose. New York: Guilford, 1985. 134-165.

Berlin, James A. Writing Instruction in Nineteenth-Century American Colleges. Carbondale: Southern Illinois UP, 1984.

Bernstein, Basil. Class, Codes and Control: Towards a Theory of Educational Transmissions. 3 vols. 2nd ed. Boston: Routledge \& K. Paul, 1977.

Berthoff, Ann E. Forming/Thinking/Writing: The Composing Imagination. Upper Montclair, NJ: Boynton/Cook, 1982.

Burke, Kenneth. A Rhetoric of Motives. Berkeley: U of California P, 1969.

Daniels, Harvey and Steven Zemelman. A Writing Project : Training Teachers of Composition from Kindergarten to College. Portsmouth, NH: Heinemann Educational, 1985.

Delpit, Lisa D. "The Silenced Dialogue: Power and Pedagogy in Educating Other People's Children. Harvard Education Review 58 (1988): 280-98.

Flower, Linda and John R. Hayes. "A Cognitive Process Theory of Writing." CCC 32 (1981): 365-87.

Freire, Paulo. Pedagogy of the Oppressed. Trans. Myra Bergman Ramos. New York: Herder and Herder, 1970.

Giroux, Henry. Theory and Resistance in Education: A Pedagogy for the Opposition. London: Heinemann, 1983.

Gramsci, Antonio. Selections from the Prison Notebooks. Ed. and Trans. Quintin Hoare and Geoffrey Nowell Smith. New York: International, 1971.

Perl, Sondra. "The Composing Processes of Unskilled College Writers." Research in the Teaching of English 13 (1979): 317-36.

Rose, Mike. "Rigid Rules, Inflexible Plans, and the Stifling of Language: A Cognitivist Analysis of Writer's Block." CCC 31 (1980): 389-400.

Rose, Mike. "Narrowing the Mind and Page: Remedial Writers and Cognitive Reductionism." CCC 39 (198 ) : 267-302. 
Villanueva, Victor. “On Writing Groups, Class, and Culture: Studying Oral and Literate Language Features in Writing." Writing With: New Directions in Collaborative Teaching, Learning, and Research. Eds. Sally Barr Reagan, Thomas Fox, and David Bleich. Albany: SUNY UP, 1994, 123-39. 


\section{OUR APARTHEID: WRITING INSTRUCTION \& INEQUALITY}

The first appointment in rhetoric and composition to the Graduate School and University Center of the City University of New York, Ira Shor is the teacher-scholar chiefly responsible for giving currency and meaning to the term "critical teaching" in such works as Critical Teaching and Everyday Life (1980), Empowering Education (1992), and When Students Have Power (1996). Also author of critiques of educational policy and social conditions affecting education, notably the book Culture Wars (1986), he brings the two strands of his work together in this discussion of the social contexts of basic writing and freshman composition. His call for an end to remedial placement, first made at the CBW workshop, elaborated on the discussion list $C B W-L$, led the editors to send him some questions to address, if he chose. Developing from that e-mail exchange, his response eventually became this carefully argued and researched essay.

Basic writing as a field was born in crisis nearly thirty years ago. It has grown in crisis amid declining conditions for mass education (Berliner and Biddle, 1995). This state of permanent crisis unfortunately shows no sign of letting-up: Conservative lawmakers hungry to lower taxes for the wealthy and for corporations appear eager to cut BW and public college budgets. Perhaps many in authority believe that allegedly illiterate BW students don't belong in college in the first place. The corporate New World Order is generating lots of burger-flipping jobs for $\$ 5.50$ an hour (a new McDonald's breaks ground every four hours somewhere in the world) so why spend for mass higher education? Oppressed by dollar-politics, BW teachers and students are in a hole discussed by John Kenneth Galbraith in The New Industrial State (1967): "It is the vanity of educators that they shape the education system to their preferred image. They may not be without influence but the decisive force is the economic system" (238). Galbraith wrote that statement on the eve of BW's explosion. A brief look backward may help us figure out where we are and where we might go from here.

The collegiate language enterprise of which BW is the junior partner began over a century ago when Harvard instituted freshman composition. As the best historians in our field tell us, Harvard invented comp in the last decades of the 19th century when the American university system was expanding and changing to meet the needs of the new industrial capitalism. Accumulated knowledge and research were fast becoming essential to production and profit-making. New machines and processes were needed as well as new forms of management, accounting, and marketing. Such periods of wild economic ex- 
pansion place great stress on the status quo, threatening the elite which had benefited from the old order. What new arrangements could industrialize society without changing power relations? Sudden demands for labor and knowledge unsettle the status quo. As the Italian philosopher Antonio Gramsci argued, when power relations become insecure, questions of language often come to the fore. In colleges a century ago, curriculum for the new insecure order included required writing courses called "composition." As Richard Ohmann wrote in English in America, Harvard's restrictive model of freshman comp spread like "kudzu" from coast to coast, becoming a linguistic gatekeeper to upward mobility in the new system being secured then by captains of industry and education. Sharon Crowley has identified the upper-class bias of the new universal comp requirement which began "as an attempt to certify that students who enrolled under the new elective system were suitable 'Harvard men.' In other words, the universal requirement began life as an instrument of exclusion" ("Response" 89). This use of elite language instruction to exclude some and to socialize others, studied by the late Jim Berlin, the late Donald Stewart, Bob Connors, and Susan Miller most notably, helped protect unequal power relations in a time of great change, through subordinating writing to reading, by demoting teaching and composing below research and literature. "English" as a field took literature and literary scholarship as its professional body-of-knowledge, relegating comp to the menial status of curricular cop and sorting machine. For students, performing well in disembodied language classes became the correct usage gate to certification for upper-level courses leading to upper-level jobs. I call this language policy "comp for containment, control, and capital growth," a tool that ironically produced the nation's first literacy crisis, at Harvard in 1894, after a board of overseers had examined the writings of the nation's most privileged collegians. Looking back on 120 years of the lit/comp culture war in language arts, we could say that comp has been the cranky subject of constant reform efforts by dedicated and ingenious teachers, the repository of what Leonard Greenbaum thirty years ago called "the tradition of complaint."

BW is a younger sibling in the comp story. BW has added an extra sorting-out gate in front of the comp gate, a curricula mechanism to secure unequal power relations in yet another age of instability, the protest years of the 1960s and after. To help secure the status quo against democratic change in school and society, a BW language policy producing an extra layer of control was apparently needed to discipline students in an undisciplined age. At the time of BW's explosive birth, the system was under siege by mass demands for equality, access, and cultural democracy. Since then, the economy, short in graduate labor until about 1970, has been unable to absorb the educated workers pro- 
duced by higher education in the past 25 years. In this scenario, BW has helped to slow the output of college graduates. BW, in sum, has functioned inside the larger saga of American society; it has been part of the undemocratic tracking system pervading American mass education, an added layer of linguistic control to help manage some disturbing economic and political conditions on campus and off.

In terms of undemocratic tracking, mass schooling sorts each student cohort by race, class, and gender, so that each new generation of eager schoolkids becomes shaped into the existing inequities of our society. America has never invested equally in all its children, not from the moment Horace Mann in Massachusetts in the 1840s boldly declared schooling as "the great equalizer." The open secret of undemocratic life in America is that children of poor and working families get far fewer resources at school and at home than do rich kids (something criticized 80 years ago by John Dewey in Democracy and Education and more recently by Jonathan Kozol in Savage Inequalities). Just compare community colleges to the top 100 selective campuses. Economically, if schools and colleges were in fact great equalizers, what might we expect by now? More equality? Well, despite the immense expansion of education credentials in the general population since 1970, the wealth and income gap between rich and working families is actually increasing (see Mantsios; Henwood; Holmes). People of color still have twice the unemployment rate of whites (Bureau of Labor Statistics, 160-163). White kids are twice as likely as black kids to graduate college (Postsecondary Education Opportunity, 3). Women are still over-represented in college majors and doctoral fields that pay the least; only $25 \%$ of tenured faculties are female (Digest of Education Statistics, Tables 221, 235).

Mass education and its language policies have not equalized the genders, the races, or the classes. Instead, formal education offers a top-down, business-oriented agenda: basic skills, vocationalism, work discipline, and citizenship. These objectives aim to fit students into the unequal way things are, to ease them into a hostile job market and unequal power relations organized by and for the few. But all has not gone smoothly. A crisis in this story of language for containment emerged when mass higher education became a near-entitlement in the egalitarian 1960s, when social movements disturbed the smug postWar status quo; BW emerged soon after as a new "identity," a new field of control to manage the time, thought, aspirations, composing, and credentials of the millions of non-elite students marching through the gates of academe.

About maintaining inequality in a time of disruption, I'm reminded of an incident recorded by historian David Tyack in Turning Points in American Educational History (1967). Tyack tells the story of an idealistic Northern schoolmarm who went South after the Civil 
War to teach freed slaves. She is scorned by local respectables for teaching "social equality" instead of sticking to the ABC's. Before the War, it was a crime to teach slaves to read and write; white teachers were fined and literate slaves beaten or worse (for some dramatization of this, see the recent film Nightjohn). Then, after the War, the defeat of the slavocracy created a democratic opening. History moved forward to new possibilities that could disturb white supremacy. To contain the threat to white domination, the old elite favored a language policy of basic skills, that is, the ABC's are as far as instruction should go for former slaves. It seems that basic skills approaches (which dominate BW according to a number of reports) have a friendly fit with an unequal status quo.

Another example that comes to mind is Gunnar Myrdal's 1944 classic An American Dilemma: The Negro Problem, published after some delay because its anti-racist content might cause problems for a racist nation at war, especially when white and black American soldiers were in segregated units in Europe and the Pacific. Myrdal, examining Southern schools, noticed that black students were being tracked into agricultural jobs (boys) and domestic service (girls) even though these labor markets were declining. Myrdal noted that the curriculum for black students was very basic in their segregated schools. Some forty years later, John Goodlad's 8-year study A Place Called School reported a similar racial division. Black and Latino students were over-represented in the lowest-paying vocational programs. One of Goodlad's brilliant coresearchers, Jeannie Oakes, focused specifically on tracking. Her book Keeping Track described in some detail the basic skills/vocational sorting out of students; she noted the absence of research data showing that tracking/ability grouping improves the learning of students. Research on ability grouping may not support tracking (see Welner and Oakes, 1996), but tracking remains a pervasive practice in education for political reasons to help maintain inequality in society, I am arguing.

Politically, then, BW is a containment track below freshman comp, a gate below the gate. Sociologist Burton Clark described this sorting mechanism as a remedial "subcollege" in his famous 1960 essay "The Cooling-Out Function in Higher Education." Clark examined how entry-testing, assessment practices, counseling, and remedial writing courses help the institution (in this case, the community college) lower the aspirations of students defined as "latent terminals." This coolingout function through testing and remediation has continued in the decades since Clark first identified it in mass higher education. I examined "cooling-out" in terms of three major conservative campaigns in the 1970s and 1980s: career education, the (fake) literacy crisis/backto-basics movement, and education-for-excellence (see my Culture Wars). I saw these three nominally educational programs as actually 
political campaigns against the egalitarian opening of the 1960s, reiterating how the Southern plantocracy tried to close the opening represented by the Civil War. In what I've called "the conservative restoration" that followed the activist 1960s, these regressive campaigns reflected a theme in school and society of "settling for less." Part-time job:s are less than full-time jobs; non-union labor is paid less than union work. In education, BW is less than freshman comp, below comp, often non-credit bearing, so its rise since the 1960 s into an empire of segregated remediation fits an age when the status quo urgently needed to divide and conquer and depress young people aroused for social change and for economic success.

While BW enables colleges to divide incoming students into regular and remedial groups, economically speaking, BW helps slow down the students' progress towards the college degree which could enable them to expect higher wages in the job market. The BW empire also depresses the wage package for teachers because so many remedial courses are taught by underpaid, overworked (female) adjuncts. Students pay rising tuition for courses lowered in stature and credit, taught by unprotected, unorganized teachers getting depressed wages and few benefits. This arrangement lowers the output of college grads and of $\mathrm{PhDs}$ (because overworked, underpaid $\mathrm{BW} /$ comp teachers have too little time and money to work steadily on their dissertations). These two outcomes of BW help ease the shortage of good jobs, especially now that several hundred thousand jobs have been lost to cheap-labor Mexico since NAFTA, according to the Economic Policy Institute in Washington. Remember that teenage girls in Mexico work for a dollar or tivo an hour, doing jobs for which North Americans were paid \$8$12 /$ hour. Workers in Haiti make about $\$ 2.40 /$ day, in China $\$ 2 /$ day, in Vietnam less. Well-educated, male, English-speaking, universitytrained, computer scientists in India get $\$ 10,000$ /year, a quarter the salary paid here for similar graduates. With corporate America downsizing and globalizing, with CEOs now earning about 145 times the average pay of their employees, with the top $1 \%$ now controlling $42 \%$ of the nation's wealth, mass higher education can threaten the stability or legitimacy of the status quo if it graduates too many deserving students into an American economy unwilling to pay them what they are worth as it sends jobs abroad. As I see it, these immoral conclitions cry out for critical teaching in our writing courses. Critical classirooms would invite students to focus on their everyday life in the system causing our problems (see my Empowering Education and When Students Have Power). Overall, then, I view BW as one mechanism that functions to ease the growing conflict between corporate economic policy and a mass of aspiring students who are being deterred from 
democracy and from the American Dream. That Dream is being denied to us and our students. The consequences of denying the American Dream were urgently on the mind of some top policy planners 25 years ago, as recorded in Career Education (1974) by Nixon's Commissioner of Education Sidney Marland (known as "the father of career education"), especially Marland's conversations with HEW boss Elliot Richardson, where they discussed their fears that underemployed college grads would cause political unrest, a worry also expressed at that time by economist Richard Freeman in The Overeducated American (1976).

I expect that some in our field are uncomfortable with these economic and political implications of our profession. When it comes to writing instruction, few of us are likely to claim that it's easy or transparent work, but many probably find it safer to stick to technical issues. Some colleagues defend BW by arguing that it provides a sanctuary to protect students who would be thrown out of college even sooner if not for a sheltered program. Is this true? So many gifted and dedicated writing teachers devote themselves to their students' success. Is their devotion being mistaken for BW itself saving students? I think here of Mike Rose's brilliant and patient tutoring of his students at UCLA (Lives on the Boundary). Mike's tutorial labors meant a lot for those students' development, but Mike is not a special advocate for BW, being rather critical of "remediation." Yet others in the field, like Karen Greenberg have advocated the benefits of BW for students. I want to see hard evidence that BW courses shelter more than they shunt. It's not helpful for BW advocates like Greenberg to argue that " $36 \%$ of the students who graduated from Hunter within the last five years were students who completed basic writing courses. Moreover, approximately $55 \%$ of the students who graduated from Hunter within eight years are basic writing 'graduates'" (69). These figures mean very little. What must be proved is that these students could not have graduated without BW. Was BW a shelter essential to their progress or was BW a delay in their progress towards a degree they could have gained sooner without BW? And how many students were discouraged from going on because of the tuition-charging non-credit remedial courses taught by underpaid adjuncts? How many were discouraged by bogus entry and exit exams like the infamous Writing Assessment Test (WAT) at Hunter and other campuses of the City University of New York? These, it seems to me, are the hard questions BW advocates must answer to justify the maintenance of BW beneath freshman comp, along with the maintenance of expensive testing/placement bureaucracies that centralize administrative control. Testing regimes transfer power from classrooms, teachers, and students at the bottom to administrators at the top, not a healthy outcome if we want education for democracy. 
My questions here also connect to Peter Dow Adams's suggestive local research at his community college about students who evaded BW' and succeeded in freshman comp at a higher rate than those who took the remedial course. On the other hand, we have Joe Trimmer ancl even BW-advocate Greenberg telling us that BW is still mired in skill-and-drill methods and workbooks, a point made also by Sharon Crowley vis-a-vis the "repressive formalism" and traditional grammar: instruction still dominating half the comp enterprise ("A Personal Essay"). Further, we have to wonder about BW/comp when testing advocate Ed White ("An Apologia") joined Brian Huot to tell us that a shocking $49 \%$ of colleges apparently use SAT, ACT, or some other NON-WRITING short-answer test to place students in WRITING classes (see also Glau, 82, for another case of ACT/SAT used for placement). Another $48 \%$ use the notorious timed, impromptu essay famously graded on the 1-6 scale (like the CUNY WAT), which Peter Elbow and the late Alan Purves described as an invalid test of writing ability.

I'm reminded of what Mina Shaughnessy wrote about the kind of anti-writing context offered in the timed impromptu: "Without strategies for generating real thought, without an audience he cares to write for, the writer must eke out his first sentence by means of redundancy and digression, strategies that inevitably disengage him from his grammatical intuition as well as his thought" (82). Lastly, I also think about the 1994 CCCC "Writing Assessment: A Position Statement" which opposed the isolated conditions of impromptu exams and which poirted to the racial implications of short-answer instruments: "...standarclized tests, usually designed by large testing organizations, tend to be for accountability purposes, and when used to make statements about student learning, misrepresent disproportionately the skills and abilities of students of color" (433).

Given this disturbing picture of placement testing in BW's operation, how can we continue to support it? In my imagination, I see a vast burial ground called "Field of BW/Comp" where love of knowledge and critical writing too often go to die. I was on the run from this granmar-graveyard when I first proposed social literacy in 1980 in my book Critical Teaching And Everyday Life, and which Lee Odell has argued for wonderfully in "Basic Writing in Context: Rethinking Academic Literacy."

Tracking and testing are the Twin Towers of Unequal City whesein BW resides. These towers rose from an American foundation of low-spending and hostile-management directed to non-elite studentis. Can there be BW without bogus placement and tracking mechanisms? Can BW withstand a democratic gaze? Tom Hilgers has answered: "It is my belief that bad assessment is what gets most students 
labeled as 'basic writers.' Bad assessment drives the curriculum and the evaluation of most basic writing courses..." (69). BW requires punitive placement regimes to feed and justify it. How do some students get designated for the remedial subcollege known as BW if not for a placement process now grossly dominated by short-answer exams or the infamous, one-shot, timed, impromptu essay? This bogus assessment of writing is the cheapest way to get the greatest control of teachers, students, curriculum, and costs, not a surprising choice for a system that always spent the least on the majority of students, a system on the defensive after the activist 60 s saw comp requirements erode in the face of student protests, only to reappear with a vengeance during the manufactured literacy crisis of the 1970s (which Sharon Crowley has discussed in several places and which I wrote about as "the conservative restoration in school and society" in Culture Wars, previously mentioned.)

Top-down testing has little to do with bottom-up learning and a lot to do with institutional control. To sum up, top-down assessment and required $\mathrm{BW} /$ comp are linguistic policy for containing three things: the costs of mass higher education (while lavish funds are spent on elite campuses), the potential of critically "writing and reading the world" as the late Paulo Freire put it, and the output of college grads whose aspiring numbers are already overwhelming a job market seeking cheap labor. Thus, I see the BW/comp story as part of a long history of curricula for containment and control, part of the system of school tracking to divide and deter non-elite students in school and college. The students themselves are tested and declared deficient by the system, which blames the apparently illiterate and cultureless victim, stigmatizing the individual as the problem while requiring BW/ comp as the remedy. The structure now in place helps maintain the inequality built over the last century or two, tilting resources to elite students and lush campuses, rewarding those who speak and look like those already in power. This arrangement is undemocratic and immoral.

Still, I must say here that writing teachers in the trenches do heroic labor against great odds. I know about the dedication of BW teachers because I taught BW at the City University of New York for 15 years. I still teach freshman comp in the working-class district of the academy at Staten Island College. My criticism of the history and politics of BW/comp is not a criticism of my colleagues, who more often than not are wonderful teachers. To make better use of our professional talents and dedication, we could begin with Peter Elbow's ideas for restructuring writing courses (see Composition for the Twenty-First Century). Basically, Peter recommends that portfolio assessment replace the bogus timed impromptu writing test. He also suggests that all students be enrolled into an extended writing class that would graduate 
stridents as they complete their course projects, not on a semester timetable. Peter endorses the excellent experiments underway at South Carolina by Rhonda Grego and Nancy Thompson, who set up writing studios as peer-group tutorials adjunctive to regular writing classes. I also like thè experiments by Barbara Gleason and Mary Soliday at City College of New York, where they use an expanded freshman comp course over two semesters which mixes erstwhile basic writers with regular students, abandoning BW as a tracking device. I urge people to contact these colleagues and to read their work as well as Peter's and Lee Odell's and also Bruce Herzberg's excellent report on servicelearning at Bentley College ("Community Service and Critical Teaching").

We also need to revive the Wyoming Resolution of 1987, to pick up where brave Jim Slevin, Sharon Crowley, and others have brought us, in terms of relentlessly exposing the shameful foundations of "English" as a field, the ugly subordination of composition to literature, the destructive denigration of teaching to publication, the expanding exploitation of underpaid, overworked part-time instructors.

In this regard, I propose we urge CCCC to declare a "Labor Policy": "All positions in the field are designated full-time, to be divided at any program only at the request of instructors themselves shculd any choose not to work full-time. Split positions would carry full-time benefits even if some prefer less-than-full course-loads." Regarding the costs of this Labor Policy, some may think that money does not exist to pay for it. I disagree. Any who wonder where the money is should note the booming economy and the vast military budget; then, find out how big a surplus your local BW/comp programs are generating each year, like the $\$ 1$ million generated by the former comp program at Minnesota, I was told. BW/comp is a cash cowfull-tuition paid by students while part-time wages are paid to teachers. No costly equipment needed as in engineering labs or nursing departments. BW/comp is like the former colony of India, the jewel in the crown, a territory generating lots of wealth for the imperial metropoles of lit, grad school, and administration. In terms of enforcing the Labor Policy, I would suggest that any institution not complying be targeted vigorously by CCCC with a "corporate campaign": high-profile negative publicity informing prospective students, teachers, and parents that this college's labor and language policies interfere with good teaching and learning. The time to take this kind of action is long overdue. Echoing in my thoughts here is Edwin Hopkins's 191:? lead article in the very first issue of the spanking new NCTE journal, where Hopkins gave a decisive "No" to the question, "Can Good Cornposition Teaching Be Done Under Present Conditions?"

If we are serious about teaching well and about students learning to write passionately and to think critically; if we are serious about 
democratic education in a democratic society; then we need a Labor Policy on the one hand and a curricular policy against tracking, testing, and skills-based instruction on the other. Let's promote ethnographic, context-oriented, community literacy, which I and others like Linda Flower have advocated. We can invite students to do literacy projects about their education, the college, the community, their jobs, or society-at-large, including media criticism and media production. Many of us have already moved away from skill-and-drill workbook exercises, away from disembodied language work, towards critical literacy mobilized by the students' natural language competencies, something emphasized by John Mayher in his profound book Uncommon Sense.

BW/comp teachers committed to cultural democracy and critical literacy can examine their local conditions and decide what strategies for change would work best at the places where we work. For example, good mainstreaming experiments, like those at South Carolina and City College, appear to require structural changes, thematic changes, different course/credit/staffing structures as well as new student-centered subjects and methods, like the literacy narratives deployed by Soliday and Gleason at City College (see Soliday's "From the Margins to the Mainstream"). Sometimes it is said that we get the history we deserve, which is another way of saying that resistance to anti-educational regimes limits the destructive status quo and opens constructive possibilities beyond the givens of the corporate economic agenda. In the late 1990s, after two decades of conservative restoration and cutbacks in school and society, many teachers and students feel vulnerable, isolated, disoriented, and powerless. This is understandable, given the great assault on equality and cultural democracy launched after the activist 1960s against public education, women, children, minorities, labor unions, affirmative action, and gay rights. Feeling vulnerable, many think little or nothing can be done. I don't agree. A lot has already been done and is being done right now. The literature in the field is rich in material supporting those who want to develop democratic language arts (see Auerbach). All around the country, teachers are experimenting, testing the limits, like the exemplary experiments I already mentioned at City College and South Carolina (see also Grego and Thompson's "Repositioning Remediation").

What to do? as Elsbeth Stuckey asks in The Violence of Literacy. Find allies with whom to study, talk, experiment, and plan campaigns against testing, against tracking, and against the imposition of skillsbased teaching, what Paulo Freire famously named the "banking" method. Don't confront the lion alone, Paulo said when he was alive. Work with colleagues and allies. Remarkable progress has been made in these conservative times - progress in feminist, multicultural, student-centered, and critical pedagogies, despite the growth in testing 
and in part-time labor. As Paulo told us in A Pedagogy for Liberation, "Education is politics" (46). He urged us to think that the future was made by what we did today. Adrienne Rich, companion to Mina Shaughnessy in the heroic Open Admissions days at City College, wrote, "My daily life as a teacher confronts me with young men and women who have had language and literature used against them, to keep them in their place, to mystify, to bully, to make them feel powerless" (63). Similarly, Tom Fox insisted, "The need is not so much to initiate students into the discourse community, to teach them the particular forms of language in the academy. Instead, we need to convince students that this community is theirs, that it will not work against their identity and their interests" (75). Likewise, John Rouse concluded that "Any decision about language teaching is a moral and political decision" (12). Finally, Carole Edelsky said that "Retheorizing language education to make it serve education for democracy means highlighting the relationship of language and power.... It means figuring out and then spelling out how systems of domination are part of reading and writing, part of classroom interaction, part of texts of all kinds and doing that as part of our constant and primary, not secondary, enterprise" (255).

We know the unequal society in whose arms we came of age; we can learn the history and politics that brought undemocratic arrangements into being at our worksites and elsewhere; we can take some risks together as citizens to change society and as teachers to change the conditions of our work, against language policies that divide and discourage, in favor of inspired learning, critical writing, equal funding and humane democracy. Farewell to educational apartheid; farewell to tests, programs and classes supporting inequality; farewell to the triumphant Harvard legacy now everywhere in place, constantly troubled, widely vulnerable, waiting for change.

\section{Works Cited}

Adams, Peter Dow. "Basic Writing Reconsidered." Journal of Basic Writing 12.1 (1993): 22-36.

Auerbach, Elsa. "Literacy and Ideology." Annual Review of Applied Linguistics 12 (1992): 71-85,

Berlin, James A. Rhetoric and Reality: Writing Instruction in American Colleges, 1900-1985. Carbondale, IL: Southern Illinois UP; 1987.

- -. - " "Poststructuralism, Cultural Studies, and the Composition

Classroom: Postmodern Theory in Practice," Rhetoric Review 11.1(1992): 16-33.

- - - "Postmodernism, the College Curriculum, and Composition." In Composition in Context: Essays in Honor of Donald C. Stewart. Ed. W. Ross Winterowd and Vincent Gillespie. Carbondale, IL: South- 
ern Illinois UP, 1994: 46-61.

Berliner, David C. and Bruce J. Biddle. The Manufactured Crisis: Myths, Fraud, and the Attack on America's Public Schools. Reading, MA: Addison-Wesley, 1995.

Bureau of Labor Statistics. Employment and Earnings. January 1996.

CCCC Committee on Assessment. "Writing Assessment: A Position Statement." CCC 46.3(1995): 430-437.

Connors, Robert J. "Crisis and Panacea in Composition Studies: A History." In Composition in Context, 86-105.

- - -."Rhetoric in the Modern University: The Creation of an Underclass." In The Politics of Writing Instruction: Postsecondary. Ed. Richard Bullock and John Trimbur. Portsmouth, NH: Boynton, 1991: 55-84.

Clark, Burton. "The Cooling-Out Function in Higher Education." American Journal of Sociology 65(1960): 569-576.

Crowley ,Sharon. "A Personal Essay on Freshman Composition." Pretext 12(1991): 155-176.

- - - "Response to Edward M. White." JBW15.1 (1996): 88-91.

- - - " "Composition's Ethic of Service, the Universal Requirement, and the Discourse of Student Need." JAC 15.2 (1995): 227-239.

Department of Education. High School and Beyond. Washington, DC, 1996.

Dewey, John. Democracy and Education. 1916: New York: Free Press, 1966.

Digest of Education Statistics. National Center for Education Statistics, Washington, DC, 1996.

Edelsky, Carole. "Education for Democracy." Language Arts 71(1994): 252-257.

Elbow, Peter. "Writing Assessment in the 21st Century: A Utopian View." In Composition for the Twenty-First Century: Crisis and Change. Ed. Lynn Bloom, Donald Daiker, and Edward White. Carbondale, IL: Southern Illinois UP, 1996: 83-100.

Flower, Linda . "Literate Action." In Composition for the Twenty-First Century, 249-260.

Fox, Tom. "Basic Writing as Cultural Conflict." Journal of Education 172.1(1990): 65-83.

Freeman, Richard. The Overeducated American. New York: Academic Press, 1976.

Galbraith, John Kenneth. The New Industrial State. Boston: HoughtonMifflin, 1967.

Glau, Gregory. "The 'Stretch Program': Arizona State University's New Model of University-Level Basic Writing Instruction." WPA 20 (1996): 79-87.

Goodlad, John. A Place Called School. New York: McGraw-Hill, 1984. Gramsci, Antonio. Selections From The Prison Notebooks Of Antonio 
Gramsci. Ed. and Tr. by Quintin Hoare and Geoffrey Nowell Smith.

New York: International Publishers, 11th printing , 1992.

Greenbaum, Leonard. "The Tradition of Complaint." College English

31.2(1969): 174-187.

Greenberg, Karen. “The Politics of Basic Writing." JBW12.1(1993): 6971.

Grego, Rhonda and Nancy Thompson. "Repositioning Remediation:

Renegotiating Composition's Work in the Academy." CCC 47.1(1996): 62-84.

Henwood, Doug. "Trashonomics." In White Trash: Race and Class in America. Ed. Matt Wray and Annalee New. New York: Routledge, 1997, 177-189.

Herzberg, Bruce. "Community Service and Critical Teaching." CCC 45.3(1994): 307-319.

Hilgers, Thomas L. "Basic Writing Curricula and Good Assessment Practices: When'er Shall the Twain Meet?" JBW14.2(1995): 68-74.

Holmes, Steven A. "Income Disparity Between Poorest and Richest Rises." New York Times. 10 June 1996, A1.

Hopkins, Edwin. "Can Good Composition Teaching Be Done Under Present Conditions?" The English Journal 1(1912): 1- 10.

Huot, Brian. "A Survey of College and University Writing Placement Practices." WPA 17(1994): 49-65.

Mann, Horace. The Republic and the School: Horace Mann on the Education of Free Men. Ed. Lawrence Cremin. New York: Teachers College Press, 1957.

Marland, Sidney Percy. Career Education: A Proposal for Reform. New York, McGraw-Hill, 1974.

Mantsios, Gregory. "Class in America: Myths and Realities." In Race, Class and Gender in the United States: An Integrated Study. Ed. Paula

S. Rothenberg. 3rd edition. New York: St. Martin's, 1995, 131-143.

Mayher, John. Uncommon Sense. Portsmouth, NH: Heinemann, 1990.

Miller, Susan. Textual Carnivals: The Politics of Composition. Carbondale, IL: Southern Illinois UP, 1991.

Myrdal, Gunnar. An American Dilemma: The Negro Problem. 1944; New York: Harper and Row, 1964.

Oakes, Jeannie. Keeping Track. New Haven: Yale UP, 1985.

Odell, Lee. "Basic Writing in Context: Rethinking Academic Literacy." JBW14.1 (1995): 43-56.

Ohmann, Richard. English in America. New York: Oxford UP, 1976.

- - - . Politics of Letters. Middletown, CT: Wesleyan UP, 1987.

Postsecondary Education Opportunity. Iowa City, May 1994.

Purves, Alan. "Apologia Not Accepted." CCC 46.4(1995): 549-550.

Rich, Adrienne. "Teaching Language in Open Admissions." In On Lies,

Secrets, and Silence. New York: Norton, 1979, 51-68.

Rose, Mike. Lives on the Boundary. New York: Penguin, 1990. 
Rouse, John. "The Politics of Composition," College English 41.1(1979): 1-12.

Shaughnessy, Mina. Errors And Expectations. New York: Oxford UP, 1977.

Shor, Ira. Critical Teaching and Everyday Life. Chicago: U of Chicago P, 1980.

- - - Culture Wars: School and Society in the Conservative Restoration 1969-1984. Boston: Routledge, 1986.

- - - Empowering Education: Critical Teaching for Social Change. Chicago: U of Chicago P, 1992.

- - - When Students Have Power: Negotiating Authority in a Critical Pedagogy. Chicago: U of Chicago P, 1996.

- - - and Paulo Freire. A Pedagogy for Liberation: Dialogues on Transforming Education. Westport, CT: Greenwood, 1987.

Soliday, Mary. "From the Margins to the Mainstream: Reconceiving Remediation." CCC 47.1(1996): 85-100.

Stewart, Donald. "Harvard's Influence on English Studies: Perceptions from Three Universities in the Early Twentieth Century." CCC 43.4(1992): 455-471.

Stuckey, Elsbeth. The Violence of Literacy. Portsmouth, NH: Boynton/ Cook, 1990.

Trimmer, Joe. "Basic Skills, Basic Writing, Basic Research." JBW 6.1(1987): 3-9.

Tyack, David B. Turning Points in American Educational History. Cambridge, MA: Harvard UP, 1967.

Welner, Kevin G. and Jeannie Oakes. "(Li)ability Grouping: The New Susceptibility of School Tracking Systems to Legal Challenges." Harvard Educational Review 66.3(1996): 451-470.

White, Edward M. "An Apologia for the Timed Impromptu Essay Test." CCC 46.1(1995): 30-45. 


\section{CUMULATIVE INDEX FOR JBW: THE FIRST 15 VOLUMES (1975-1996)}

Adams, Peter Dow. "Basic Writing Reconsidered" 12.1 (1993): 22-36.

Agnew, Eleanor. "Basic Writers in the Workplace: Writing Adequately for Careers after College." 11.2 (1992): 28-46.

Anderson, Kristine F. "Using a Spelling Survey to Develop Basic Writers' Linguistic Awareness: A Response to Ann B. Dobie." 6.2 (1987): 72-78.

Andrews, Susan B. and John Creed. "Publication Project in Alaska Offers Ways to Open New Worlds to Basic Writing Students." 13.1 (1994): 3-13.

Anokye, Akua Duku. "Oral Connections to Literacy: The Narrative." 13.2 (1994): 46-60.

Armstrong, Cherryl. "Reexamining Basic Writing: Lessons from Harvard's Basic Writers." 7.2 (1988): 68-80.

Bartholomae, David. "Inventing the University." 5.1 (1986): 4-23.

- - . "Teaching Basic Writing: An Alternative to Basic Skills." 2.2 (1979): 85-109.

_ - - "The Tidy House: Basic Writing in the American Curriculum." 12.1 (1993): 4-21.

Beaugrande, Robert de and Mar Jean Olson. "Using a 'WriteSpeak-Write' Approach for Basic Writers." 10.2 (1991): 4-29.

Belanger, Kelly. "Gender and Teaching Academic Discourse: How Teachers Talk About Facts, Artifacts, and Counnterfacts." 13.2 (1994): 61-82.

Belanoff, Pat. "The Myth of Assessment." 10.1 (1991): 54-66.

Benson, Beverly, Mary P. Deming, Debra Denzer, and Maria

Valeri-Gold. "A Combined Basic Writing/English as a Second

Language Class: Melting Pot or Mishmash?" 11.1 (1992): 58-74.

Berg, Anna and Gerald Coleman. "A Cognitive Approach to Teaching the Developmental Student." 4.2 (1985): 4-23.

Berger, Mary Jo. "Funding and Support for Basic Writing: Why Is There So Little?" 12.1 (1993): 81-89.

Berthoff, Ann E. "Recognition, Representation, and Revision." 3.3 (1981): 19-32.

- - -. “What Works? How Do We Know?" 12.2 (1993): 3-17.

Beyer, Barry K. and Anita Brostoff. "An Approach to Integrating Writing into a History Course." 2.4 (1980): 36-52.

Bizzell, Patricia. "Power, Authority, and Critical Pedagogy." 10.2 (1991):

54-70. 
Bloom, Lynn Z. "Finding a Family, Finding a Voice: A Writing Teacher Teaches Writing Teachers." 9.2 (1990): 3-14.

- - - "A Name With a View." 14.1 (1995): 7-14.

Bolin, Bill. "Encouraging Students to (Continue to) Share Authority in the Classroom: A Response to Patricia Bizzell." 12.2 (1993): 77-85.

Boorstein, Karen. "Four for One: The Study of Derivational Suffixes for Basic Writing Students." 2.3 (1979): 59-67.

Bradford, Annette. "Applications of Self-Regulating Speech in the Basic Writing Program." 4.2 (1985): 38-47.

Brannon, Lil and Gordon Pradl. "The Socialization of Writing Teachers." 3.4 (1984): 28-37.

Brannon, Lil and Jeanette Harris. "Recognizing the Basic Writer's Vocabulary Acquisition Sequence." 2.3 (1979): 76-81.

Brereton, John. "The Doctorate Program in Composition at Wayne State University." 3.2 (1981): 14-22.

Brookes, Michael C. T. “A Dean's Dilemmas.” 5.1 (1986): 65-76.

Brosnahan, Irene and Janice Neuleib. "Teaching Grammar to Writers." 6.1 (1987): 28-35.

Brossell, Gordon and Mary P. Sheridan-Rabideau "Finding Basic Writing's Place." 14.1 (1995): 21-26.

Brostoff, Anita and Barry K. Beyer. "An Approach to Integrating Writing into a History Course." 2.4 (1980): 36-52.

Brown, Betsy E. and John T. Harwood. "Training and Evaluating Traditional and Non-Traditional Instructors of Composition." 3.4 (1984): 63-73.

Brown, Rexford G. "Schooling and Thoughtfulness." 10.1 (1991): 3-15.

- - - . "What We Know Now and How We Could Know More about Writing Ability in America." 1.4 (1978): 1-6.

Bruder, Mary Newton and Patricia R. Furey. "The Writing Segment of an Intensive Program for Students of English as a Second Language." 2.2 (1979): 67-84.

Bruffee, Kenneth A. "On Not Listening in Order to Hear: Collaborative Learning and the Rewards of Classroom Research." 7.1 (1988): 3-12.

Brutten, Sheila R. and Kyle Perkins. "Writing: A Holistic or Atomistic Entity?" 9.1 (1990): 75-84.

Buhr, Dianne and Willa Wolcott. "Attitude as It Affects Developmental Writers' Essays." 6.2 (1987): 3-15.

Buley-Meissner, Mary Louise. "'Am I Really That Bad?' Writing Apprehension and Basic Writers." 8.2 (1989): 3-20.

Burnham, Christopher. "Recruiting, Training, and Supporting Volunteer Basic Writing Instructors: A Working Program." 3.4 (1984): 14-27.

Campbell, Dianna S. and Terry Ryan Meier. "A Design for a Developmental Writing Course for Academically Underprepared Black 
Students." 1.2 (1976): 20-30.

Cannon, Sally I. and Kay Harley . "Failure: The Student's or the Assessment's?" 15.1 (1996): 70-87.

Clark, Irene Lurkis. "Listening and Writing." 3.3 (1981): 81-90.

Clark, J. Milton and Carol Peterson Haviland. "Language and Authority: Shifting the Privilege." 14.1 (1995): 57-66.

Clark, J. Milton and Carol Peterson Haviland. "What Can Our Students Tell Us About Essay Examination Designs and Practices?" 11.2 (1992): 47-6().

Cochran, Effie Papatzikou. "Giving Voice to Women in the Basic Writing and Language Minority Classroom." 13.1 (1994): 7890.

Cody, Jim. "The Importance of Expressive Language in Preparing Basic Writers for College Writing." 15.2 (1996): 95-111.

Coleman, Gerald and Anna Berg. "A Cognitive Approach to Teaching the Developmental Student." 4.2 (1985): 4-23.

Collins, James L. "Basic Writing and the Process Paradigm." 14.2 (1995): 3-18.

Comprone, Joseph. "Graduate Programs for Teachers of Basic Writing: The University of Louisville's Ph.D. in Rhetoric and Composition." 3.2 (1981): 23-45.

Costello, Jacqueline. "Promoting Literacy Through Literature: Reading and Writing in ESL Composition." 9.1 (1990): 20-30.

Creed, John and Susan B. Andrews. "Publication Project in Alaska Offers Ways to Open New Worlds to Basic Writing Students." 13.1 (1994): 3-13.

Crowley, Sharon. "A Response to Ed White's 'The Importance of Placement and Basic Studies.'” 15.1 (1996): 88-91.

Curtis, Marcia S. and Sara L. Stelzner. "A Questioning Voice: Instructors and Basic Writers Interact." 6.1 (1987): 55-64.

D'Eloia, Sarah. “Teaching Standard Written English." 1.1 (1975): 5-13.

- - - . "The Uses - and Limits - of Grammar." 1.3 (1977): 1-48.

Dash, Irene. "Those 'Bulbous Liver-Colored' Words." 2.3 (1979): 8890.

Davidson, David M. "Sentence Combining in an ESL Writing Program." 1.3 (1977): 49-62.

Deem, James M. and Sandra A. Engel. “Developing Literacy through Transcription." 7.2 (1988): 99-107.

Deming, Mary P., Beverly Benson, Debra Denzer, and Maria Valeri-Gold. "A Combined Basic Writing/English as a Second Language Class: Melting Pot or Mishmash?" 11.1 (1992): 58-74.

Desy, Jeanne. "Reasoned Writing for Basic Students: A Course Design." 1.2 (1976): 4-19.

Dixon, Kathleen G. "Intellectual Development and the Place of Narrative in 'Basic' and Freshman Composition." 8.1 (1989): 3-20. 
DiYanni, Robert. "Sound and Sense: Writing about Music." 2.4 (1980): 62-71.

Dobie, Ann B. "Orthographical Theory and Practice, or How to Teach Spelling." 5.2 (1986): 41-48.

- - - "Orthography Revisited: A Response to Kristine Anderson." 7.1 (1988): 82-83.

Dykstra, Pamela D. “.Say It, Don't Write It: Oral Structures As Framework for Teaching Writing." 13.1 (1994): 41-49.

Eisenberg, Anne. "The Trouble with Teaching Vocabulary." 2.3 (1979): 5-14.

Elbow, Peter. "Toward a Phenomenology of Freewriting." 8.2 (1989): 42-71.

Elifson, Joan M. and Katharine R. Stone. "Integrating Social, Moral, and Cognitive Developmental Theory: Implications of James Fowler's Epistemological Paradigm for Basic Writers." 4.2 (1985): 24-37.

Elliot, Norbert. "Narrative Discourse and the Basic Writer." 14.2 (1995): 19-30.

Emig, Janet. “Mina Pendo Shaughnessy.” 13.1 (1994): 92-94.

Engel, Sandra A. and James M. Deem. "Developing Literacy through Transcription." 7.2 (1988): 99-107.

Epes, Mary. "Tracing Errors to Their Sources: A Study of the Encoding Processes of Adult Basic Writers." 4.1 (1985): 4-33.

Epes, Mary, Carolyn Kirkpatrick, and Michael G. Southwell. "The COMP-LAB Project: An Experimental Basic Writing Course." 2.2 (1979): $19-37$.

Farrell, Thomas J. “Developing Literate Writing." 2.1 (1978): 30-51.

Feldman, Patricia, Paul Hunter, Nadine Pearce, Sue Lee, Shirley Goldsmith, and Holly Weaver. "Competing Epistemologies and Female Basic Writers." 7.1 (1988): 73-81.

Fishman, Joshua A. "Ethnocultural Dimensions in the Acquisition and Retention of Biliteracy." 3.1 (1980): 48-61.

Fitzgerald, Kathryn R. "Computerized Scoring? A Question of Theory and Practice." 13.2 (1994): 3-17.

- - - " "Rhetorical Implications of School Discourse for Writing Placement." 7.1 (1988): 61-72.

Flower, Linda. "Revising Writer-based Prose." 3.3 (1981): 62-74.

Forman, Janis. "Notes Toward Writing Across the Curriculum: Some Collaborative Efforts." 2.4 (1980). 12-21.

Fox, Len. "On Acquiring an Adequate Second Language Vocabulary." 2.3 (1979): 68-75.

Fox, Tom. "Standards and Access." 12.1 (1993): 37-45.

Furey, Patricia R. and Mary Newton Bruder. "The Writing Segment of an Intensive Program for Students of English as a Second Language." 2.2 (1979): 67-84. 
Gaillet, Lynde Lewis. "A Legacy of Basic Writing Instruction." 12.2 (1993): 86-99.

Gallagher, Brian. "Vocabulary in Writing for Business: Six Propositions for Pedagogical Use." 2.3 (1979): 40-58.

Gamble, Kenneth R. and Walter S. Minot. "Self-Esteem and Writing Apprehension of Basic Writers: Conflicting Evidence." 10.2 (1991): 116-124.

Garnes, Sara. "Preparing the Ideal Teacher of Basic Writing." 3.4 (1984): 4-13.

Garnes, Sara and Andrea Lunsford. "Anatomy of a Basic Writing Program." 2.2 (1979): 38-51.

Gay, Pamela. "Rereading Shaughnessy from a Postcolonial Perspective." 12.2 (1993): 29-40.

Gebhardt, Richard C. "Training Basic Writing Teachers at a Liberal Arts College." 3.2 (1981) 46-63.

Gergen, Constance A. and G. Genevieve Patthey-Chavez. "Culture as an Instructional Resource in the Multiethnic Composition Classroom." 11.1 (1992): 75-96.

Gilbert, Janet R. “Patterns and Possibilities for Basic Writers." 6.2 (1987): 37-52.

Goldberg, Marilyn K. “Overfamiliarity: A Cognitive Barrier in Teaching Composition." 4.1 (1985): 34-43.

Goldsmith, Shirley, Paul Hunter, Nadine Pearce, Sue Lee, Patricia Feldman, and Holly Weaver. "Competing Epistemologies and Female Basic Writers." 7.1 (1988): 73-81.

Goldstone, Richard. "In Memoriam Mina Shaughnessy 1924-1978." 13.1 (1994): 99-102.

Gorrell, Donna. "Freedom to Write-Through Imitation." 6.2 (1987): 53-59.

Gould, Christopher. "Teaching Literature to Basic Writers." 8.1 (1989): 57-66.

Gould, Christopher and John Heyda. "Literacy Education and the Basic Writer: A Survey of College Composition Courses." 5.2 (1986): 8-27.

Gray, Barbara Quint. "Dialect Interference in Writing: A Tripartite Analysis." 1.1 (1975): 14-22.

Gray, Barbara Quint and Alice Trillin. "Animating Grammar: Principles for the Development of Video-Tape Materials." 1.3 (1977): 77-91.

Gray-Rosendale, Laura. "Revising the Political in Basic Writing Scholarship." 15.2 (1996): 24-49.

Greenberg, Karen L. "The Politics of Basic Writing." 12.1 (1993): 64-71. Greene, Brenda M. "Empowerment and the Problem Identification and Resolution Strategies of Basic Writers." 11.2 (1992): 4-27.

Gregg, Noel and Patricia J. McAlexander. "The Roles of English Teachers and LD Specialists in Identifying Learning Disabled Writers: Two Case Studies." 8.2 (1989): 72-86. 
Gunner, Jeanne. "The Status of Basic Writing Teachers: Do We Need a 'Maryland Resolution'?" 12.1 (1993): 57-63.

Hake, Rosemary. "With No Apology: Teaching to the Test." 1.4 (1978): 39-62.

Halsted, Isabella. "Putting Error in Its Place." 1.1 (1975): 72-86.

Harley, Kay and Sally I. Cannon. "Failure: The Student's or the Assessment's?" 15.1 (1996): 70-87.

Harris, Jeanette and Lil Brannon. "Recognizing the Basic Writer's Vocabulary Acquisition Sequence." 2.3 (1979): 76-81.

Harris, Joseph. "Negotiating the Contact Zone." 14.1 (1995): 27-42.

Harris, Muriel. "Evaluation: The Process for Revision." 1.4 (1978): 8290.

Harris, Muriel and Katherine E. Rowan. "Explaining Grammatical Concepts." 8.2 (1989): 21-41.

Hartwell, Patrick. "Choosing Your Doctoral Program." 3.4 (1984): 7475.

Harwood, John T. and Betsy E. Brown. "Training and Evaluating Traditional and Non-Traditional Instructors of Composition." 3.4 (1984): 63-73.

Hashimoto, Irvin Y. "Adult Learning and Composition Instruction." 4.1 (1985): 55-67.

- - . "Pain and Suffering: Apostrophes and Academic Life." 7.2 (1988): 91-98.

- - -. "Sensitizing Beginning Teachers of Writing." 3.4 (1984): 55-62.

Haviland, Carol Peterson and J. Milton Clark "Language and Authority: Shifting the Privilege." 14.1 (1995): 57-66.

Haviland, Carol Peterson and J. Milton Clark. "What Can Our Students Tell Us About Essay Examination Designs and Practices?" 11.2 (1992): 47-60.

Hays, Janice N. "Models of Intellectual Development and Writing: A Response to Myra Kogen et al." 6.1 (1987): 11-27.

- - - " "Socio-Cognitive Development and Argumentative Writing: Issues and Implications from One Research Project." 7.2 (1988): 42-67.

Herendeen, Warren. "Of Tricksters and Dilemmas in ESL Writing Classes: An Epistolary Account." 5.2 (1986): 49-58.

Heyda, John and Christopher Gould. "Literacy Education and the Basic Writer: A Survey of College Composition Courses." 5.2 (1986): 8-27.

Hilgers, Thomas. "Basic Writing Curricula and Good Assessment Practices." 14.2 (1995): 68-74.

Hindman, Jane E. "Reinventing the University: Finding the Place for Basic Writers." 12.2 (1993): 55-76.

Hirsch, E. D., Jr. "Culture and Literacy." 3.1 (1980): 27-47.

- - - "Opening Remarks at an MLA Session in Memory of Mina 
Shaughnessy, December 28, 1979." 13.1 (1994): 95-98.

Hirsch, Kate Ferguson. "Writing and the Law: A Composition Course for Pre-Law Students." 2.4 (1980): 82-94.

Hoddeson, David. “The Reviser's Voices." 3.3 (1981): 91-108.

Hoggart, Richard. “The Importance of Literacy." 3.1 (1980): 74-87.

Hoover, Regina M. "In the Beginning: The Word." 2.3 (1979): 82-87.

Horning, Alice S. "The Trouble with Writing Is the Trouble with Reading." 6.1 (1987): 36-47.

Hunter, Paul, Nadine Pearce, Sue Lee, Shirley Goldsmith, Patricia Feldman, and Holly Weaver. "Competing Epistemologies and Female Basic Writers." 7.1 (1988): 73-81.

Jensen, George H. "Bureaucracy and Basic Writing Programs; or, Fallout from the Jan Kemp Trial." 7.1 (1988): 30-37.

- - - "The Reification of the Basic Writer." 5.1 (1986): 52-64.

Jie, Gao and Marie Jean Lederman. "Instruction and Assessment of Writing in China: The National Unified Entrance Examination for Institutions of Higher Education." 7.1 (1988): 47-60.

Johns, Ann M. "The ESL Student and the Revision Process: Some Insights from Schema Theory." 5.2 (1986): 70-80.

Johnson, Paula. "Writing Face to Face." 2.2 (1979): 7-18.

Johnson, Sarah Coprich. "Making a Place for Music in Basic Writing." 14.2 (1995): 31-37.

Jones, William. "Basic Writing: Pushing Against Racism." 12.1 (1993): 72-80.

Jonz, Jon. “Using Pooled Judgments to Develop Tests of Basic Writing." 6.2 (1987): 16-25.

Kamin, June. "Writing: Painting with Words." 2.3 (1979): 91-95.

Keithley, Zoe. "'My Own Voice': Students Say It Unlocks the Writing Process." 11.2 (1992): 82-102.

Kelly, Lou. "Writing as Learning for Basic Writing Teachers and Their Students." 3.4 (1984): 38-54.

Kinder, Rose Marie. "A Piece of the Streets." 10.1 (1991): 67-72.

Kirkpatrick, Carolyn, Mary Epes and Michael G. Southwell. "The COMP-LAB Project: An Experimental Basic Writing Course." 2.2 (1979): 19-37.

Kirch, Ann. "A Basic Writer's Topoi for Timed Essay Tests." 15.2 (1996): 112-124.

Kirsch, Gesa. "Students' Interpretations of Writing Tasks: A Case Study." 7.2 (1988): 81-90.

Koehler, Boyd and Kathryn Swanson. "Basic Writers and the Library: A Plan for Providing Meaningful Bibliographic Instruction." 9.1 (1990): 56-74.

Kogen, Myra. "The Conventions of Expository Writing." 5.1 (1986): 24-37

Krishna, Valerie. “The Syntax of Error." 1.1 (1975): 43-49. 
Kroll, Barbara. "The Rhetoric/Syntax Split: Designing a Curriculum for ESL Students." 9.1 (1990): 40-55.

Kunz, Linda Ann. "X-Word Grammar: Offspring of Sector Analysis." 1.3 (1977): 63-76.

Larson, Richard L. "Selected Bibliography of Writing on the Evaluation of Students' Achievements in Composition." 1.4 (1978): 91100.

Laurence, Patricia. “Error's Endless Train: Why Students Don't Perceive Errors." 1.1 (1975): 23-42.

- - - "The Vanishing Site of Mina Shaughnessy's Errors and Expectations." 12.2 (1993): 18-28.

Lay, Nancy. "Chinese Language Interference in Written English." 1.1 (1975): 50-61.

- - - "Learning From Natural Language Labs." 11.2 (1992): 74-81.

Lazere, Donald. “Orality, Literacy, and Standard English." 10.2 (1991): 87-98.

Lederman, Marie Jean. “Why Test?" 7.1 (1988): 38-46.

Lederman, Marie Jean and Gao Jie. "Instruction and Assessment of Writing in China: The National Unified Entrance Examination for Institutions of Higher Education." 7.1 (1988): 47-60.

Lee, Sue, Paul Hunter, Nadine Pearce, Shirley Goldsmith, Patricia Feldman, and Holly Weaver. "Competing Epistemologies and Female Basic Writers." 7.1 (1988): 73-81.

Liebman, JoAnne. "Contrastive Rhetoric: Students as Ethnographers." 7.2 (1988): 6-27.

Lloyd-Jones, Richard. "What We Will Be." 5.2 (1986): 3-7.

Lu, Min-Zhan. "Redefining the Legacy of Mina Shaughnessy: A Critique of the Politics of Linguistic Innocence ." 10.1 (1991): 26-40.

Lunsford, Andrea. "Aristotelian Rhetoric: Let's Get Back to the Classics." 2.1 (1978): 2-12.

_ - - "Assignments for Basic Writers: Unresolved Issues and Needed Research." 5.1 (1986): 87-99.

- - - . "Intellectual Property, Concepts of Selfhood, and the Teaching of Writing." 11.2 (1992): 61-73.

Lunsford, Andrea and Sara Garnes. "Anatomy of a Basic Writing Program." 2.2 (1979): 38-51.

Lyons, Chopeta. "Spelling Inventory." 4.2 (1985): 80-83.

Lyons, Robert. "Mina Shaughnessy and the Teaching of Writing." 3.1 (1980): 3-12.

MacGowan-Gilhooly, Adele. "Fluency First: Revising the Traditional ESL Sequence." 10.1 (1991): 73-87.

Maher, Jane. "A Full and Good World from Mina P. Shaughnessy: Her Life and Work." 15.2 (1996): 3-23.

Maimon, Elaine. "Cinderella to Hercules: Demythologizing Writing Across the Curriculum." 2.4 (1980): 3-11. 
Martinez, Joseph G. R. and Nancy C. Martinez. "Reconsidering Cognition and the Basic Writer: A Response to Myra Kogen." 6.2 (1987): 79-82.

Martinez, Joseph G. R. and Nancy C. Martinez. "Who is Alien in the Developmental Classroom? A Comparison of Some Student/ Teacher Values." 8.2 (1989): 99-112.

Matthews, Roberta S. "The Evolution of One College's Attempt to Evaluate Student Writing." 1.4 (1978): 63-70.

Mayher, John S. "Uncommon Sense in the Writing Center." 11.1 (1992): 47-57.

McAlexander, Patricia J. and Noel Gregg. "The Roles of English Teachers and LD Specialists in Identifying Learning Disabled Writers: Two Case Studies." 8.2 (1989): 72-86.

McAndrew, Donald A. "Handwriting Rate and Syntactic Fluency." 9.1 (1990): 31-39.

McQuade, Donald and Marie Ponsot. "Creating Communities of Writers: The Experience of the Queens English Project." 3.2 (1981) 7989.

Meeker, Linda Hanson. "Pragmatic Politics: Using Assessment Tools to $(\operatorname{Re})$ Shape a Curriculum." 9.1 (1990): 3-19.

Meier, Terry Ryan and Dianna S. Campbell. "A Design for a Developmental Writing Course for Academically Underprepared Black Students." 1.2 (1976): 20-30.

Metzger, Elizabeth. "A Scheme for Measuring Growth in College Writing." 1.4 (1978): 71-81.

Middendorf, Marilyn. "Bakhtin and the Dialogic Writing Class." 11.1 (1992): 34-46.

Mills, Helen. "Language and Composition: Three Mastery Learning Courses in One Classroom." 1.2 (1976): 44-59.

Millward, Jody. "Placement and Pedagogy: UC Santa Barbara's Preparatory Program." 9.2 (1990): 99-113.

Minot, Walter S. and Kenneth R. Gamble. "Self-Esteem and Writing Apprehension of Basic Writers: Conflicting Evidence." 10.2 (1991): 116-124.

Miraglia, Eric. "A Self-Diagnostic Assessment in the Basic Writing Course." 14.2 (1995): 48-67.

Mische, Monica and Rosemary Winslow. "The Hero's Performance and Students' Quests for Meaning and Identity: A Humanities and Writing Course Design." 15.2 (1996): 76-94.

Mlynarczyk, Rebecca. "Finding Grandma's Words: A Case Study in the Art of Revising." 15.1 (1996): 3-22.

Moberg, Goran (George). "The Revival of Rhetoric: A Bibliographic Essay." 9.2 (1990): 66-82.

Moran, Charles. "A Model for Teacher Training Programs in.the Field of Writing." 3.2 (1981): 64-78. 
Moss, Robert F. “Using TV News in Basic Writing Classes.” 6.1 (1987): 65-77.

Murray, Donald M. "Making Meaning Clear: The Logic of Revision." 3.3 (1981): 33-40.

Neuleib, Janice and Irene Brosnahan. "Teaching Grammar to Writers." 6.1 (1987): 28-35.

Newkirk, Thomas. "Barriers to Revision." 3.3 (1981): 50-61.

Newman, Michael. "Correctness and Its Conceptions: The Meaning of Language Form for Basic Writers." 15.1 (1996): 23-38.

Nichols, Randall G. "Word Processing and Basic Writers." 5.2 (1986): 81-97.

Nochimson, Martha. "Writing Instruction Across the Curriculum: Two Programs." 4.2 (1980): 22-35.

Noguchi, Rei R. "Transformational-Generative Syntax and the Teaching of Sentence Mechanics." 6.2 (1987): 26-36.

Odell, Lee. "Basic Writing in Context: Rethinking Academic Literacy." 14.1 (1995): 43-56.

Otte, George. "Computer-Adjusted Errors and Expectations." 10.2 (1991): 71-86.

- - - " "The Deference Due the Oracle: Computerized Text Analysis in a Basic Writing Class." 8.1 (1989): 46-56.

Parisi, Hope A. "Involvement and Self-Awareness for the Basic Writer: Graphically Conceptualizing the Writing Process." 13.2 (1994): 33-45.

Parker, Frank. "Dyslexia: An Overview." 4.2 (1985): 58-67.

Patterson, Orlando. "Language, Ethnicity, and Change." 3.1 (1980): 6273.

Patthey-Chavez, G. Genevieve and Constance A. Gergen. "Culture as an Instructional Resource in the Multiethnic Composition Classroom." 11.1 (1992): 75-96.

Pearce, Nadine, Paul Hunter, Sue Lee, Shirley Goldsmith, Patricia Feldman, and Holly Weaver. "Competing Epistemologies and Female Basic Writers." 7.1 (1988): 73-81.

Perkins, Kyle and Sheila R. Brutten. "Writing: A Holistic or Atomistic Entity?" 9.1 (1990): 75-84.

Petrie, Ann. "Teaching the Thinking Process in Essay Writing." 1.2 (1976): 60-67.

Petrosky, Anthony R. and Susan V. Wall. "Freshman Writers and Revision: Results from a Survey." 3.3 (1981): 109-122.

Pierog, Paul. "Coaching Writing." 1.2 (1976): 68-77.

Ponsot, Marie. "Total Immersion." 1.2 (1976): 31-43.

Ponsot, Marie and Donald McQuade. "Creating Communities of Writers: The Experience of the Queens English Project." 3.2 (1981) 7989. 
Pradl, Gordon and Lil Brannon. "The Socialization of Writing Teachers." 3.4 (1984): 28-37.

Purves, Alan C. "Clothing the Emperor: Towards a Framework Relating Function and Form in Literacy." 10.2 (1991): 33-53.

- - - . "Rhetorical Communities, the International Student and Basic Writing." 5.1 (1986): 38-51.

- - - . "Teaching People Who Don't Write Good." 14.1 (1995): 15-20.

Rankin, David. "Audience and the Composing Process." 3.3 (1981): 75-80.

- - -. "Reading, Listening, Writing: An Integrated Approach to Teaching Exposition." 4.2 (1985): 48-57.

Reagan, Sally Barr. "Warning: Basic Writers at Risk-The Case of Javier." 10.2 (1991): 99-115.

Reiff, John D. “The In-Course Writing Workshop in a Program of Writing Across the Curriculum." 2.4 (1980): 53-61.

Reigstad, Tom J. "Perspectives on Anxiety and the Basic Writer: Research, Evaluation, and Instruction." 4.1 (1985): 68-77.

Rizzo, Betty and Santiago Villafane. "Spanish Influence on Written English." 1.1 (1975): 62-71.

Ronald, Katharine and Hephzibah Roskelly. "Listening as an Act of Composing." 5.2 (1986): 28-40.

Rondinone, Peter. "Teacher Background and Student Needs." 10.1 (1991): 41-53.

Roskelly, Hephzibah, ed. "Survival of the Fittest: Ten Years in a Basic Writing Program." 7.1 (1988): 13-29.

Roskelly, Hephzibah and Katharine Ronald. "Listening as an Act of Composing." 5.2 (1986): 28-40.

Rowan, Katherine E. and Muriel Harris. "Explaining Grammatical Concepts." 8.2 (1989): 21-41.

Roy, Emil L. "Computerized Scoring of Placement Exams: A Validation." 12.2 (1993): 41-54.

Samuels, Marilyn Schauer. "Norman Holland's 'New Paradigm' and the Teaching of Writing." 2.1 (1978): 52-61.

Sanborn, Jean. "Obstacles and Opportunities: Sentence Combining in Advanced ESL." 6.2 (1987): 60-71.

Schor, Sandra. "An Alternative to Revising: The Proleptic Grasp." 6.1 (1987): 48-54.

- - -. "The Short, Happy Life of Ms. Mystery." 10.1 (1991): 16-25.

Scott, Jerrie Cobb. "Literacies and Deficits Revisited." 12.1 (1993): 4656.

Segall, Mary T. “Embracing a Porcupine: Redesigning a Writing Program." 14.2 (1995): 38-47.

Severino, Carol. "Inadvertently and Intentionally Poetic ESL Writing." 13.2 (1994): 18-32.

- - . “An Urban University and Its Academic Support Program: 
Teaching Basic Writing in the Context of an 'Urban Mission.'” 15.1 (1996): 39-56.

- - - " "Where the Cultures of Basic Writers and Academia Intersect:

Cultivating the Common Ground." 11.1 (1992): 4-15.

Shaughnessy, Mina P. “The English Professor's Malady." 3.1 (1980): 91-97.

- - - “The English Professor's Malady." 13.1 (1994): 117-24.

- - - . "The Miserable Truth." 3.1 (1980): 109-114.

_ - - "Open Admissions and the Disadvantaged Teacher." 3.1 (1980): 104-108.

- - - "Some Needed Research on Writing." 3.1 (1980): 98-103.

- - - "Some New Approaches Toward Teaching." 13.1 (1994): 103-16.

- - _. "Statement on Criteria for Writing Proficiency." 3.1 (1980): 115-119.

Sheridan-Rabideau, Mary P. and Gordon Brossell. "Finding Basic Writing's Place." 14.1 (1995): 21-26.

Sills, Caryl Klein. "Arguing from First-Hand Evidence." 11.2 (1992): 103-10.

Sirc, Geoffrey. "The Autobiography of Malcolm X as a Basic Writing Text." 13.1 (1994): 50-77.

Slattery, Patrick J. "Applying Intellectual Development Theory to Composition." 9.2 (1990): 54-65.

Smith, Virginia B. "Keynote Address: The First Shaughnessy Memorial Conference April 3, 1980." 3.1 (1980): 19-26.

Sommers, Nancy. "Intentions and Revisions." 3.3 (1981): 41-49.

Southwell, Michael G. , Mary Epes and Carolyn Kirkpatrick. "The COMP-LAB Project: An Experimental Basic Writing Course." 2.2 (1979): 19-37.

Stanley, Linda C. "'Misreading' Students' Journals for their Views of Self and Society." 8.1 (1989): 21-31.

Stelzner, Sara L. and Marcia S. Curtis. "A Questioning Voice: Instructors and Basic Writers Interact." 6.1 (1987): 55-64.

Sternglass, Marilyn S. "Commitment to Writing and Complexity of Thinking." 5.1 (1986): 77-86.

- - - " "The Need For Conceptualizing at All Levels of Writing Instruction." 8.2 (1989): 87-98.

Stone, Katharine R. and Joan M. Elifson. "Integrating Social, Moral, and Cognitive Developmental Theory: Implications of James Fowler's Epistemological Paradigm for Basic Writers." 4.2 (1985): 24-37.

Stotsky, Sandra. "Teaching the Vocabulary of Academic Discourse." 2.3 (1979): 15-39.

Stygall, Gail. "Politics and Proof in Basic Writing." 7.2 (1988): 2841.

Swanson, Kathryn and Boyd Koehler. "Basic Writers and the Library: A Plan for Providing Meaningful Bibliographic Instruction." 9.1 (1990): 56-74. 
Taylor, Karl K. "DOORS English - The Cognitive Basis of Rhetorical Models." 2.2 (1979): 52-66.

Thaler, Ruth. "Art and the Written Word." 2.4 (1980): 72-81.

Thomas, Joan Krater and Jane Zeni. "Suburban African-American Basic Writing, Grades 7-12: A Text Analysis." 9.2 (1990): 15-39.

Tricomi, Elizabeth Taylor. "Krashen's Second-Language Acquisition Theory and the Teaching of Edited American English." 5.2 (1986): 59-69.

Trillin, Alice. "A Writer's Process: A Conversation with Calvin Trillin." 3.3 (1981): 5-18.

Trillin, Alice and Barbara Quint Gray. "Animating Grammar: Principles for the Development of Video-Tape Materials." 1.3 (1977): 77-91.

Trimmer, Joseph F. "Basic Skills, Basic Writing, Basic Research." 6.1 (1987): 3-10.

Valeri-Gold, Maria, Beverly Benson, Mary P. Deming, and Debra Denzer. "A Combined Basic Writing/English as a Second Language Class: Melting Pot or Mishmash?" 11.1 (1992): 58-74.

Villafane, Santiago and Betty Rizzo. "Spanish Influence on Written English." 1.1 (1975): 62-71.

Wall, Susan V. and Anthony R. Petrosky. "Freshman Writers and Revision: Results from a Survey." 3.3 (1981): 109-122.

Weaver, Holly, Paul Hunter, Nadine Pearce, Sue Lee, Shirley Goldsmith, and Patricia Feldman. "Competing Epistemologies and Female Basic Writers." 7.1 (1988): 73-81.

White, Edward. "The Importance of Placement and Basic Studies: Helping Students Succeed Under the New Elitism." 14.2 (1995): 75-84.

- - - "Mass Testing of Individual Writing: The California Model." 1.4 (1978): 18-38.

Wiener, Harvey S. "Inference: Perspectives on Literacy for Basic Skills Students." 11.1 (1992): 16-33.

- - - "Preparing the Teacher of Writing." 3.2 (1981): 5-13.

Williams, Joseph. "Re-evaluating Evaluating." 1.4 (1978): 7-17.

Wilson, Allison. "Black Dialect and the Freshman Writer." 4.1 (1985): 44-54.

Winslow, Rosemary and Monica Mische. "The Hero's Performance and Students' Quests for Meaning and Identity: A Humanities and Writing Course Design." 15.2 (1996): 76-94.

Wolcott, Willa. "Evaluating a Basic Writing Program." 15.1 (1996): 5769.

- - - "A Longitudinal Study of Six Developmental Students' Performance in Reading and Writing." 13.1 (1994): 14-40.

Wolcott, Willa and Dianne Buhr. "Attitude as It Affects Developmental Writers' Essays." 6.2 (1987): 3-15.

Yelin, Louise. "Deciphering the Academic Hieroglyph: Marxist Literary Theory and the Practice of Basic Writing." 2.1 (1978): 13-29. 
Yorio, Carlos. "The Other Side of the Looking Glass." 8.1 (1989): 32-45.

Young, Morris. "Narratives of Identity: Theorizing the Writer and the Nation." 15.2 (1996): 50-75.

Zak, Frances. "Exclusively Positive Responses to Student Writing." 9.2 (1990): 40-53.

Zamel, Vivian. "Through Students' Eyes: The Experiences of Three ESL Writers." 9.2 (1990): 83-98.

Zeni, Jane and Joan Krater Thomas. "Suburban African-American Basic Writing, Grades 7-12: A Text Analysis." 9.2 (1990): 15-39.

\section{Note:}

\section{A Brief History}

$J B W$ has been in existence since 1975; the first two issues were administered by an Editorial Board which included the following City College of New York (CCNY) faculty members: Sarah D'Eloia, Virginia Epperson, Barbara Quint Gray, Isabella Halsted, Valerie Krishna, Patricia Laurence, Nancy Lay, Betty Rizzo, and Mina Shaughnessy. Doris Fassler and Marylea Meyersohn joined the Editorial Board for the next two issues and Isabella Halsted and Patricia Laurence no longer served on the Board. Sarah D'Eloia (Sarah D'Eloia Fortune in 1985) became the editor in 1980 . In 1981, JBW went through a major transition: it was no longer purely a CUNY publication; it had a National Advisory Board including Edward P. J. Corbett, Frank D' Angelo, Janet Emig, E.D. Hirsch, Jr., Lee Odell, Edward M. White, and Joseph M. Williams.

In 1985 Lynn Quitman Troyka was named editor; her tenure from 1986 to 1988 marked another watershed for JBW: the journal became refereed, the Editorial Board was expanded, the Editor's Column was begun, JBW began to come out regularly two times a year (spring and fall), and the biennial Mina P. Shaughnessy Writing Award for the best JBW article was established. Then, in 1989, Bill Bernhardt and Peter Miller came on board as co-editors and continued to increase the readership and the scholarship of JBW. Six years later, in 1995, Karen Greenberg and Trudy Smoke took over as co-editors. After working on three issues together, Karen stepped down. George Otte joined Trudy for the Fall 1996 issue, and George and Trudy continue to edit the journal.

The first fourteen (1975-1985) issues of the Journal of Basic Writing were theme issues which usually began with an introduction by one of the members of the editorial board.

Vol. 1 \#1 (1975) Error -- Introduction by Mina Shaughnessy, 1-4.

Vol. 1 \#2 (1976) Courses -- Introduction by Mina Shaughnessy, 1-3.

Vol. 1 \#3 (1977) Uses of Grammar - The Introduction was contained 
in D'Eloia's article, "The Uses - and Limits - of Grammar," 1-48. Vol. 1 \#4 (1978) Evaluation - no introduction.

Vol. 2 \#1 (1978) Applications: Theory Into Practice - A Prefatory Note by Marylea Meyersohn, 1 .

Vol. 2 \#2 (1979) Programs - Introduction by Barbara Quint Gray, 3-5.

Vol. 2 \#3 (1979) Vocabulary -- Introduction by Betty Rizzo, 1-4.

Vol. 2 \#4 (1980) Reinforcement -- Introduction by Sarah D'Eloia, 1-2.

Vol. 3 \#1 (1980) Toward A Literate Democracy -- Preface, 1-2.

Vol. 3 \#2 (1981) Training Teachers, Part I -- Introduction by Sarah D'Eloia, 1-3.

Vol. 3 \#3 (1981) Revision - Introduction by Sarah D'Eloia Fortune, 14.

Vol. 3 \#4 (1984) Training Teachers, Part II -- Introduction by Sarah D'Eloia Fortune, 1-4.

Vol. 4 \#1 (1985) Basic Writing and Social Science Research, Part I Introduction by Sarah D'Eloia Fortune, 1-3.

Vol. 4 \#2 (1985) Basic Writing and Social Science Research, Part II, Introduction by Sarah D'Eloia Fortune, 2-3.

As was initiated by Lynn Troyka, each editor or set of co-editors has written an Editorial Column to open each issue since 1986. Once $J B W$ became a refereed journal, there have been fewer special theme issues: the 1993 Special Issue on the Fourth National Basic Writing Conference Plenaries, the 1994 Special Commemorative "Remembering Mina Shaughnessy," and this issue based on the CCCC Basic Writing Workshop on Class, Race, and Culture. 


\section{News and Announcements}

The Writing Program Administrators announce the Fall 1997 Regional Conference, Developing Writers: High School to College. October 17-18, 1997 at California State University. Featured speakers: Richard Haswell, Alice Roy, Shirley Brice Heath and Montserrat Fontes. Deadline for registration: September 1, 1997. Send \$35 (\$25 students) payable to English Programs/WPA to Mark L. Wiley, Southern California WPA, Department of English, California State University, Long Beach, 1250 Bellflower Blvd. MHB 409, Long Beach, CA 90840. For additional information visit their web site at http:// www.csulb.edu/ writing.

January 7-10, 1998: CCCC Winter Workshop on Teaching Composition to Undergraduates: Constant Change and Perennial Wisdom in the Teaching of Writing will be held at the Sheraton Sand Key Resort, Clearwater Beach, FL. The workshop is designed to offer professional development opportunities to teachers in two- and four-year colleges through a three-strand workshop program: Technology and Writing, Basic Writers and ESL Students, and Diverse Contexts for Writing. Program co-chairs are Lillian Bridwell-Bowles and Ben Wiley. Information 1-800-369-NCTE, ext. 205.

The National Center for Developmental Education announces the Kellogg Institute for the training and certification of developmental educators to be held June 26-July 24, 1998. The Institute program consists of a summer session at Appapachian State University, Boone, North Carolina, followed by a fall term practicum project on the home campus of training participants. Information: Elaini Bingham or Maggie Mock (704) 262-3057.

CALL FOR PAPERS: Journal for the Assembly for Expanded Perspectives on Learning (JAEPL) is soliciting manuscripts for the fourth annual edition; the theme is "Mind, Body, Spirit: Teachers Making Connections." Possible areas for consideration include: schema theory as body based, poststructuralist textualities, ecofeminism, writing as healing, silence, and ethics. Send 4 copies of 12-15 page manuscripts (APA style) by January 31, 1998 to Linda Calendrillo, Co-Editor of JAEPL, Department of English, 600 Lincoln Ave., Eastern Illinois University, Charleston, IL 61920, email jaepl@cctr.umkc.edu. Inquiries Kristie S. Fleckenstein, Co-Editor of JAEPL, University of MissouriKansas City, Kansas City, MO 64110-24999. 


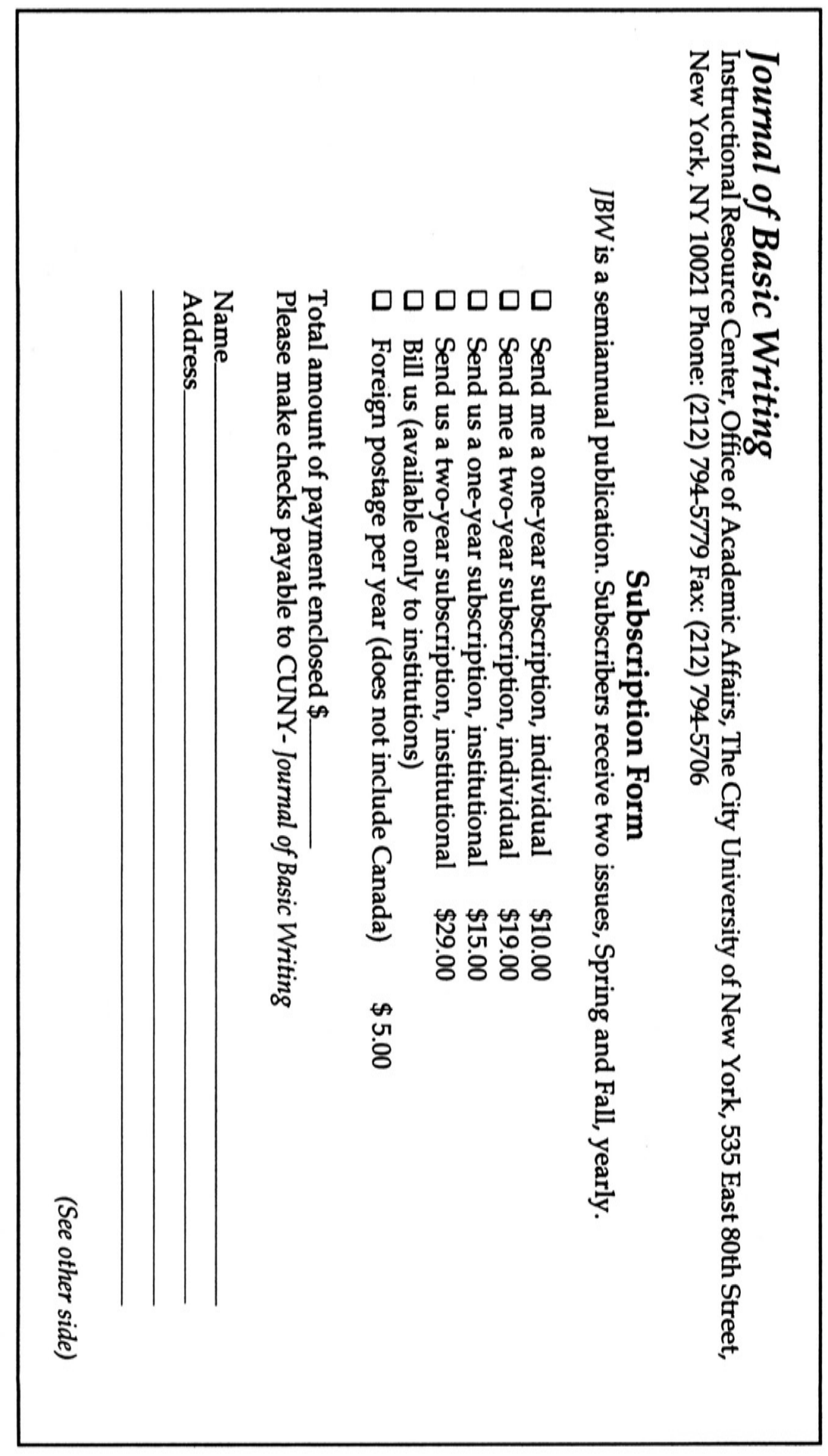




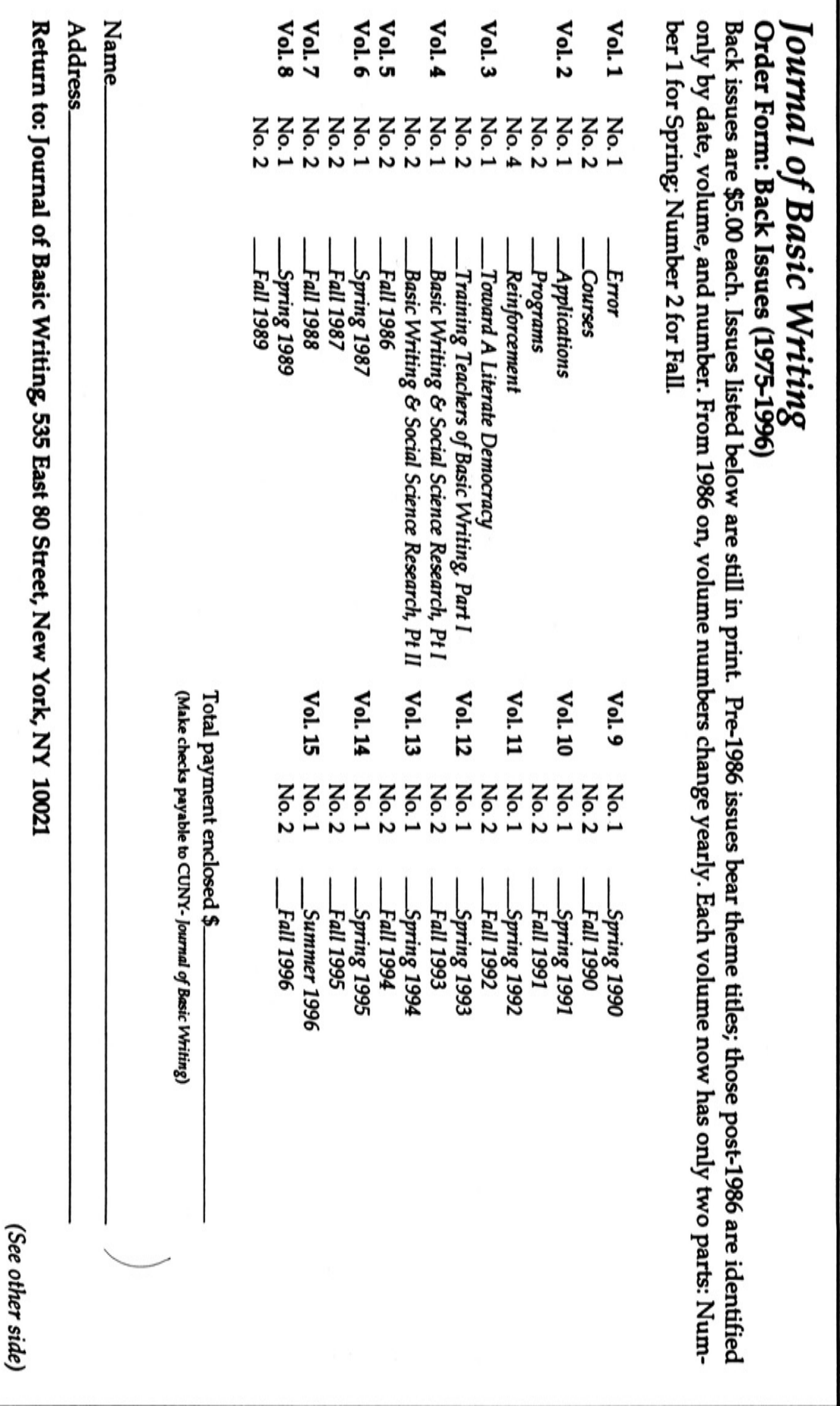





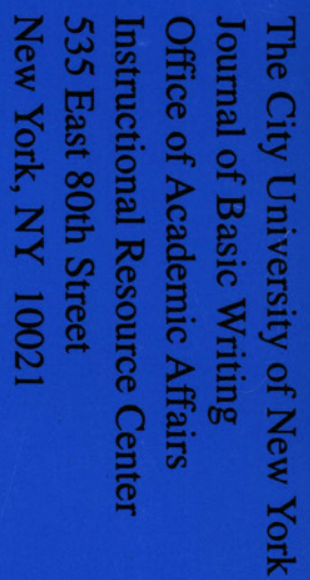

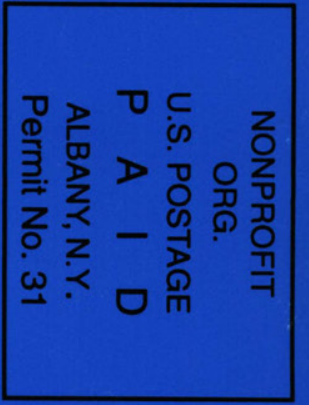

